\title{
WestVirginiaUniversity
}

THE RESEARCH REPOSITORY @ WVU

Graduate Theses, Dissertations, and Problem Reports

2003

\section{Performance of doweled concrete joints subjected to fatigue loading}

Appalaraju Vetsa

West Virginia University

Follow this and additional works at: https://researchrepository.wvu.edu/etd

\section{Recommended Citation}

Vetsa, Appalaraju, "Performance of doweled concrete joints subjected to fatigue loading" (2003). Graduate Theses, Dissertations, and Problem Reports. 1361.

https://researchrepository.wvu.edu/etd/1361

This Thesis is protected by copyright and/or related rights. It has been brought to you by the The Research Repository @ WVU with permission from the rights-holder(s). You are free to use this Thesis in any way that is permitted by the copyright and related rights legislation that applies to your use. For other uses you must obtain permission from the rights-holder(s) directly, unless additional rights are indicated by a Creative Commons license in the record and/ or on the work itself. This Thesis has been accepted for inclusion in WVU Graduate Theses, Dissertations, and Problem Reports collection by an authorized administrator of The Research Repository @ WVU. For more information, please contact researchrepository@mail.wvu.edu. 


\title{
PERFORMANCE OF DOWELED CONCRETE JOINTS SUBJECTED TO FATIGUE LOADING
}

\author{
Appalaraju Vetsa \\ Thesis submitted to the \\ College of Engineering and Mineral Resources \\ at West Virginia University \\ for the degree of
}

\author{
Master of Science \\ in \\ Mechanical Engineering \\ Dr. Samir N. Shoukry, Chair \\ Dr. Jacky C. Prucz \\ Dr. Kenneth H. Means
}

Mechanical and Aerospace Engineering Department

Morgantown, West Virginia

2003

Keywords: Dowel bar, Shokbar, Experimental testing, Instrumentation, Contact Stresses, Simulated rigid pavement joints, 3D Finite Element Modeling 


\begin{abstract}
PERFORMANCE OF DOWELED CONCRETE JOINTS SUBJECTED TO FATIGUE LOADING

Appalaraju Vetsa

Distress in concrete transverse joints is often initiated due to the development of excessive stresses at the dowel/concrete interface. Recent studies indicated the existence of two types of stresses i.e. compressive stresses at the top and bottom of the dowel and tensile stresses at both sides of the dowel bar. These stresses are the primary concern as they are believed to be a major factor for the failure of rigid pavement joints.
\end{abstract}

Dr.Shoukry invented a new dowel design named shokbar that significantly reduces the magnitude of such contact stresses. The primary objective of this study is to characterize the behavior of shokbars versus regular dowels. Simulated rigid pavements joints were used for an experimental and finite element study where both devices were subjected to static and fatigue loading. The magnitude of stresses and strains induced at dowel concrete interface as well as relative displacement at joints were measured. It was found that significantly large tensile and compressive stresses were developed at dowel/concrete interface than at shokbar/concrete interface. It is also found that the relative displacements observed at the joints of shokbar specimen remained constant through out the fatigue testing, where as the relative displacements varied very much in case of joints at regular dowel specimen.

In this study, three dimensional finite element models were developed simulating the experimental concrete specimens. A very good match between the experimental and finite element model results was observed. Static test results indicate that shokbars were able to reduce compressive and tensile strains at bar/concrete interface by $50 \%$ and $75 \%$ respectively. Fatigue test results indicate that for 5 million cycles of loading, shokbars maintained constant values of compressive and tensile strains as well as vertical relative displacement across the joints. On the other hand, regular dowel bars experienced an increase in tensile strain to almost $100 \%$ of their initial value, while displacements and bearing stresses showed signs of concrete wear. 
Dedicated to my beloved brother "SURYA" 


\section{ACKNOWLEDGEMENTS}

I am thankful to my advisor Dr. Samir N. Shoukry for providing an excellent research atmosphere, guidance and assistance throughout my research work. I am very grateful to his invaluable support during the difficult stages of my personal life.

Thanks to Dr. Jacky C. Prucz and Dr. Kenneth H. Means for being on my committee and providing me valuable suggestions.

I express my sincere thanks to Mr. Mourad Y. Riad and Mr. Gergis W. William for their assistance and suggestions throughout this research work.

I am thankful to my parents, brothers and my little angel Vyshnavi for their love, support and inspiration.

I am thankful to Shiva, Rajeev, Sasi, Praveen, and each and every one who helped me through out my research work. 


\section{TABLE OF CONTENTS}

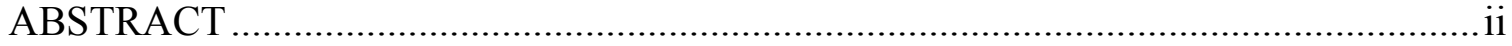

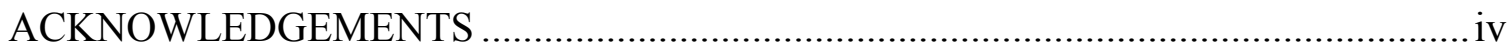

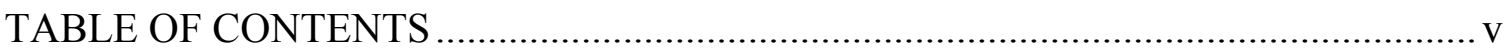

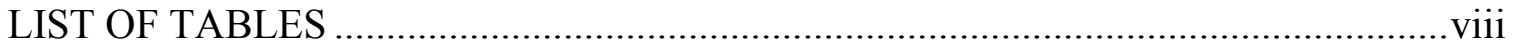

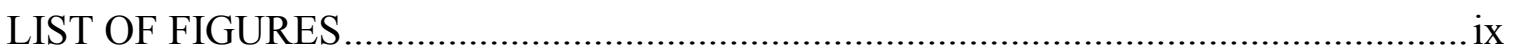

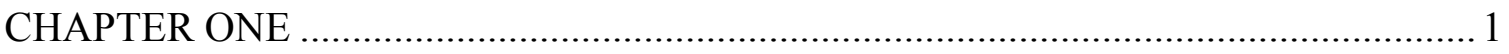

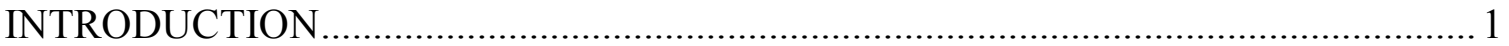

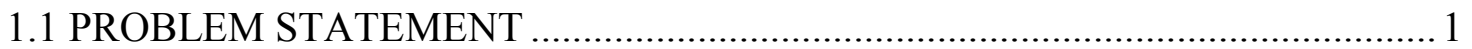

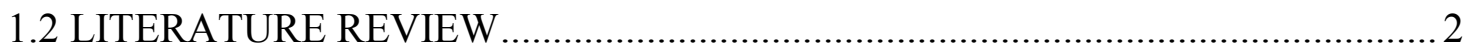

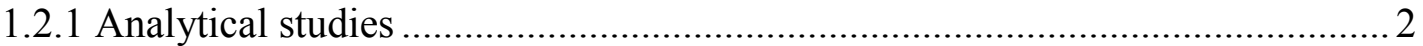

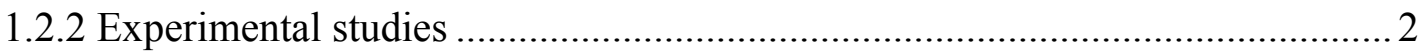

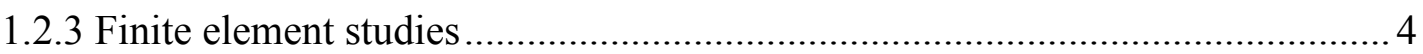

1.2.4 Investigation of alternative dowel materials and shapes .................................. 7

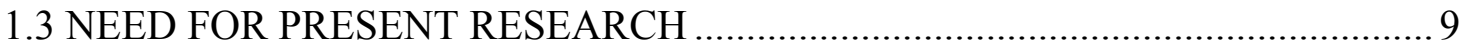



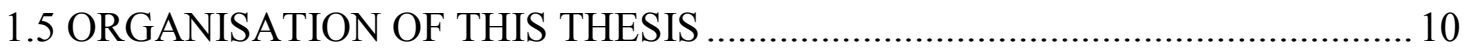

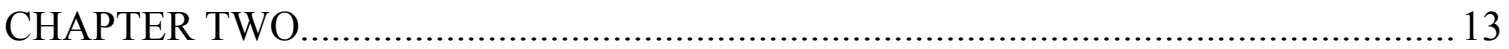

DESIGN FEATURES AND MANUFACTURING OF SHOKBARS.............................. 13

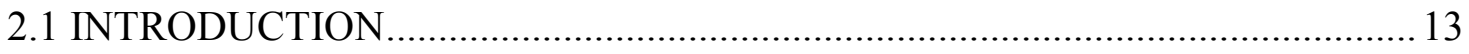

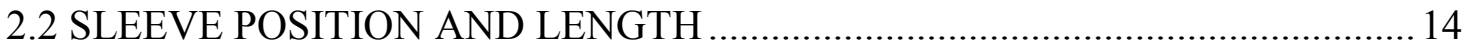

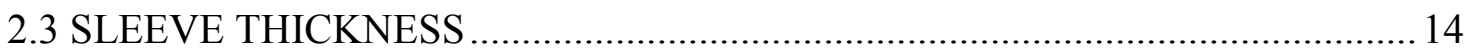

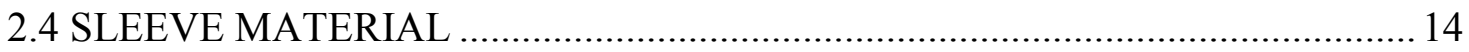

2.5 SLEEVE/DOWEL CONTACT INTERFACE …………................................... 15

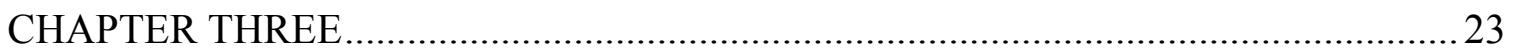



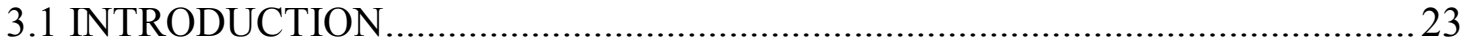

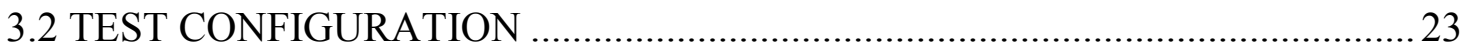

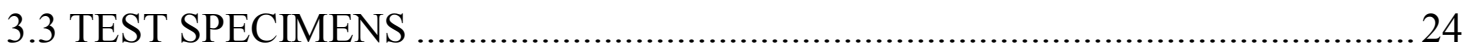

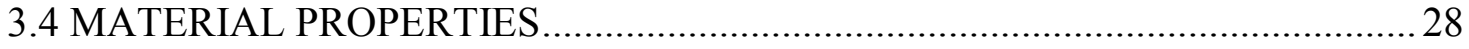

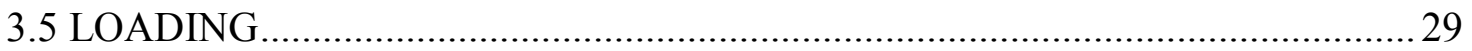




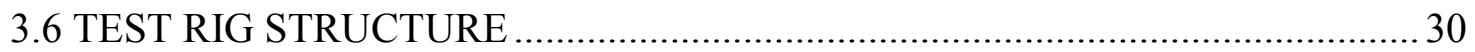

3.7 INSTRUMENTATION AND DATA ACQUISITION ........................................30

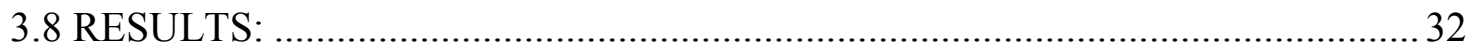

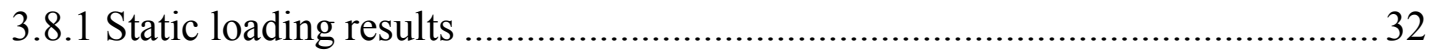

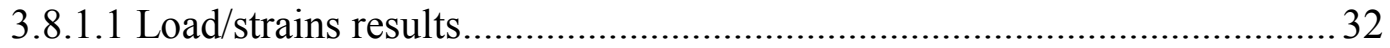

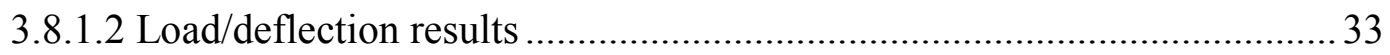

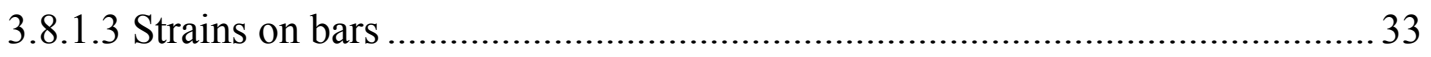

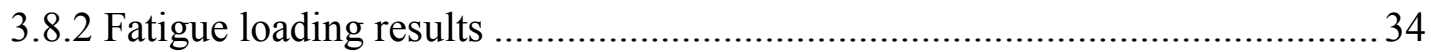

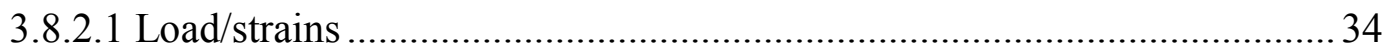

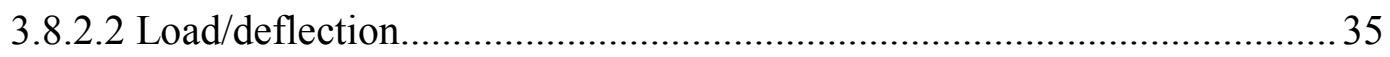

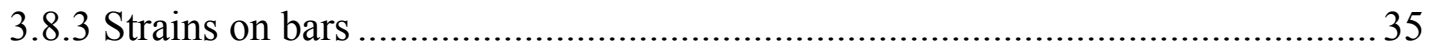

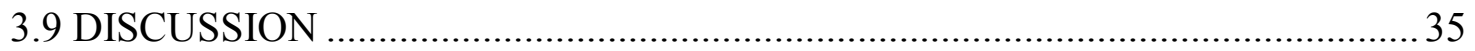

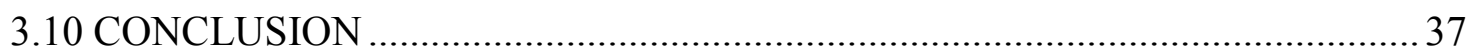

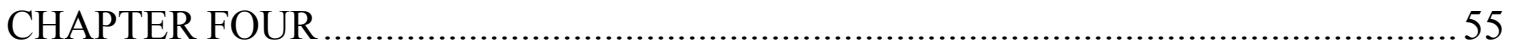

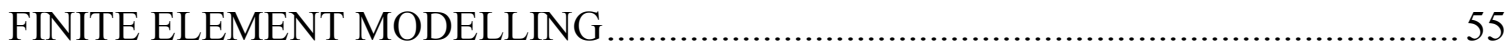

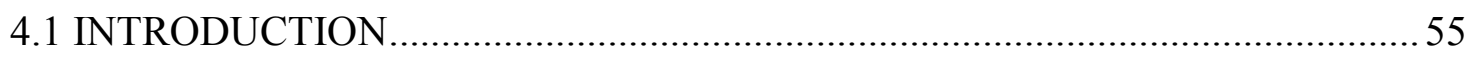

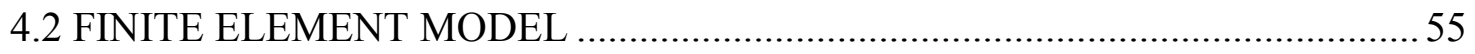

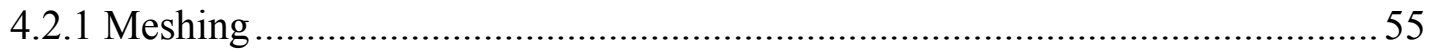

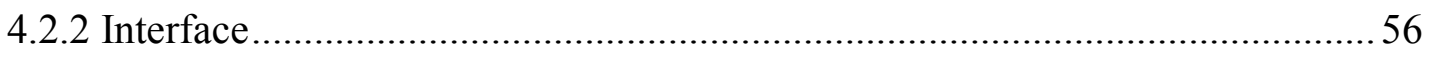

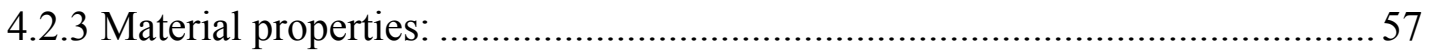

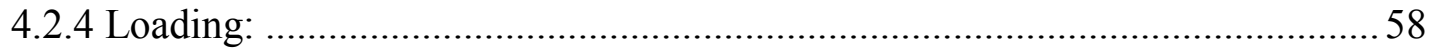

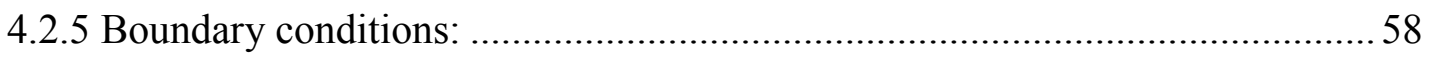

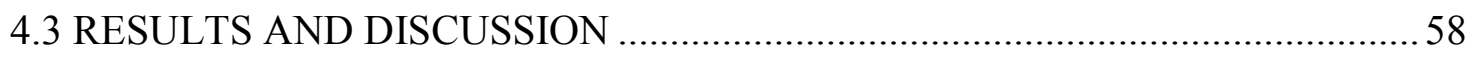

4.3.1 Location of maximum stress around the dowel bar …………........................58

4.3.2 Maximum stresses at the face of the unloaded block .........................................6 60





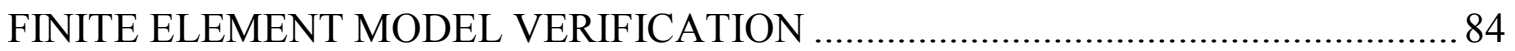

5.1 STRAINS AT BAR/CONCRETE INTERFACE ……………………….............. 84

5.1.1 Compressive strains at bar/concrete interface: ................................................ 84

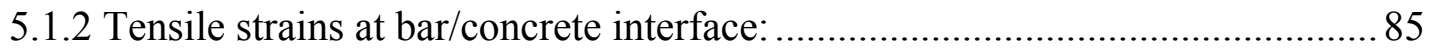


5.1.3 Tensile strains at about 0.7 inches from bar/concrete interface:

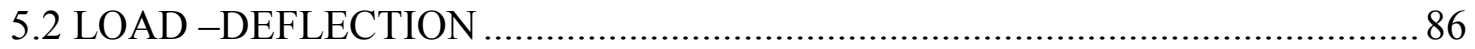

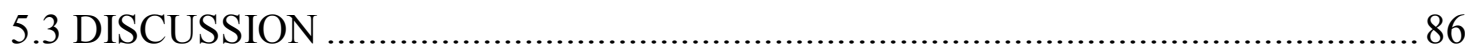

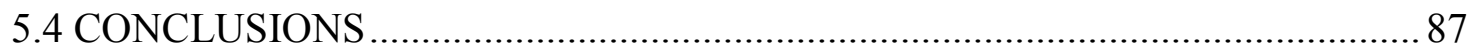



CONCLUSIONS AND FUTURE RESEARCH NEEDS .......................................... 100

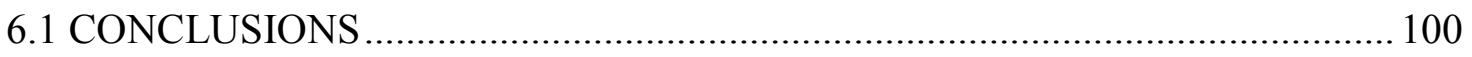

6.2 FUTURE RESEARCH NEEDS............................................................... 101

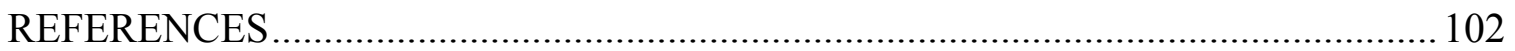

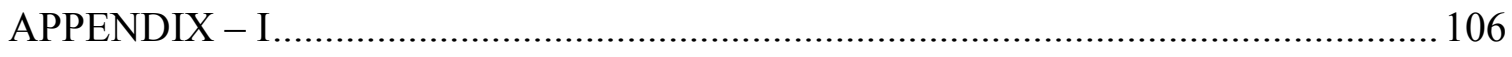

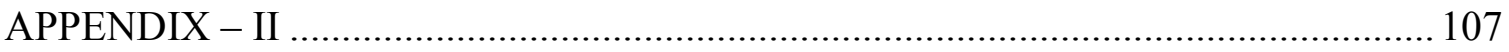

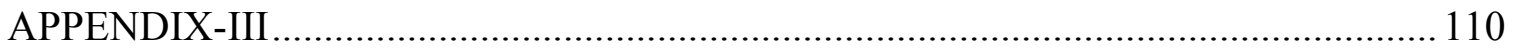

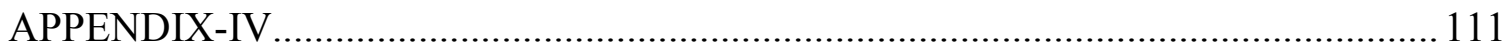




\section{LIST OF TABLES}

Table 2.1 - Physical properties of Polymer concrete ...................................................... 17

Table 3.1 - Distance from center of strain gage grid to bar/concrete interface...................... 38

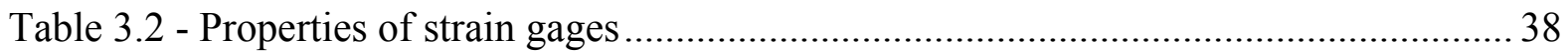

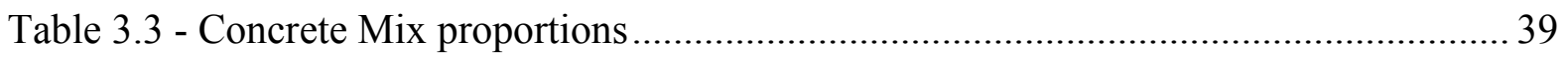

Table 3.4 - Mechanical properties of steel dowel........................................................ 39

Table 3.5 - Mechanical properties of polymer concrete material....................................... 39

Table 3.6 - Strain readings around bars subjected to static loading ................................... 40

Table 3.7 - Maximum relative displacement across joints ............................................. 41

Table 3.8 - Bending moment, Shear force and bearing stresses at bar/concrete interface...... 42

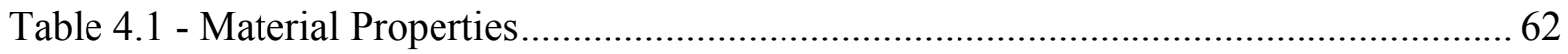

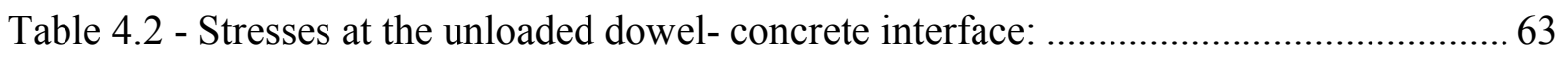

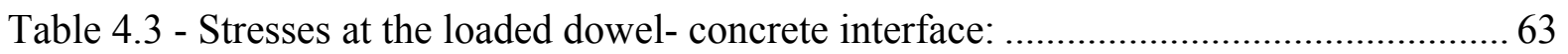




\section{LIST OF FIGURES}

Figure 1.1 - Different configuration of dowels previously employed in joints....................... 12

Figure 2.1 - Vertical stress distribution along dowel bar (Riad, 2001) .................................. 18

Figure 2.2 - Tensile Stress along the Dowel Bar (Shoukry et al., 2001)................................. 18

Figure 2.3 - Stress concentrations around Loaded Dowel (Shoukry et al., 2001) .................. 19

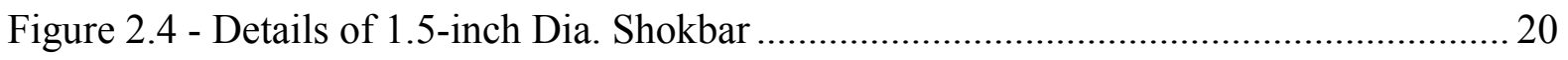

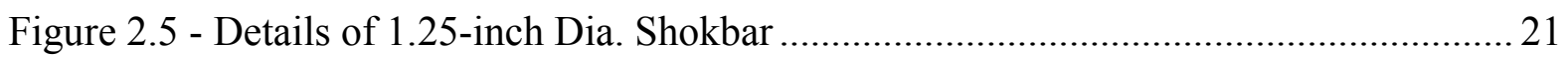

Figure 2.6 - Molds details for casting polymer concrete sleeves ......................................... 22

Figure 3.1 - Load deflection test specimens......................................................................... 43

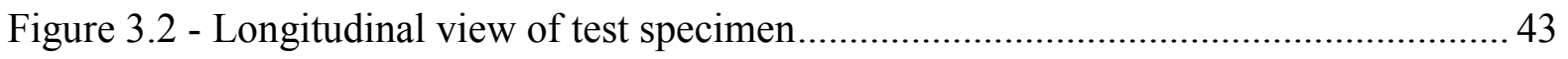

Figure 3.3 - Preparation plan for the instrumentation of dowel bar ...................................... 44

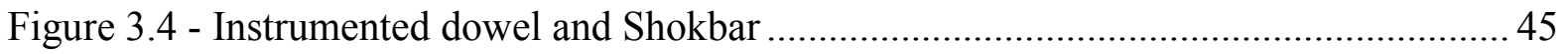

Figure 3.5 - Preparation of molds for casting end sections of specimens ................................ 46

Figure 3.6 - A number of prepared molds ready to cast end sections ..................................... 46

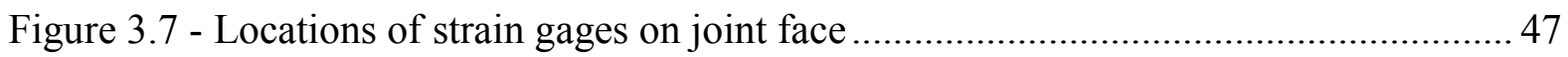

Figure 3.8 - Different stages in application of strain gages on joints faces ............................ 48

Figure 3.9 - Specimen ready for casting the middle section .................................................... 49

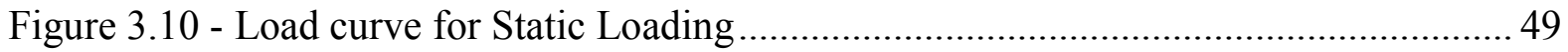

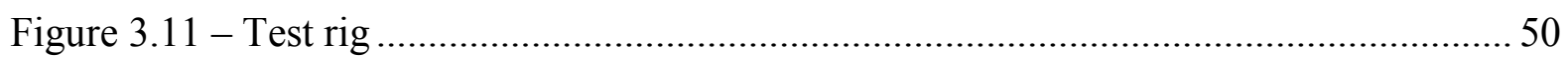

Figure 3.12 - Test rig mounted with test specimen …………....................................... 51

Figure 3.13 -Calibration curve for MTS load cell ............................................................ 52

Figure 3.14 - Compressive strains at bar/concrete interface .............................................. 52

Figure 3.15 -Tensile strains at bar/concrete interface (Tension-1) ........................................ 53

Figure 3.16 -Tensile strains at about 0.7 inches from bar/concrete interface (Tension- 2) .... 53

Figure 3.17 -Vertical relative displacements across joints........................................................ 54



Figure 4.1 - Finite element model of a double-jointed concrete specimen ............................... 64

Figure 4.2 - Finite element model of double-jointed concrete specimen with dowel bars; one end block removed

Figure 4.3 - Finite element model of double-jointed concrete specimen with polymer shokbars; one end block removed 
Figure 4.4 Finite element model of double-jointed concrete specimen with steel shokbars; one end block removed

Figure 4.5 - Meshing of polymer shokbar, steel shokbar and regular dowel .......................... 68

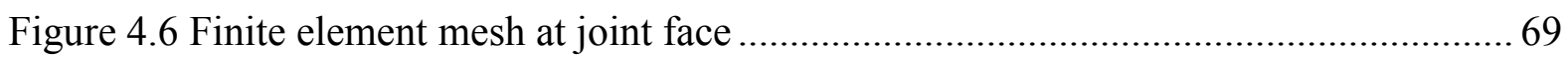

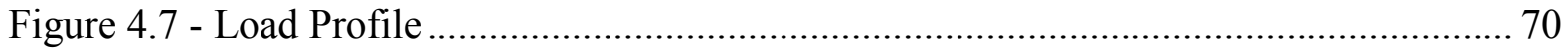

Figure 4.8 - Deformation of double joint specimen at maximum load.................................. 70

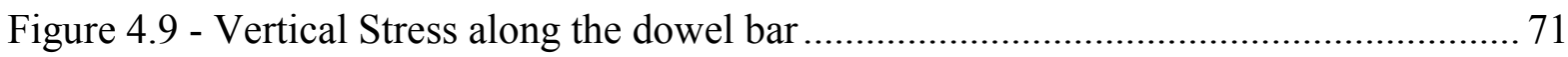

Figure 4.10 - Vertical stress at dowel concrete interface of unloaded block .......................... 72

Figure 4.11 -Vertical stress at dowel concrete interface of loaded block.............................. 73

Figure 4.12 -Maximum Shear Stress at dowel concrete interface of unloaded block............. 74

Figure 4.13- Maximum Shear Stress at dowel concrete interface of loaded block................. 75

Figure 4.14 - Maximum Principal Stress at dowel concrete interface of unloaded block ...... 76

Figure 4.15 - Maximum Principal Stress at dowel concrete interface of loaded block .......... 77

Figure 4.16 - Fringes of Maximum Principle Stress, Maximum Shear Stress and Vertical Stress around unloaded Polymer shokbar ............................................................ 78

Figure 4.17 - Fringes of Maximum Principle Stress, Maximum Shear Stress and Vertical Stress around loaded Polymer shokbar ........................................................................ 79

Figure 4.18 - Fringes of Maximum Principle Stress, Maximum Shear Stress Vertical Stress

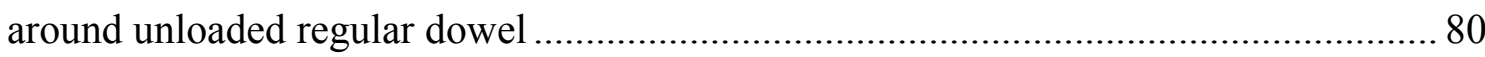

Figure 4.19 - Fringes of Maximum Principle Stress, Maximum Shear Stress Vertical Stress

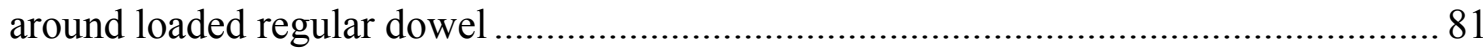

Figure 4.20 - Fringes of Maximum Principle Stress, Maximum Shear Stress Vertical Stress around unloaded Steel shokbar .

Figure 4.21 - Fringes of Maximum Principle Stress, Maximum Shear Stress Vertical Stress around loaded Steel shokbar

Figure 5.1 - Compressive strain at regular dowel/concrete interface from experiment and finite element model 88

Figure 5.2 - Compressive strain at polymer shokbar/concrete interface from experiment and finite element model

Figure 5.3 - Compressive strain at steel shokbar/concrete interface from experiment and finite element model 
Figure 5.4 - Tensile strain at regular dowel/concrete interface from experiment and finite element model

Figure 5.5 - Tensile strain at polymer shokbar/concrete interface from experiment and finite element model

Figure 5.6 - Tensile strain at steel shokbar/concrete interface from experiment and finite element model

Figure 5.7 - Tensile strain at about 0.7-in from regular dowel/concrete interface from experiment and finite element model 94

Figure 5.8 - Tensile strain at about 0.7-in from polymer shokbar/concrete interface from experiment and finite element model

Figure 5.9 - Tensile Strain at about 0.7-in from steel shokbar/concrete interface from experiment and finite element model

Figure 5.10 - Relative displacement at the joints of regular dowel specimen from experiment and finite element model 97

Figure 5.11 - Relative displacement at the joints of polymer shokbar specimen from experiment and finite element model.....

Figure 5.12 - Relative displacement at the joints of steel shokbar specimen from experiment and finite element model 99 


\section{CHAPTER ONE \\ INTRODUCTION}

\subsection{PROBLEM STATEMENT}

Dowel jointed concrete pavements are widely used because of their durability and ability to withstand different climatic conditions. They are designed and constructed to be safe, durable and economic, making road transportation. Passenger and commercial traffic has increased significantly over the past seven decades and efforts to enhance the performance of rigid pavements have also increased (ASCE, 2001).

The existence of expansive and contractive forces in concrete pavements is a result of changes in temperature and moisture through the pavement thickness. These forces may cause concrete cracks. In order to control the formation of such cracks, transverse joints are introduced along the pavement length to relieve the stresses caused by the restrained motion of the concrete material (Westergaard, 1927). Although transverse joints are successful in disciplining the formation of cracks into straight lines with an orderly uniform spacing, they represent weakness in the pavement structure. To overcome the excessive stresses developed at the joint edges under traffic loads, dowel bars are used to reduce the slabs vertical deflection as the load is transferred between adjacent slabs. The most common form of dowel bars are 18-in long, epoxy-coated, hotrolled steel bars with diameters ranging from 1.00 to 1.75 inches, depending on the pavement thickness.

The estimated amount of doweled concrete paving in the United States in 1997 was 40,850,000 square yards per year, and the estimated number of required dowel bars was $18,500,000$ per year (Porter and Braun, 1997). A study in Wisconsin showed that the for a service life of 25 years, a non-doweled pavement would cost $13.1 \%$ more than a doweled one due to maintenance and rehabilitation costs (Bischoff, 1996). It was also found that the employment of dowel bars not only enhanced pavement performance and extended its service life, but saved the Wisconsin Department of Transportation $\$ 6,000,000$ per year. 


\subsection{LITERATURE REVIEW}

\subsubsection{Analytical studies}

Snyder (1989) verified that a larger dowel diameter would ensure smaller dowel deflections, leading to reduced concrete bearing stresses and consequently decreased dowel looseness.

Sargand (2000) calculated the bearing stress in the concrete surrounding the dowel bars from bending moments and shear loads in the dowel bars using the equation

$$
\sigma_{b}=\frac{(P-\beta M)}{\left(2 \beta^{2} E I\right)} K
$$

Where: $\sigma_{b}=$ Bearing stress on the concrete

$K=$ stiffness of dowel support (assumed to be $900,000 \mathrm{pci}$ )

$P=$ Shear force on one dowel

$M=$ Bending moment on dowel

$\beta=4 \sqrt{\frac{K d}{4 E I}}=$ Dowel relative stiffness

$d=$ dowel diameter

$E$ = young's modulus of dowel

$I=$ moment of inertia of dowel.

Acknowledged efforts were conducted during the past two decades, to study several structural parameters that affect the dowel performance. Such studies explored new techniques to overcome some drawbacks that were found responsible for several types of joint distresses. Interest was directed through two main courses; investigating alternative dowel bar shapes and dimensions, and applying alternative materials to the dowels.

\subsubsection{Experimental studies}

Cioko et al. (1979) studied the relative ability of dowels to transfer load across joints. Load and deflection relations were studied by applying a set of incremental static loads between repetitive loading after 5,000, 20,000, 100,000, 300,000, 600,000 and 1750,000 cycles for a load $10,000 \mathrm{lb}$ on slab specimens. It was indicated that an increase in joint width, load magnitude, and repetitions increased dowel looseness, and 
consequently decreased the load transfer efficiency of the dowels. The results indicated that the dowel specimens lost $4-9 \%$ of their initial capacity as a result of the application of repeated loads.

Sargand and Hazen (1994) studied the load transfer mechanism under traffic loading. Field monitoring of instrumented sites provided strain data that enabled the calculation of the induced stresses in concrete, deflection at joints, moments and shear forces in dowels. Based on the results from the study, one of the conclusions was that larger diameter and stiffer bars transferred more loads across the joint.

Hammons (1997) conducted a laboratory scale experimental study on five jointed rigid pavement models as a part the work presented for the purpose of developing a 3D finite element model of rigid pavements. Each pavement model consisted of two Portland cement concrete slabs, 36 × 48 × 2 inch separated by a joint, and supported by rubber block simulating the subgrade. The joint was mounted with smooth steel dowel bars 0.25 in diameter, 15.5 in long and spaced at 4 in center to center. The testing was conducted by applying a load on one side of the joint through displacement controlled hydraulic actuator acting on a circular rubber pad at a rate of $0.01 \mathrm{inch} / \mathrm{min}$. Collected data consisted of surface strains and displacements on the top of the slabs. Load deflection curves and load strain traces were plotted for each test. The presented plots indicated that the maximum load transfer efficiencies occurred at low loads. As the load was increased, it was noticed that localized crushing of the slabs developed at dowel/concrete contacts. The experiments confirmed the observations and predictions that the effectiveness of the load transfer mechanism decreases with localized damage in the immediate vicinity of the joint.

Sargand (2000) presented an experimental study to evaluate the dowel response under environmental conditions, by monitoring the strains induced in dowel bars during concrete curing, and under applied dynamic loads. The collected data indicated that the stiffness of dowel bars resisted slab curling inducing high amounts of bending moments in the dowels. It was indicated that the bearing stresses at the dowel bars due to temperature and moisture changes exceeded the allowable bearing capacity of concrete, which would lead to expect some progressive concrete deterioration at the dowel interface and a reduction in load transfer efficiency over time. Analyzing the dynamic 
bending moments in the dowel bars due to traffic loading represented by Falling weight deflectometer tests showed them to be minor to those induced due to environmental changes.

\subsubsection{Finite element studies}

The application of Finite element method to rigid pavements started in the early 1970's. Wang et al. (1972) studied the response of rigid pavements subjected to wheel loadings using a linear finite element model. The slab was modeled with medium-thick plate elements assuming Kirchoff plate theory. Slab stresses and deflections were computed with both continuous foundation and Winkler foundation models. The results assuming continuous foundation yielded higher stresses and deflections.

Tabatabaie and Barenberg (1980) developed a more general finite element program called ILLI-SLAB, which is still in use today. ILLI-SLAB utilizes medium thick plate and the subgrade is modeled as a Winkler foundation. Dowel bars are at joints are modeled as discrete bar elements, and shear transfer via aggregate interlock or keyway is modeled with spring elements. Verification of models developed with ILLI-SLAB was achieved by comparison with theoretical solutions for stresses and displacements, as well as comparison with actual field test data from the AASHTO Road Tests (1962) and tests of concrete pavement on cement treated sub bases. Studies were performed to examine the effects of load transfer efficiency on the behavior of plain jointed concrete pavement as well as the effect of transverse crack spacing on load stresses in continuously reinforced concrete pavement. One of the main conclusions from the early studies using ILLI-SLAB was that joint must be modeled accurately to predict the possibility of permanent subgrade deformation and slab distress near the slab corners. Tayabji et al. (1986) developed the program JSLAB for analyzing pavements resting on a Winkler foundation. The model incorporates features similar to ILLI-SLAB, utilizing plate elements to model the slab and a bonded or unbonded case. Dowels were modeled with modified beam elements that incorporated the effect of shear deformation and the elastic support provided by the concrete. As in ILLI-SLAB, aggregate interlock and keyways were modeled with springs. 
Ionnades et al. (1984) developed models that employed medium thick plate bending elements; as a result, shear stresses and normal stresses through the thickness of the plate were not considered, limiting the effectiveness of the models for detailed stress analysis. In addition, the concrete was modeled linearly elastic, and aggregate interlock shear transfer was incorporated with linear spring elements. Dynamic load effects were not considered.

A different approach to pavement modeling was implemented in GEOSYS, a finite element package developed by Agbabian Associates (Analytical Modeling of RockStructure Interaction, 1973), and modified, in the late 1980's by Ioannides et al. (1988). Linear isoparametric 8-node brick elements were used to create a three-dimensional mesh of a slab placed on a cube of soil. An iterative scheme was implemented to account for the stress-dependent behavior of fine-grained cohesive soils. Switching from the plate theory to a more general solid modeling approach allowed the use of the package for modeling multilayered flexible pavements in addition to rigid pavements. The threedimensional modeling made the code much more versatile; however, moving wheel loads were still treated as static ones.

Starting in early 1990's the importance of introducing dynamic loads in the finite element evaluation of pavement behavior was realized and several dynamic codes were developed or modified. A dynamic finite element code DYNA-SLAB (modified ILLISLAB) was developed by (Chatti et al., 1994) for the analysis of jointed rigid concrete pavements subjected to moving transient loads. The algorithm gives both in time and frequency domains. The subgrade was modeled using two options. The first option models subgrade as a damped Winkler foundation consisting of frequency-dependent springs and dashpots. The second option treats subgrade as a viscoelastic layered system (series of plates) on a rigid or deformable half-space. Moving load was presented by a global load vector composed of zero entries except at the nodes of those elements over which the load was applied. The block of non-zero values of load vector was prescribed to change from one group of elements to another as the load moves along the slab system. Local displacement shape functions formulations were used at time-dependent positions of load as it moved from one plate to another. The results from this package showed close correlation with the experimental data obtained for a jointed concrete pavement. 
Zaghloul et al. (1994) introduced the use of commercially available three dimensional finite element programs in pavement studies by using ABAQUS to determine the load equivalence factors. The slab and subgrade were modeled using 3-D brick elements, and dowels were modeled using bar elements. The use of bar elements in this case does not accurately simulate the behavior of the dowel bar; since bar elements behave as keys to transfer shear forces, due to their aspect dimensional ratio, neglecting bending. Another study using ABAQUS was developed by (Uddin et al., 1996) examined the effect of pavement discontinuities on surface deflections of a pavement subjected to falling weight deflectometer (FWD) load. In this study, the slab, cement treated base, and subgrade were modeled using 3D elastic brick elements, pavement cracks were modeled using gap elements, and dowels at the transverse joint were modeled using beam elements.

Shoukry and William (1998) examined the effect of dowel bar looseness on the load transfer efficiency across the joint. This was achieved through 3D finite element modeling of two dowel jointed concrete slabs subjected to FWD load. The study revealed the distribution of the maximum principal stresses developed around the dowel bar, indicating the formation of high stress intensity in the concrete material reaching $480 \mathrm{psi}$ when a looseness of 0.008 in is applied.

Channakeshava et al. (1993) developed a non-linear, 3D static finite element model of plain concrete pavement with doweled joints. The concrete slab was modeled using a plastic constitutive model augmented by a smeared cracking model, and progressive softening of dowel load transfer was considered. Dowel bars were modeled using discrete bending elements, with three discrete non-linear springs connecting each end of the dowel to the slab, to account for looseness. The use of nonlinear springs at the end of the dowels, allowed the effects of local stress concentrations to occur. Among the findings of this study, it was observed that dowel-concrete interface stiffness is reduced due to high stress concentrations near the dowel. To capture the effect of local stress concentrations, a localized joint response analysis was performed, in which a typical joint region was cut out of the pavement and supported rigidly, and loaded through the dowel. Channakeshava observed in this study that the development of tensile stress component in the elements above the dowel, along with large compressive stresses in the elements 
below the dowel. However, the exact location and the magnitude of the tensile stresses were not identified.

William and Shoukry (2000) developed a three-dimensional finite element model that is specifically designed to examine the stresses within the vicinity of dowel bars. The model features an extremely fine finite element mesh near the transverse joint that enables accurate simulation of dowel-concrete interfaces. Their analysis showed agreement with Westergaard's solution that curling stresses due to temperature gradient are not affected by the change in slab length. Their results of transverse stresses indicated small differences Westergaard's solution. This difference indicated that the presence of dowel bars self-weight and interfaces with concrete (which are not considered by Westergaard) played a role in increasing the transverse stress. The finite element computed longitudinal stress was in good agreement with that calculated using Westergaard's equation.

Riad (2001) presented an experimental and finite element study on simulated pavement structures. Both the finite element and experimental results indicated the existence of two types of stresses at the dowel-concrete interface, i.e., the development of compressive stresses at the top and bottom of the dowel and the formation of tensile stresses at both sides of the dowel bar. It was found that tensile stresses were more critical and they exceed the allowable tensile strength of the concrete material, which initiated a tensile crack in the concrete on the sides of the dowel bar. He concluded that the state of induced stresses around the dowel bar in straight joints and skewed joints are quite similar and skewing the joint did not enhance the performance of the dowel bar.

\subsubsection{Investigation of alternative dowel materials and shapes}

A review conducted by (Porter and Braun, 1997) reported that six states were the most interested in alternative dowel materials; New York, Kansas, West Virginia, Ohio, Iowa, and North Dakota. Although long term performance of alternative dowel materials are still too soon to be evaluated, it was indicated that $79 \%$ of the investigated materials were glass fiber reinforced plastics, with the use of E-Glass encapsulated in vinyl-ester and epoxy resins predominant. The feasibility of using fiberglass reinforced plastic (FRP) devices in lieu of steel tie bars in longitudinal joints as corrosion free bars was conducted 
by Applied Pavement Technology Inc. Considering bars, Channels, and I-beam shapes, it was concluded that more cross sectional area was needed for FRP devices and that in terms of material cost, they were more expensive than regular steel bars. The study also indicated that, more research was needed to assess the increase of pavement service life if corrosion was successfully prevented. Fiber reinforced composite dowels and tie bars were tested on full-scale slab specimens for static, fatigue and dynamic loading among a study conducted by Porter et al. (1993). This investigation concluded that the performance of 1.75-inch fiber reinforced dowels spaced at 8 inches were comparable to that of 1.5-inch steel dowels spaced at 12 inches. Another study by Sargand et al. (1994) examining load transfer mechanism under traffic loading through field testing and finite element modeling found that the performance of 1.5 -inch diameter fiber glass dowels approached that of 1.0 in diameter steel dowels. A comprehensive review of hot-dip galvanizing and epoxy or PVC coating protection systems for steel reinforcement was presented among a study conducted by American Society of Civil Engineers (1995). This study examined the application in manufacturing, and discussed choices in protective systems. Four Types of dowels were investigated in a study by Sargand and Cindar (1997) in which 1.5-inch diameter steel and fiberglass dowels along with 1.5-inch high steel and fiberglass I beams were field tested to measure the forces placed on dowels due to dynamic loading and environmental effects. In this study the 1.5 -inch diameter steel dowel performed most efficiently in all 4 types, while the fiberglass I beam experienced the lowest moments. Eddie (1999) used scaled models under simulated static and cyclic loads to conduct a comparison of performances of glassform dowels, fiber dowels, and steel dowels in transferring loads. In his study, Eddie used 1.5-inch diameter fiber reinforced plastic dowels to efficiently transfer loads comparable to 1.25-inch steel dowels. Another study conducted by Eddie et al. (2001) used static and cyclic laboratory testing in addition to field-testing to investigate the performance of glass fiber reinforced polymer (GFRP) dowels in comparison with epoxy coated steel dowels. This investigation showed that 1.5- inch diameter GFRP dowels spaced at 12-inch were inadequate to transfer loads for the expected pavement life. It was also stated that current guidelines for steel dowels cannot be applied for GFRP dowels. Using the Minnesota accelerated loading facility (Snyder et al., 2001) an investigation of the relative long-term 
performance of various types and sizes of dowels retrofit across transverse joints and cracks was conducted. It was reported in this study that use of stainless-steel clad dowels did not significantly reduce the performance of regular epoxy-coated retrofit dowels. However fiber reinforced plastics and grout filled stainless steel tubes showed potential reduction in long term performance due their higher flexibility.

Other types of dowel bars reported in the literature included cold-drawn bars partly encased in Monel metal tubing, galvanized hot rolled bars incased in sheet metal sleeves, all with various coatings. Other quite non-conventional dowels consisted of structural members such as 3 inch I beams or 2-inch channels. Figure 1.1 illustrates examples of the aforementioned devices.

\subsection{NEED FOR PRESENT RESEARCH}

Dowel jointed concrete pavements are subjected to several millions of loading cycles during their lifetime. Over the years, many studies have been conducted to examine the mechanical behavior of doweled transverse joints. Faulting and spalling are observed in concrete pavements due to traffic loads and temperature variations. They are primarily associated with joint related distresses (Neeraj, 2001). Premature damage can develop at early age due to excessive forces caused by dowel bending (Sargand, 2000). The bending of dowels is caused by slab curling which in turn is caused by temperature and moisture differential through the slab thickness. Previous studies indicated that dowel concrete interaction is an important factor in influencing load transfer efficiency (Ozbeki et al., 1985). Although dowel bars improve pavement performance, transverse joint damage is the most common form of distress observed on concrete pavements. In most cases, such damage is attributed to improper functioning of the doweled connections. Aside from commonly reported problems such as placement misalignment and corrosion, the presence of looseness around embedded dowel bars drastically affects the performance.

Detailed finite element models of doweled transverse joints subjected to traffic loading revealed the existence of high tensile stresses in the concrete that surround the dowels (Shoukry and William, 2001). The study showed that such stresses produce more severe level of damage to the dowel socket than the compressive regions laying on top 
and bottom of the dowel. The compressive zones are formed by direct contact between the dowel and concrete as the load approaches the joint edge. Excessive stresses in concrete that supports the dowels are obviously responsible for various forms of damage developed at transverse joints. Thus, it is important to investigate the performance of new alternative design ideas that would lead to reduction of such high stresses and fulfill the goal of efficient load transfer across transverse joints.

\subsection{STUDY OBJECTIVES}

A new design for a load-transferring device is needed. The key to this design is to formulate a better shape and material in the region of high tensile and compressive stresses that would provide a better distribution and eliminate their severity. The new design should maintain high properties of stiffness and moment of inertia and in the same time allow free expansion and contraction of joints. Based on the results of a detailed Three Dimensional Finite Element models of transverse joints Shoukry and William (2001) suggested a new dowel bar design called Shokbar that was shown to drastically reduce the state of stress in the concrete surrounding dowel bars. The Shokbar consists of a traditional epoxy coated steel dowel on which two steel or polymer sleeves are fitted so that the dowel can slide freely on their internal diameter while their outside surfaces have full bond with the concrete. A full description of the shokbar is given in chapter 2 .

The objective of this research is to explore the performance of Shokbar in comparison with traditional dowel bar when the specimens are subjected to fatigue loading. The comparison includes the stresses in the concrete around the dowel, the loaddisplacement relation, and straining action on the dowels.

\subsection{ORGANISATION OF THIS THESIS}

This thesis presents the research work conducted to explore the behavior of doweled joints in comparison with that of the new dowel design (Shokbars). The scope of this research involves a laboratory experimental program in which rigid pavement joints are being tested under static and fatigue loading, and a 3D finite element simulation of the testing arrangement. The thesis is arranged in the following sequence.

- Chapter 1 is an introduction to the topic, featuring a background to rigid pavement joints and stating the objective of this thesis. 
- Chapter 2 provides detailed description of the new dowel design (Shokbar) including its various features, dimensions, material composition and a theoretical background showing basis for its expected superior behavior over regular dowels.

- Chapter 3 describes the experimental testing program including the test setup, construction of specimens, loading configurations, and the collected data results. The objective of these tests is to explore the behavior of doweled joints subjected to static as well as fatigue loading, and conduct a conclusive comparison between the behaviors of dowel bars versus shokbars. A comparison between the behaviors of Shokbars versus regular dowels is conducted.

- Chapter 4 includes a detailed description of the 3D finite element study. In this chapter, Finite element models that simulate the experimental arrangements and their features are presented. The finite element models serve to predict the state and magnitude of strains and stresses at bar/concrete interface as well as the relative displacement at the joints.

- Chapter 5 shows the correlation between the predicted data from the Finite element study and those collected from the experimental program. Such a comparison presents a verification of the results calculated from the finite element models and in the same time shows the level of accuracy and precision of the experimental data.

- Chapter 6 summarizes the drawn conclusions from the research program, and offers new proposals for future research needs related to this topic. 


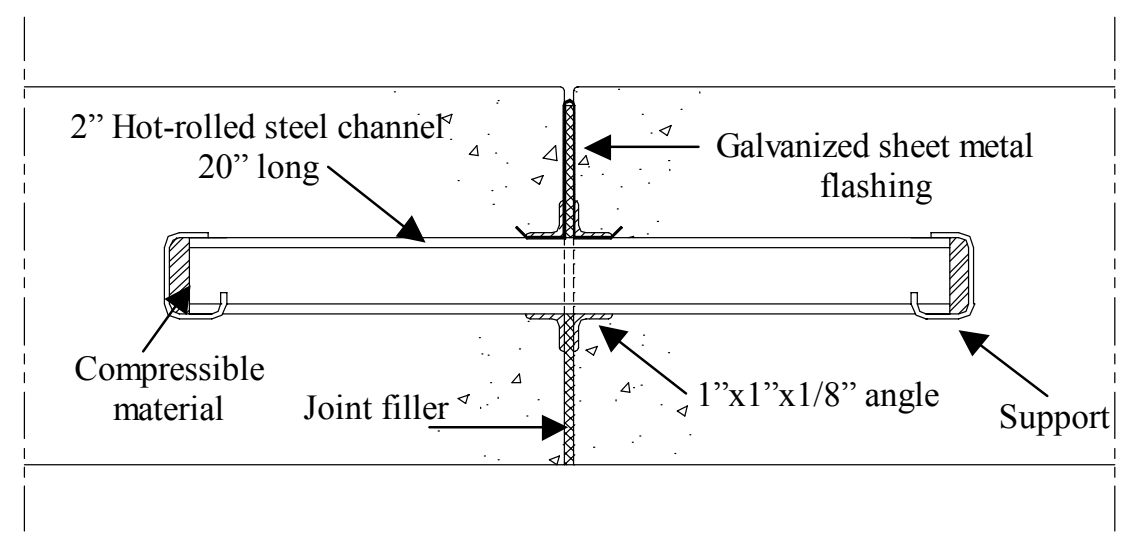

(a) Channel-dowel joint

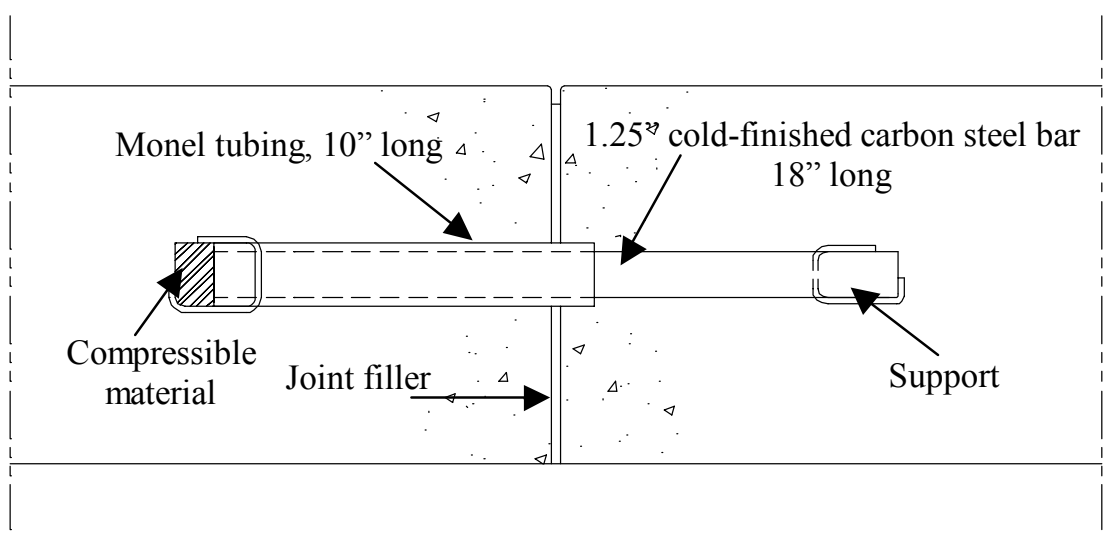

(b) Monel Dowel



(c) Dowel with sleeve

Figure 1.1 - Different configuration of dowels previously employed in joints 


\section{CHAPTER TWO}

\section{DESIGN FEATURES AND MANUFACTURING OF SHOKBARS}

\subsection{INTRODUCTION}

As wheel loads pass over doweled pavement joints, the dowel bars transfer a portion of this load to the adjacent slab through shearing force and bending moments on the bars. This load transfer mechanism induces a high level of contact stresses in the concrete that surrounds the dowel. Studies of stresses around dowel bars showed that two zones of compressive stress concentration lay on top and bottom of the dowel bar (Friberg, 1938). Depending on the bearing capacity of the concrete, crushing of concrete material at those locations can occur, creating an oblonging void space in the positions of direct contact with the dowel which is prone to increase after a significant number of vehicles have passed over the joint. The existence of such void deteriorates the ability of dowels to transfer the load effectively.

Detailed three-dimensional finite element modeling of the dowel-concrete interface revealed the existence of tensile stress concentration zones that lay on both sides of the loaded dowel (Shoukry and William, 2001). Although the tensile stress decays significantly as the distance from the joint face increases, the stress magnitude is high enough to cause smeared cracks on both sides of the dowel. These findings were verified through experimental testing on simulated doweled joint specimens subjected to static, dynamic and fatigue loading ( $\operatorname{Riad}, 2001)$. While crushing of concrete on top and bottom of the dowel depend on the bearing capacity of concrete material, formation of tensile cracks occur first; once the modulus of rupture of the material is reached. Although these tensile cracks are not expected to propagate to a large depth from the joint face, they will most likely reduce the fatigue life, and load transfer efficiency across the joint (Shoukry et al., 2002). A parametric investigation within this study concluded that concrete contact stresses remain significantly high when better class concrete is used, or when the slab thickness is increased. Also it was shown that an increase in dowel diameter is unlikely to cause significant reduction of the stress magnitude. Thus a new dowel design "Shokbar" was developed aiming to reduce the magnitude of contact stresses, and preserve the load transfer efficiency of doweled joints through the service life of 
pavement. The new design makes use of two steel sleeves that slide on the traditional dowel. The sleeves eliminate direct dowel concrete contact at the region of high tensile stresses.

\subsection{SLEEVE POSITION AND LENGTH}

Figure 2.1 illustrates the distribution of vertical stresses on top of a loaded dowel calculated using Friberg's (1938) equation in comparison with the stresses obtained from a three dimensional finite element model (Riad, 2001). The 3DFE results indicate that high compressive stresses occur at the face of the joint, and diminish sharply as the distance from the joint face is increase. Since Friberg's solution is based on the assumption of uniform modulus of dowel support along the dowels, the 3DFE solution is considered more accurate.

Figure 2.2 shows the distribution of vertical stress (tensile stress) at the dowel/concrete interface on the side of the dowel (Shoukry and William, 2001). The Figure indicates that the high magnitudes of tensile stresses occur at the face of the joint, and decreases to a minimum value within the first two inches inside the concrete slab. Based on this, the protective sleeves are placed 0.5-in away from the joint face and its length is chosen to be 1.5 -in.

\subsection{SLEEVE THICKNESS}

Figure 2.3 illustrates the distribution of concrete stresses around a loaded dowel (Shoukry and William, 2001). The regions where detrimental tensile stresses develop lay within a radial distance of 0.25 -in from the dowel edge. Therefore it is evident that a replacement of the concrete material within 0.25 -in around the dowel with a stronger one will be sufficient to absorb these stresses. Thus a 0.25 -in thick sleeve would be sufficient to absorb all the tensile stresses around the dowel.

\subsection{SLEEVE MATERIAL}

The material selected for the sleeves have to be of better characteristics than concrete both in compression and in tension in order to withstand the compressive and tensile contact stresses. Several materials were tested including steel, polymer concrete,

polyurethane, and hard rubber. Out of those materials Polyurethane and hard rubber were 
eliminated as candidates based on the analysis of Riad (2000). Steel offers a better property than regular concrete in terms of range of elasticity, and less susceptibility to brittle damage. Steel material is also more resistant to fatigue loading than concrete, and could support the dynamic effect of wheel loads. However, making the sleeves out of steel would be expensive due to the required tolerance between the sleeve's inner diameter and the dowel. To overcome the problem of machining tolerance the sleeves can be formed by casting polymer concrete around the dowel. Polymer concrete is a chemically engineered product that uses a reactive resin as a binder to develop a compound that has extremely high strength properties. In our application, FX-826, polymer concrete manufactured by Fox Industries was selected for manufacturing the sleeves. This product uses methyl methacrylate (MMA) as a resin binder, that when mixed with hardener filler material produces a paste that can be worked out in any required shape. The produced polymer concrete has high compressive, flexural, and tensile splitting strengths. When set, this product is not affected by freeze-thaw cycles and develops an abrasion resistant surface. It is also chemically resistant to sulfates, deicing chemicals, and acids.

\subsection{SLEEVE/DOWEL CONTACT INTERFACE}

The outside surface of the sleeve should have a permanent bond with the concrete while the inside surface should allow free sliding of the dowel inside the sleeve with minimum friction. In the case steel sleeves, (Figures 2.4(a) and 2.5(a)) their inner diameter was machined with a clearance of $0.15 \mathrm{~mm}$ with the outside surface of the dowel. This clearance was filled with silicon compound that provides permanent lubricant and corrosion protection of the interface. Considering the constant daily motion of the joints as they open and close, any type of protective paint applied on the sleeve inner surface is prone to gradually disintegrate by friction contact. Therefore a thin coat of the Dow Corning ${ }^{\circledR} 111$ compound was selected to serve this purpose.

The polymer concrete sleeves, Figure 2.5, were formed by casting on 0.002 in thick sheet of Teflon thick rapped tightly around the bar. The Teflon sheet considerably reduces friction between the solidified polymer sleeve and the sliding dowel. The casting of polymer concrete required the use of a mould. Different materials were assessed for 
the manufacturing of molds including wood, Teflon, and aluminum. The wooden molds proved to be the most appropriate, while the Teflon molds suffered from change in dimensions due to creep, and aluminum molds showed certain difficulties with extracting out the product due to surface adhesion. Figure 2.6 shows details of the molds that were used to cast polymer concrete sleeves for 1.5 " and 1.25 " polymer concrete shokbars. Each mold consisted of two identical parts that when put back to back together formed the shape of the sleeve.

Molds are centered along the dowel, closing on the steel bar and the middle separator, and the whole device is held in an upright position where one sleeve could be cast and set to cure. The assembly is turned upside down, and the second sleeve is cast, and set to cure. This procedure takes about 2 to 3 hours in the lab; after which the molds are taken apart. Prior to placing polymer concrete in the wooden molds a layer of Teflon sheets is wrapped around the steel dowel. The polymer concrete sleeves not only provide a homogenous medium with the surrounding concrete material of the slab, but also ensure minimum clearance with the dowel with no additional cost. The surfaces of the sleeves were tapered, as illustrated in Figures 2.4(b) and 2.5(b), in order to facilitate extraction of the molded polymer from the wooden mould. 
Table 2.1 - Physical properties of Polymer concrete

\begin{tabular}{|c|c|c|c|c|c|}
\hline Concrete property & 1 hr. & 2 hrs. & 8 hrs. & 4 days & 7 days \\
\hline $\begin{array}{c}\text { Compressive Strength, psi (ASTM C-109, } \\
\text { Mod.) }\end{array}$ & 8,000 & 8,500 & 9,000 & 11,000 & 12,000 \\
\hline Tensile Strength, psi (ASTM C-190) & 1,400 & 1,600 & 1,650 & 1,750 & 1,800 \\
\hline Flexural, psi (ASTM C-348) & 3,400 & & 3,470 & & \\
\hline
\end{tabular}




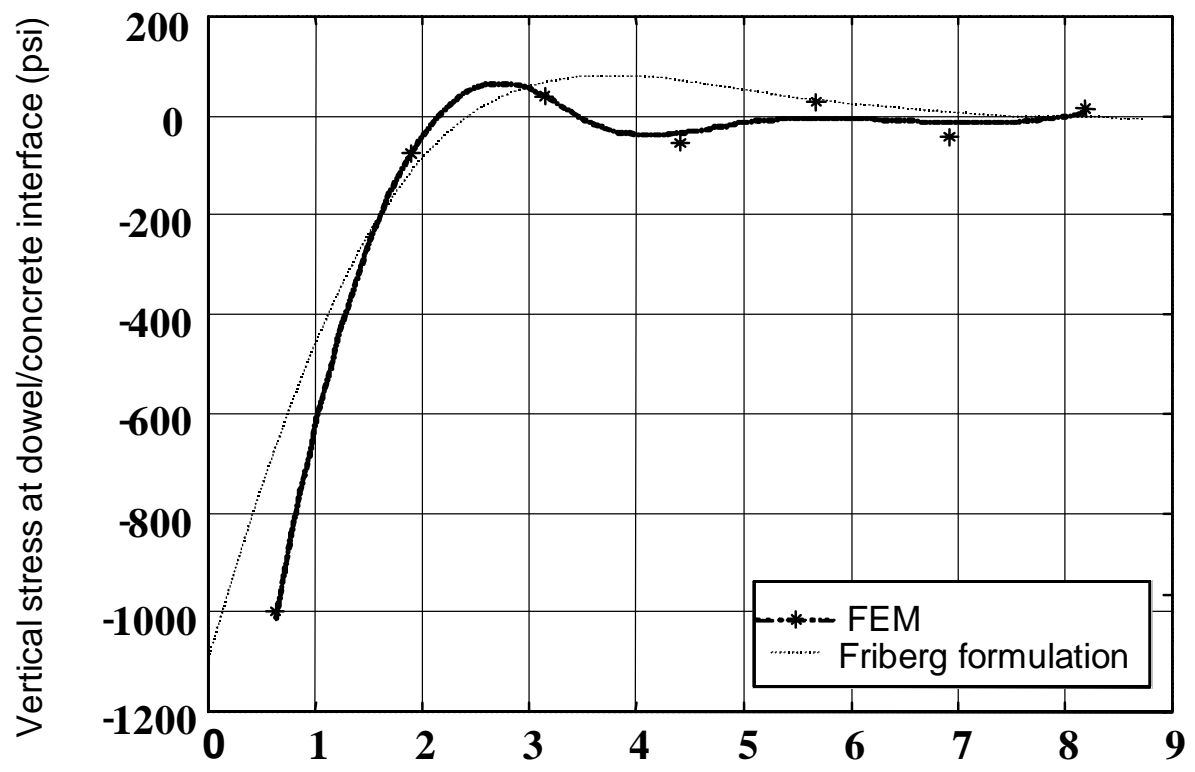

Distance along dowel bar from edge of loaded slab (in)

Figure 2.1 - Vertical stress distribution along dowel bar (Riad, 2001)

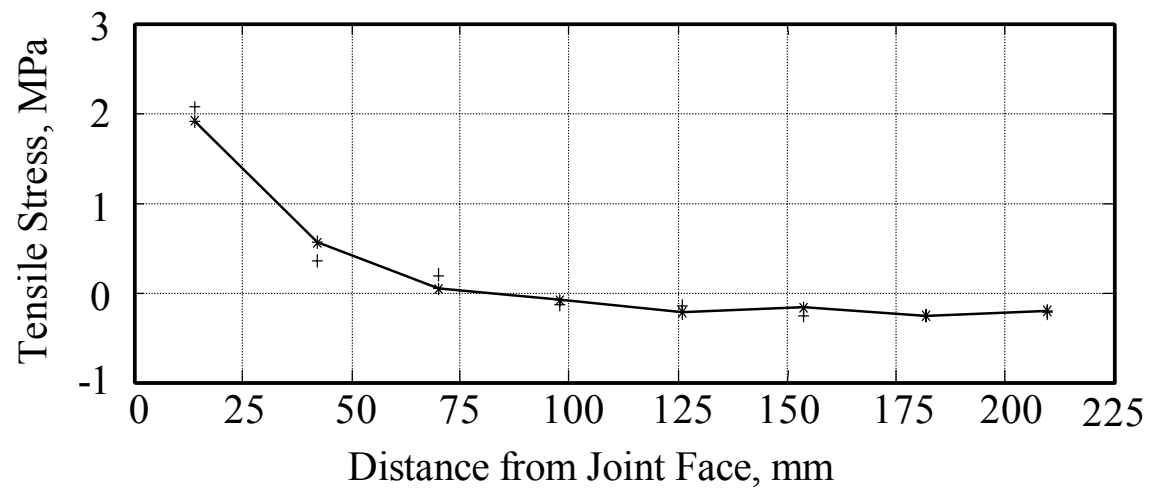

Figure 2.2 - Tensile Stress along the Dowel Bar (Shoukry et al., 2001) 


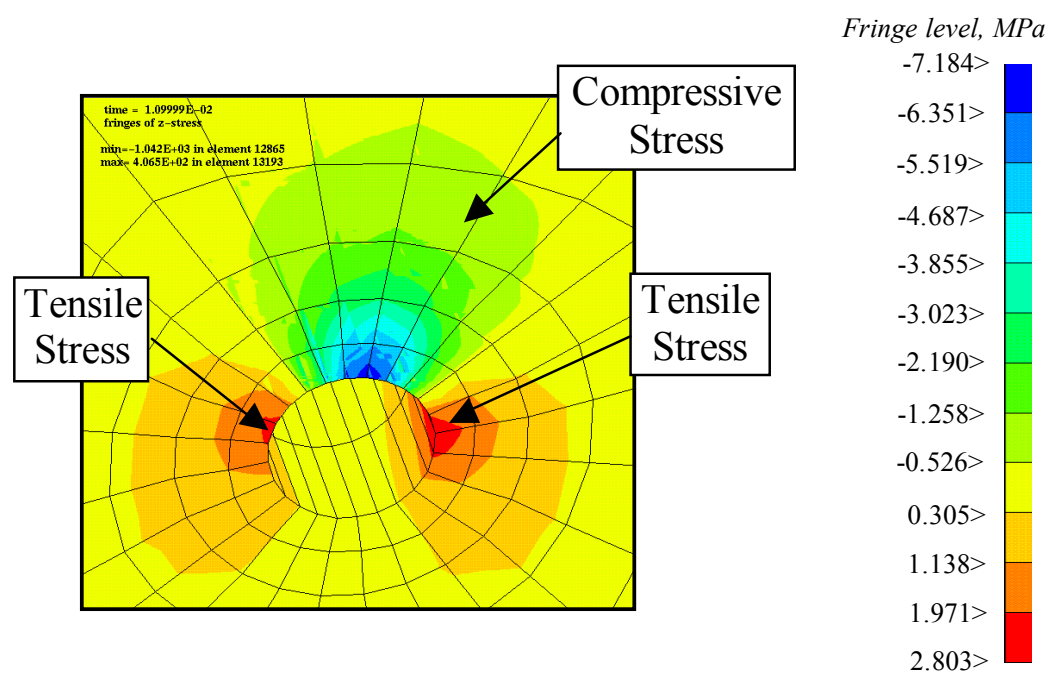

Figure 2.3 - Stress concentrations around Loaded Dowel (Shoukry et al., 2001) 


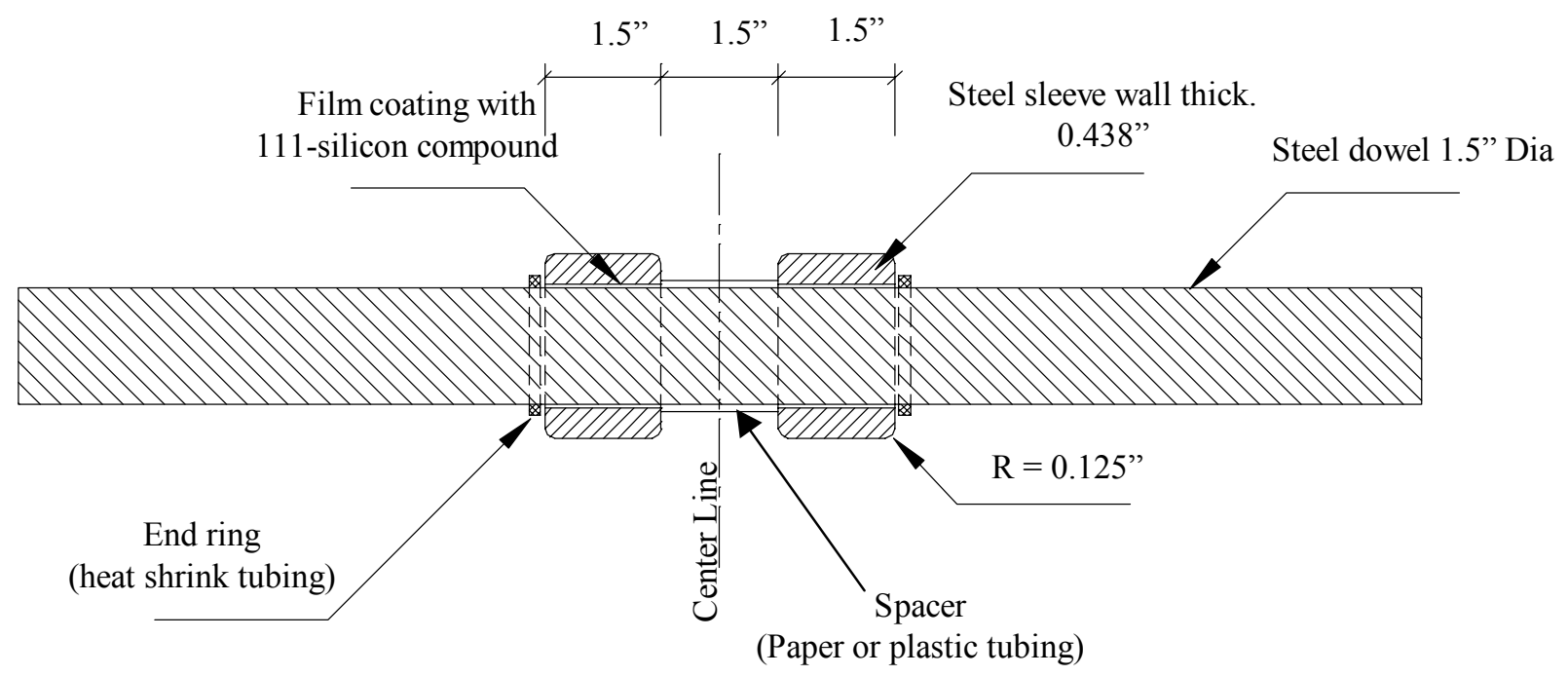

Figure 2.4(a) - Steel shokbar 1.5-inch Dia.

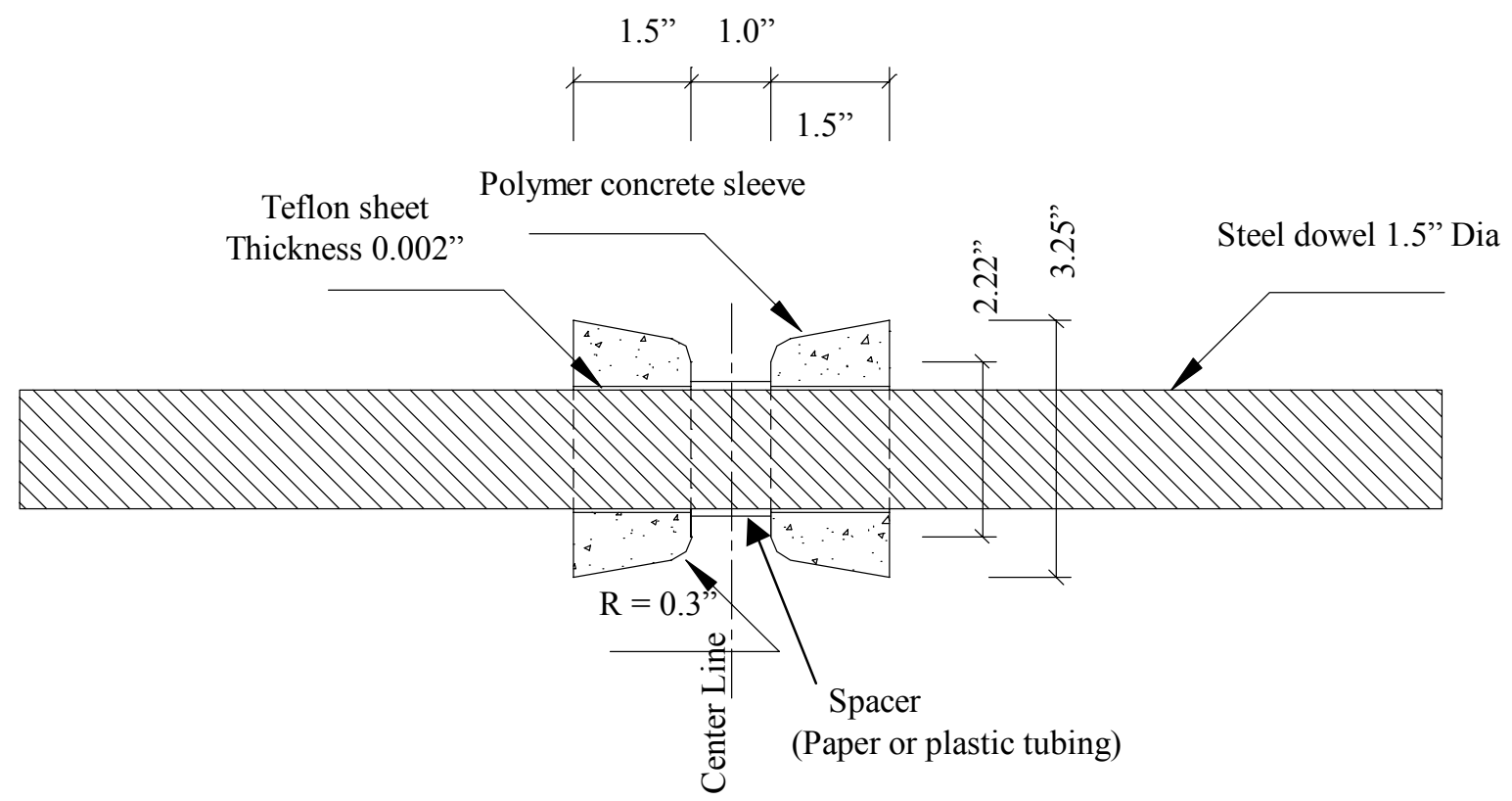

Figure 2.4(b) - Polymer shokbar 1.5-inch Dia.

Figure 2.4 - Details of 1.5-inch Dia. Shokbar 


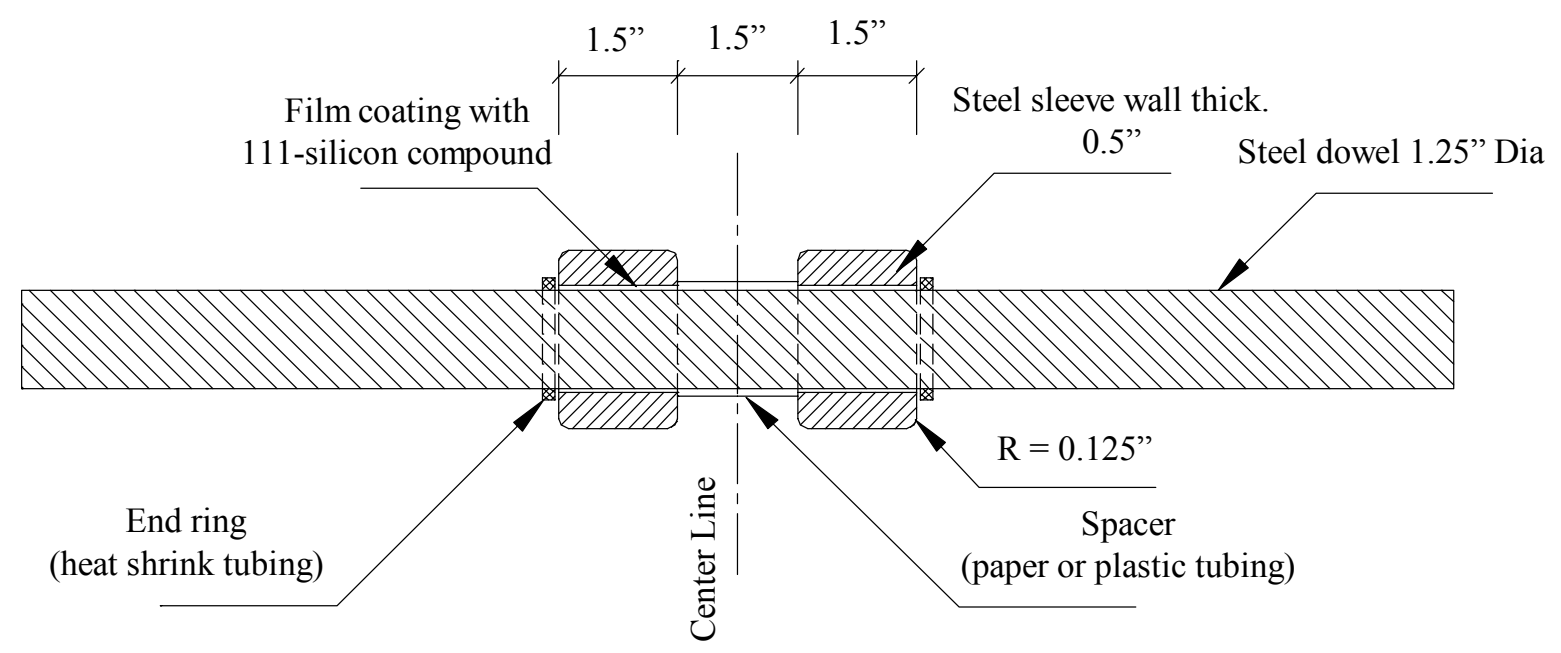

Figure 2.5(a) - Steel shokbar 1.25-inch Dia.
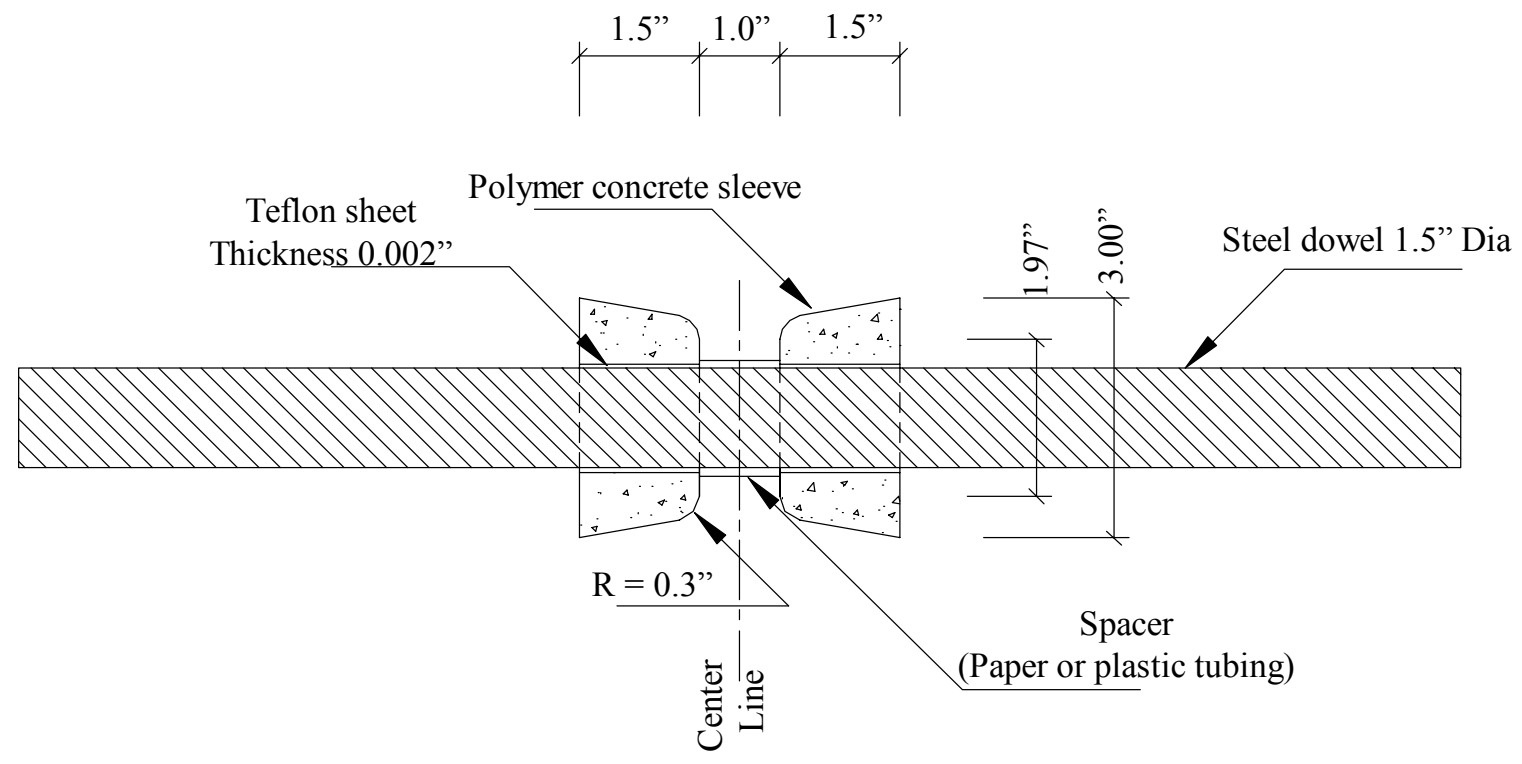

Figure 2.5(b) - Polymer shokbar 1.25-inch Dia.

Figure 2.5 - Details of 1.25-inch Dia. Shokbar 


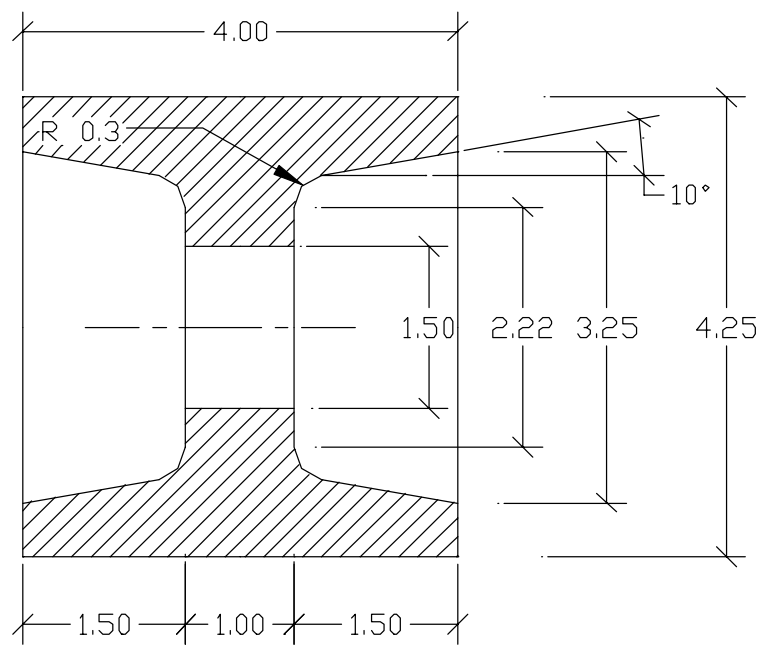

(a) Polymer shokbar 1.5-inch Dia.

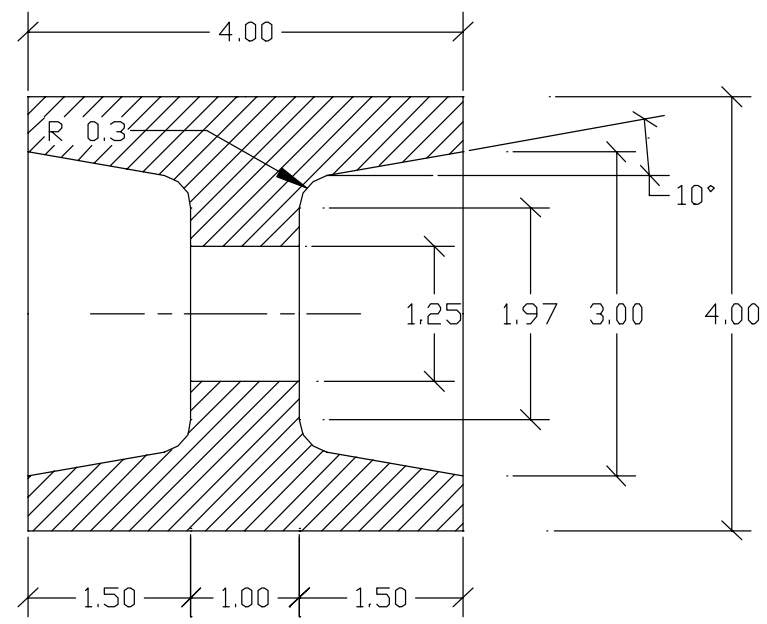

(a) Polymer shokbar 1.25-inch Dia.

Figure 2.6 - Molds details for casting polymer concrete sleeves 


\section{CHAPTER THREE EXPERIMENTAL STUDY}

\subsection{INTRODUCTION}

In this chapter, an experimental study on simulated doweled joints is presented. Experiments were conducted to characterize the performance of shokbars in comparison with regular dowel bars and to validate the findings from a finite element model that will be presented in Chapter 4. Simulated joints were initially subjected to static loading and then followed by fatigue loading for five million cycles of loading. Strains in critical locations in the concrete specimen, dowel bending moment, dowel shear force, and the relative displacements at the joints were measured.

\subsection{TEST CONFIGURATION}

The overall configuration of the test was based on the Standard Method of Test for Coated Dowel Bars specified by the American Association of State Highway and Transportation Officials (AASHTO) designation T 253-76. Three load-deflection tests were conducted on three identical specimens, each having two joints containing one type of load transfer device. In this case, six dowels of the same type are tested for one set of specimens. Each specimen consists of casting concrete blocks around two bars in a manner to simulate two 12-in long highway contraction joints. The joints are cast into molds, properly consolidated, and moisture cured then placed in a test machine and loaded. The end sections are provided with suitable hold-down devices to prevent rotation. Loading was applied on the joints with a specific loading rate and magnitude that provide similar types of stresses and deflections experienced in the field. In this

study, the load was applied at the rate of $1500 \mathrm{lb} / \mathrm{min}$ until a load of $4000 \mathrm{lb}$ was obtained. The deflection of the loaded center section with respect to supported stationary ends was measured under $4000 \mathrm{lb}$ maximum load as per the standard test procedure. For the purpose of this study, more features were added to the test, and more data were collected in order to investigate the response of the joints as well as conduct a conclusive comparison between the behaviors of each dowel design. Collected data included strains at the face of the joint around each device, straining actions of the bars, and fatigue characteristics of the joints were also investigated with this data. 


\subsection{TEST SPECIMENS}

Following AASHTO T253-76, the test specimens consisted of three groups each contained three specimens fitted with one type of loading transfer device. These were regular coated dowel bars, steel shokbars, and polymer shokbars. In total 9 specimens were constructed as illustrated in figure 3.1, and 18 joints were tested. The specimen dimensions were chosen according the AASHTO T253-76 specifications and are shown Figure 3.2. The construction of the specimens was performed in four stages:

1. Preparation of instrumented dowels and shokbars.

2. Construction of molds and casting of end sections of specimens.

3. Application of strain gages on the joint faces.

4. Casting of loaded section of the joint.

\section{Preparation of instrumented dowels and shokbars:}

All bars used for regular dowels and shokbars in this study had a common diameter of 1.25 inches and a length of 18 inches. The dowel bars and shokbars were prepared for application of strain gages in designated locations in order to record the strains developed within the bars as a result of loading. Considering symmetry, only one dowel in each specimen was instrumented. Previous studies have shown that the dominant forces on dowel bars are shear forces and moments about $\mathrm{x}$-axis, while moment about y-axis, torque and axial forces do not contribute significantly to the response of dowels (Sargand and Hazen, 1994). Therefore instrumentation of the bars was aimed at collecting data for shearing forces and bending moments. Meanwhile, axial forces could be easily calculated using the same sensors provided the bending moments data. Each instrumented bar had undergone careful procedure to mount and moisture-insulate the strain gages at their proper locations, with the goal of producing instrumented dowel with almost no change in its characteristics or its outside surface profile. To figure out the bending moments and axial forces, two wire-resistance uniaxial strain gages mounted on the top and bottom of the dowel at its mid-span as illustrated in Figure 3.3. Strain gage type CEA-06-500UW-120 manufactured by Micro-measurements was used. When the dowel is loaded, the strain data are recorded and post processed to calculate the built in bending moments and axial forces using the following equations: 
Moment acting on the dowel, $M=\frac{\left(\varepsilon_{\text {top }}-\varepsilon_{\text {bottom }}\right)}{2 y} \times E I$

(Equation 3.1)

Where: $\varepsilon_{\text {top }}=$ Strain on top of dowel

$\varepsilon_{\text {bottom }}=\quad$ Strain on bottom of dowel

$E \quad=\quad$ Young's modulus of dowel

$I=$ Moment of inertia of dowel cross section

$A \quad=\quad$ Cross-sectional area of dowel

$$
\text { Axial force }=\left(\varepsilon_{\text {top }+} \varepsilon_{\text {bottom }}\right) E A / 2
$$

Shearing strains were measured using a 90 degrees rosette mounted on one side of the dowel as illustrated in Figure 3.3. The strain rosette type CEA-06-187UV-120 manufactured by Micro-measurements was used for this purpose. Shearing forces on the dowel were calculated using the following equation:

$$
\text { Vertical shear force, } P=\frac{3}{4}\left(\varepsilon_{1}-\varepsilon_{2}\right) \times G A \quad \text { (Equation 3.3) }
$$

Where: $\varepsilon_{l}=$ Strain in leg of rosette directed upward

$\varepsilon_{2}=\quad$ Strain in leg of rosette directed downward

$G=$ Shear modulus of dowel material

The strain gages were bonded to machined flats as shown in Figure 3.3. After bonding, the lead wires from each strain gauge were passed through a shallow groove that extend from the end of the machined flat to the dowel end as illustrated in Figure 3.3. The grooves were then filled with steel epoxy (JB Weld) and special moisture and electrical isolative epoxy was cased on each strain gage so that the cylindrical form of the dowel is fully restored. After the bars were instrumented, steel sleeves were added to the bars to form steel shokbars shown in Figure 3.4. Similarly polymer concrete was cast on the instrumented dowels to form polymer shokbars.

\section{Construction of molds and casting of end sections}

Concrete specimens were cast in wooden forms prepared according to the required dimensions. In order to be able to mount strain gages on the face of the joint, it 
was necessary to cast the end sections first and set them to cure. The end sections consisted of two concrete end blocks encasing half the length of the dowels and/or shokbars. Wooden bottom boards and three out of four sides were prepared as molds to cast the end sections. Steel plates $1 / 4$ inches thick were prepared for the fourth side, which form the face of the joint. Steel plates were used in order to provide a fairly smooth and finished surface that would facilitate mounting of strain gages once the blocks were cured. Dowel bars and/or shokbars were mounted perpendicular to the steel plate, passing through a circular opening centered on the joint. In order to be able to remove the sides of the molds once the blocks were set, the steel joint face was split in half vertically at the center, and held together with steel strips. Figure 3.5 illustrates the construction of molds and installation of dowels and shokbars. Figure 3.6 shows a part of the prepared molds ready to cast the ends sections of specimens. The end sections were cast, consolidated by vibration and the side forms are removed 24 hours after initial setting. The blocks are set to moist cure for 14 days prior to application of strain gages.

\section{Application of strain gages on the joint faces:}

Although certain measures were taken to provide a suitable concrete surface at the

face of the joint, it was necessary to follow special preparation procedures in order to ensure that the strain gages are properly applied to the joint surface. These provisions serve to protect the gage from mechanical damage and from hostile environment of concrete and moisture. The use of steel plates within the forms at the face of the joint helped to minimize the surface irregularities to a great extent. On the other hand, formation of small pockets of air bubbles resulting from the action of consolidating the mix by vibration was inevitable in some cases. This problem prevented the installation of gages at a few locations.

Uniaxial strain gages were applied on the joint surface at locations where maximum stresses develop once the specimens are loaded. Strain gages were installed on both sides and underneath the bars to record tensile and compressive strains respectively. Although symmetry exists on both sides of the bar, it was decided to install gages on both sides as a precautionary measure taking into account that recording strains at locations of tensile stress concentrations on concrete surface is very delicate and sensitive task where vulnerability of the gages highly expected. The reason for recording tensile strains at a 
distance from the bars is to provide additional data that would help verify the finite element models. Special care was taken in order to mount the gages as close as possible to the bar/concrete interface in order to capture the strain concentration developed around the bar perimeter. Figure 3.7 shows the location where gages were installed and the accompanying distance variables are listed in Table 3.1.

All applied gages were from the wire resistant type manufactured by Micro measurements group. Smaller gage lengths were designated for those closer to the bar/concrete interface in order to avoid averaging of strains over long distances that may fall outside the stress concentration zones. The tension-1 gages selected are CEA-06250UW-120 and CEA-06-500UW-120 applied on either side of the bar. TYPES CEA-06500UW-120, and WK-06-10CBE-350 were designated for tension-2 (the distant gages from the bars), which laid in wider strain zones. Table 3.2 shows the main features and specifications of each strain gage.

Installation of strain gages was done with special care in order to ensure that strains on the surface of concrete are fully transmitted to the strain gage. Soils and contaminants were removed from concrete surface with water. Surface irregularities were removed by paper gritting. A Conditioner was applied generously over gaging area and cleaned with sponge. A Neutralizer was applied on the surface and cleaned with cotton sponge. Finally, the surface was cleaned with distilled water. Then, an adhesive (M-bond AE-10) was applied to the gaging area as a sealer that was worked into any voids. Once cured, this adhesive provided a suitable gage-bonding surface, and a barrier for moisture attacks that could infiltrate through the porous concrete material from the back of the gage. The gages were then bonded at their proper locations around the bars, and normal procedures were followed to attach their lead wires. The gages were environmentally protected and secured against moisture and mechanical shocks. A protective coating (Mcoat J) was applied on each gage, in order to seal the gage from moisture and contaminants. Prior to the application of the coating agent, all the exposed electrical connections and the exposed foil were covered with a layer of Teflon tape. This was necessary to provide insulation against electrical leakage and to minimize gage resistance shifts during the cure cycle. In order to ensure that the vinyl-insulated lead wires were firmly bonded to the protective coating, it was also necessary to apply a primer (M-Coat 
B) that bites into the vinyl insulation and provides a good bonding surface for the subsequent coating. When fully cured, the (M-coat $\mathrm{J}$ ) forms a rubber-like covering that provides effective barrier against moisture and protects the gages against mechanical damage. Figure 3.8 illustrates the stages in bonding the gages to the concrete surface.

4. Casting the loaded section of the joints

Once the strain gages were bonded and the protective coating was fully cured all gages were tested for the proper resistance and for insulation against electrical leakage. Foam sheets 0.4-in thick were used as separators to form the joints. These were prepared and placed to cover the end-sections faces, while the remaining sides of the forms were inserted to cast the middle part of the specimens. Figure 3.9 shows the last stage of specimen preparation where the joint separators installed, and the middle section ready for casting.

Specimens were removed from the forms and cured in accordance with the standards. Specimens were moved from one place to the other using an overhead crane, while the chains were wrapped around the lifting bars at the sides of the specimen. Maximum care was taken while removing the specimens from the casting forms, while moving the specimens from the place of construction to the test rig, and while conducting the experiments.

\subsection{MATERIAL PROPERTIES}

\section{Concrete:}

All specimens were cast using Portland cement concrete. The concrete mix was proportioned to have a compressive strength targeting 5500 psi with a slump average of 2.5 in. For each cast, eight standard concrete cylinders (6 in $\times 12$ in) were prepared to verify the compressive strength of the concrete mix. The concrete mix proportions, with a listing of used materials sources are listed in Table 3.3. All specimens were allowed to cure in a moist condition, covered with wet burlap and plastic sheets. Testing of concrete cylinders indicated a mean compressive strength of 5128 psi after 10 days, and 5764 psi after 28 days. 


\section{Steel dowels:}

All dowels used were 18 in long, regular epoxy coated dowel bars, round in cross section, with a diameter of 1.25 in. Dowels were supplied by American Highway Technology and tested by SMI Steel. Table 3.4 contains a listing the dowel material properties

\section{Polymer concrete sleeves:}

Polymer concrete was used for manufacturing of polymer concrete sleeves as a component of polymer shokbars. FX-826 polymer concrete supplied by Fox Industries was used for this purpose. The mechanical properties of this product achieved at normal room temperature $\left(70^{\circ} \mathrm{C}\right)$ are listed in table 3.5 .

\subsection{LOADING}

Specimens were tested for both static and dynamic fatigue loading. . A ramp load that increases in magnitude at a constant rate of $25 \mathrm{lbs} / \mathrm{sec}(0.111 \mathrm{KN} / \mathrm{sec})$ up to $4000 \mathrm{lbs}$ $(17.80 \mathrm{KN})$ was used for static testing. The maximum load magnitude of $4000 \mathrm{lbs}$ follows the loading specifications described in AASHTO Designation T 253-76 for testing coated dowel bars. This amount of load was also proved to produce comparable states of stresses around the load transferring devices in field joints (Riad, 2001). Figure 3.10 illustrates the load curve used for this study.

Fatigue testing was conducted to estimate the relationship between the response of jointed specimens and cyclic loading. The primary interest of fatigue testing was not to define the fatigue limit of the specimens where failure would occur at a certain number of cycles, but to compare the behavior of each device when subjected to fatigue loading. All specimens were tested at a constant rate and amplitude. Loading was applied on the specimens with a sine wave curve (mean load of $2500 \mathrm{lb}$, with a span of $1500 \mathrm{lb}$ ) configuration, where the minimum and maximum amplitudes were $1000 \mathrm{lbs}$, and 4000 lbs respectively. The fatigue effect on each specimen was verified by conducting series of static tests at an interval of $1 / 2$ million cycles, where the change in strains around the bars and deflection amplitudes were recorded. 


\subsection{TEST RIG STRUCTURE}

The test set up shown in Figure 3.11 consists of a loading frame where concrete specimens were mounted and tested. The supporting system was carefully set as highly rigid. The loading and data collection are computer controlled, thus eliminating human errors in loading and data collection. The schematic drawing is shown in Figure 3.12.

The test setup consisted of hydraulic actuator (1) manufactured by MTS that acts against a rigid steel frame (2). The actuator is capable of applying static as well as dynamic loads up to 20,000 lb. The hydraulic actuator is driven by a hydraulic pump (3). The pump is controlled by a programmable controller unit (4) that is connected to a computer (5). The computer control software automates the application of load. The program is able to apply loads of desired magnitude with selected rates of loading and unloading, as well as cyclic loading with required frequency. The load is transmitted to the specimens through a ram and is applied on a steel plate. The magnitude of the applied load is measured using a load cell (6). The specimen supporting system consists of a structural I beam (7), resting on the floor. Vertical displacements are measured using a linear voltage displacement transducer (LVDT) (8) mounted using a magnetic block. The measured data, i.e., the load magnitudes, vertical displacements, and strains are fed to the data acquisition system.

The data acquisition system is Micro Measurements System 6000 (9) that is designed for the measurement and recording of strain gauge data, loads, and displacements. This system is driven by the computer that also controls the MTS hydraulic pump.

The end blocks of the specimen (10) are fixed to the supporting system with threaded rods (11). Two LVDT's are used to collect vertical displacement data from both the unloaded and loaded side of the double joint specimen.

\subsection{INSTRUMENTATION AND DATA ACQUISITION}

All instruments used for recording data were electronic devices that were able to load and store information in real time, thus eliminating any possible human error in data collection. Instruments were selected to record data for the magnitude of the applied load, 
vertical displacements of the top surface of the joint, strains at the joint's face around the dowel bars, and moment as well as shearing strains on tested load transferring devices.

The applied load was measured using an MTS strain gage load cell, and monitored through the MTS controller unit, which also provided an additional DC output signal. Figure 3.13 illustrates the calibration curve for the load cell.

Deflections were measured using LVDT's that translate linear displacement into alternating current (AC). The AC is fed into a signal conditioner module that produces a direct current (DC) voltage proportional to the input displacement. Model 060-A797-05 manufactured by Sensotec was used to record vertical displacements with a stroke of \pm 0.5 in. The body of the LVDT was held in a fixed position by means of holders mounted on magnetic blocks, while the bottom of the core rested on the top surface of the specimen. The relative movement between the core and the body provided the displacement of the specimen surface. In order to record the relative displacement of the joint, one LVDT was placed on each side of the joint. All LVDTs used in the experiments were calibrated by the manufacturer, and prior to installation in the setup, their calibration and sensitivity were checked by monitoring the output signal versus known displacements applied by a micrometer. Calibration data sheets for the used LVDTs could be found in Appendix I. Strains were recorded through wire resistant strain gages. Details of the various strain gages used are stated in section 3.3.

System 6000 manufactured by Micro Measurements Group was used to collect and save data. The scanner model 6100 is capable of acquiring various high-speed analog inputs and digitization of multiple channels simultaneously. Sampling rate control (up to 10,000 samples per second per channel), data reduction and real-time graphic presentations were incorporated through full-featured software. The system was equipped with 20 channels that were configured to receive the following single-channel plug-in cards:

- Model 6010 Strain gage input card, for recording strain readings

- Model 6030 High level- input card, for recording load data

- Model 6040 LVDT input card, for recording displacements data from LVDTs.

The system can handle up to a total of 200,000 samples per second. The system was incorporated with a computer that ran the software, display and store the data in real time. 


\subsection{RESULTS:}

\subsubsection{Static loading results}

\subsubsection{Load/strains results}

All specimens were subjected to static loading prior to fatigue testing. The main interest was to measure three strain values around each of the load transferring devices corresponding to the zones of stress concentrations at the bar/concrete interface. All measured strains belong to the stationary end section of the specimens. The locations of the strain gages were selected to record tensile strains on the side of the bar, and compressive strains at the bottom. An additional tensile strain away from the bar/concrete interface is also monitored. The strain results recorded from the static loading are listed in Table 3.6. All strain values correspond to the load magnitude of $4000 \mathrm{lbs}$, which is the peak value in the static loading configuration. The full strain-time histories are displayed in chapter 6 where they are compared with those from the FEM. In order to conduct a study on the behavior of each load-transferring device, the strain results are reduced to mean values for each strain component. Prior to the application of the load, all strain gages were checked individually for proper resistance and stability while the specimen is mounted to the test rig. Some gages suffered from a drift in their signal while others gave incorrect resistance values. This malfunction could be attributed to failure of the bond to the concrete face, failure of soldering tabs with the lead wires, or leakage in electrical resistance. Although special care was taken in handling and mounting the specimens to the testing facility, it was inevitable that some joints would suffer from such deficiencies. The configuration of the joints with the load transferring devices being the only means of connecting the three concrete sections make the bar/concrete interface vulnerable to stresses while moving the specimens. While all gages in the compression zones were properly functional, the empty cells in Table 3.6 indicate that a few strain gages designated to the tensile zones (which were more vulnerable) failed either before testing, or during fatigue loading. The missed readings as a result of strain gage failure in the tensile zones form $14.8 \%$ of the total collected static strain data. This small amount of missed readings is inevitable in any experimental study and do not prevent from reaching quantitative values that lead to conclusive findings. 


\subsubsection{Load/deflection results}

The only parameter that the AASHTO test method intended to record was the relative deflection between the stationary and the loaded sides of the joints. The test procedure states that the maximum deflection under a static load of $4000 \mathrm{lbs}$ should not exceed a value of 0.010 inches, for the acceptance of bars. The current study of the response of various load-transferring devices included this factor, but was not limited to it. Displacements across both joints of each specimen were continuously recorded as the static load was applied. Table 3.7 shows the results of maximum relative vertical displacement across each joint corresponding to the maximum load of $4000 \mathrm{lbs}$.

\subsubsection{Strains on bars}

Uniaxial strains on top and bottom of the bars as well as shearing strains were recorded and post processed to calculate bending moments and shearing forces on each specimen. Those values were then introduced to calculate analytical bearing stresses at the bar/concrete interface. Friberg established formulas to calculate the bearing stresses at loaded dowel/concrete interface based on mathematical approaches of dowel bending. In this analysis, Friberg introduced a theoretical parameter " $k$ " known as modulus of dowel support to express the relation between bearing stresses, vertical displacement of the dowel, bending moment, and shearing force. This parameter " $k$ " is defined as the load per unit area necessary to cause unit deflection at the bearing in concrete. Using " $k$ ", Friberg established a factor " $\beta$ " which he called "Dowel relative stiffness" that incorporated physical properties of the bar. The $\beta$ is defined by the following relation:

$$
\beta=\sqrt[4]{\frac{k \cdot b}{4 E_{s} I}}
$$

Where: $\quad \begin{array}{lll}b & = & \text { bar width (diameter) } \\ E_{S} & = & \text { Modulus of elasticity of the bar material } \\ I & = & \text { Moment of inertial of bar cross section }\end{array}$

While the dowel is loaded with a downward shear and moment, Friberg estimated the vertical deflection at the face of the concrete $\left(\mathrm{y}_{\mathrm{o}}\right)$ using the following equation: 


$$
y_{o}=\frac{P-\beta M_{0}}{2 \beta^{3} E_{s} I}
$$

In which: $\quad P \quad=\quad$ Downward shearing force

$$
M_{o} \quad=\quad \text { Moment }
$$

The bearing stress at the bar/concrete interface $(\sigma)$ is simply calculated as the product of the modulus of dowel support and bar deflection.

$$
\sigma=k \times y_{o} \quad \text { (6) }
$$

Table 3.8 shows values of bending moments and shearing forces calculated according to Eqs 3.1 and 3.3. Values of measured dowel deflections from table 3.7 and corresponding bending moments and shearing forces were used to estimate modulus of dowel support “k”, and bearing stresses " $\sigma$ " from Eqs 3.5 and 3.6 respectively.

The variation in calculated shearing forces and bending moments was due to the fact that it is very hard to hold the exact position of the joints relative to the loading devices for each individual specimen. Any slight variation in the position of the strain gages mounted on the dowels relative to the position of the joints and the loading system situates the bar where the data are collected in a different deformation zone. On the other hand, the calculated modulus of dowel support seems within reasonable range.

\subsubsection{Fatigue loading results}

\subsubsection{Load/strains}

Strains at tensile and compressive zones were measured at intervals of 500,000 cycles for a total number of five million cycles. The main interest is to explore the effect of fatigue loading on the bar/concrete interface where critical zones are located.

Figures 3.14 to 3.16 show values of strains measured at tensile and compressive zones around the tested bars versus number of loading cycles. The shown values of tensile and compressive strains are the mean values collected from the six joints fitted with the same load-transferring device. Details of strains measured from strain gages are listed in Appendix II. 


\subsubsection{Load/deflection}

Figure 3.17 shows measured vertical relative displacement across the joints as a function of the number of cycles. Mean values of the 6 joints pertaining to each device are plotted in this graph. All measurements for each individual joint are recorded in Appendix III. Those measurements are difference in vertical displacements recorded from the stationary end section, and the loaded middle section of the specimens. Special care was taken in order to take displacement measures at the same location on the top surface of the joints through various cycles of fatigue loading.

\subsubsection{Strains on bars}

Bending moments and shearing forces are calculated through strain gages readings through cycles of fatigue loading. Values of straining actions have been introduces in equations 3.4 to 3.6 to calculate the variation of bearing stresses at the bar/concrete interface. Figure 3.18 shows mean results for the 6 joints of each device, and all detailed measurements and calculations could be found in Appendix IV.

\subsection{DISCUSSION}

Static testing results of various devices were presented to gauge the response of joints in terms of strains, stresses and deflections due to a particular applied load representative of traffic loading. Such response would formulate the behavior of those devices when subjected to repeatable loading, thus it is important to have a deep understanding of the impact of each device on the joints and how they compare. Referring to Table 3.6, compressive strains at the bottom zones of regular dowels measured $50 \%$ and $70 \%$ higher than values measured for polymer shokbar and steel shokbar, respectively. Results of tensile strains at the bar/concrete interface show that polymer shokbar and steel shokbar were able to reduce this value by $76 \%$ and $80 \%$, respectively, compared to those measured in the regular dowel. The behavior of polymer shokbar and steel shokbar is also recognized by the reduction in the tensile strains measured away from the bar/concrete interface (0.7-in) by $34 \%$ and $59 \%$, respectively, compared to those measured for regular dowels specimens. From Table 3.7, the relative deflection between loaded and unloaded sides of joints were found to be similar for all devices subjected to static loading. Table 3.8 indicated that the bearing stresses in the 
case of polymer shokbar and steel shokbar were calculated to be $89 \%$ and $64 \%$ smaller than those calculated for regular dowel bars. The superior behavior of shokbars over regular dowels is well observed through all aforementioned key parameters that describe the response of load transferring devices. In light of the static loading results it may be expected that a superior behavior would also be observed in fatigue loading.

Through 5 million cycles of fatigue loading, compressive strains at bar/concrete interface kept an almost similar magnitude for each individual device. Compressive strains at bar/concrete interface (Figure 3.14) showed a slight reduction in the case of polymer shokbar and steel shokbar through the first 1.5 million cycles. While this observation indicates an improvement in the behavior of these devices over regular dowel bars, this could be attributed to material stiffening with repeated loading. On the other hand, a remarkable diversion in the tensile strains at the bar/concrete interface is recognized comparing the regular dowel bars from shokbars. The tensile strains at bar/concrete interface, Figure 3.15 indicated that polymer shokbar and steel shokbar succeeded in maintaining the exact minimum level of tensile strains throughout the whole cycles of fatigue loading (5 million cycles), while tensile strains at the regular dowel/concrete interface increased with number of cycles to almost double their initial value. This fact illustrates without any doubt the effectiveness of Shokbars in maintaining the stresses at the bar/concrete interface to a constant value through fatigue loading, thus preserving load transfer efficiency across loaded joints. Tensile strains away from the bar/concrete interface were observed with minimum changes through fatigue loading as was expected, since the effect of Shokbar is primarily designed to address deficiencies at the bar/concrete interface. Tensile strains at about 0.7 inches from bar/concrete interface, Figure 3.16, than for the static case. On the other hand, uniformity of tensile strains at this location indicates that all specimens were subjected to the same loading conditions through all cycles of fatigue testing. Vertical relative displacements across the joints were observed (Figure 3.17) to maintain the same magnitude through 5 million cycles of loading in the case of Shokbars. On the other hand this value slightly decreased in the case of regular dowel bars from 2.5 to 3.5 million cycles. This observation was attributed to potential formation of a crack at the tensile zones that increase through cycles of loading and also susceptibility of particles to crush in the compression zone. The 
configuration of the test implies that if this occurs, the middle block of the specimen would be displaced downward by gravity to replace any gaps that would take place at the dowel/concrete interface, thus produce more stiffening of the specimens, which would result in an apparent decrease in relative deflections across joints.

Calculated bearing stresses from straining actions of tested devices (Figure 3.18) indicate that the largest values are recorded for the regular dowel specimens. For those pertaining to polymer shokbar specimens bearing stresses encountered minimal changes. Apparent increase in these values to be higher for the steel shokbar specimens.

\subsection{CONCLUSION}

In light of the static and fatigue test results, it is concluded that the Shokbars are very effective in reducing the stress concentration at bar/concrete interface. Polymer shokbar and steel shokbars succeeded in reducing tensile and compressive strains at bar/concrete interface by at least 2 to 3 times compared to regular dowel bars. After five million cycles of fatigue loading, compressive and tensile strains at Shokbar/concrete interface were observed to be steady with minimal changes, while tensile strains at dowel/concrete interface recorded an increase by almost double their initial values. The remarkable increase in tensile strains at regular dowel/concrete interface is an indication of susceptibility of formation of tensile crack within this zone. Shokbars also maintained steady values of relative displacement across joints through all cycles of fatigue loading. Calculated values of bearing stresses from straining actions recorded from the tested devices indicate that the largest values were found in the regular dowel specimens, and this is attributed through both static and fatigue loading. 
Table 3.1 - Distance from center of strain gage grid to bar/concrete interface

(Note: all dimensions are in inches)

\begin{tabular}{|c|c|c|c|c|c|c|}
\hline Specimen & Joint & $\boldsymbol{a}$ & $\boldsymbol{b}$ & $\boldsymbol{c}$ & $\boldsymbol{d}$ & $\boldsymbol{e}$ \\
\hline \multirow{2}{*}{ Regular dowel 1 } & 1 & 0.2 & 0.7 & 0.15 & - & 0.25 \\
\cline { 2 - 7 } & 2 & - & - & 0.15 & 0.6 & 0.25 \\
\hline \multirow{2}{*}{ Regular dowel 2 } & 1 & 0.2 & 0.7 & 0.2 & - & 0.25 \\
\cline { 2 - 7 } & 2 & - & - & 0.2 & 0.8 & 0.25 \\
\hline \multirow{2}{*}{ Regular dowel 3 } & 1 & 0.2 & 0.75 & 0.15 & - & 0.25 \\
\cline { 2 - 7 } & 2 & 0.2 & - & 0.25 & 0.7 & 0.25 \\
\hline \multirow{2}{*}{ Steel shokbar 1 } & 1 & 0.3 & 0.65 & 0.2 & 0.6 & 0.25 \\
\cline { 2 - 7 } & 2 & 0.2 & 0.55 & 0.2 & 0.6 & 0.25 \\
\hline \multirow{2}{*}{ Steel shokbar 2 } & 1 & 0.35 & 0.7 & 0.3 & 0.65 & 0.25 \\
\cline { 2 - 7 } & 2 & 0.3 & 0.7 & 0.35 & 0.7 & 0.25 \\
\hline \multirow{2}{*}{ Steel shokbar 3 } & 1 & 0.3 & 0.6 & 0.2 & 0.6 & 0.25 \\
\cline { 2 - 7 } & 2 & 0.25 & 0.6 & 0.2 & 0.6 & 0.25 \\
\hline \multirow{2}{*}{ Polymer shokbar 1 } & 1 & 0.3 & 0.65 & 0.3 & 0.65 & 0.25 \\
\cline { 2 - 7 } & 2 & - & 0.7 & 0.25 & 0.65 & 0.25 \\
\hline \multirow{2}{*}{ Polymer shokbar 2 } & 1 & 0.3 & 0.75 & 0.25 & 0.65 & 0.25 \\
\cline { 2 - 7 } & 2 & 0.6 & 1.0 & 0.2 & 0.75 & 0.25 \\
\hline \multirow{2}{*}{ Polymer shokbar 3 } & 1 & 0.3 & 0.75 & 0.25 & 0.65 & 0.25 \\
\cline { 2 - 7 } & 2 & 0.25 & 0.65 & 0.3 & 0.7 & 0.25 \\
\hline
\end{tabular}

Table 3.2 - Properties of strain gages

\begin{tabular}{|c|c|c|c|c|c|}
\hline Gage designation & $\begin{array}{c}\text { Gage } \\
\text { length } \\
\text { (in) }\end{array}$ & Resistance & $\begin{array}{c}\text { Strain } \\
\text { limit }\end{array}$ & Fatigue life & $\begin{array}{c}\text { Gage } \\
\text { factor }\end{array}$ \\
\hline CEA-06-250UW-120 & 0.25 & 120 & $\pm 5 \%$ & $10^{5}$ at $\pm 1500 \mu \mathrm{s}$ & 2.065 \\
\hline CEA-06-500UW-120 & 0.50 & 120 & $\pm 5 \%$ & $10^{5}$ at $\pm 1500 \mu \mathrm{s}$ & 2.065 \\
\hline WK-06-10CBE-350 & 1.00 & 350 & $\pm 1.5 \%$ & $10^{7}$ at $\pm 2000 \mu \mathrm{s}$ & 2.05 \\
\hline
\end{tabular}


Table 3.3 - Concrete Mix proportions

\begin{tabular}{|c|c|c|c|c|}
\hline Constituent & Item & Supplier & $\begin{array}{l}\text { Wt. } \\
(l b)\end{array}$ & $\begin{array}{l}\text { Abs. Vol. } \\
\text { (cu.ft.) }\end{array}$ \\
\hline $\begin{array}{l}\text { Cementitious Materials } \\
\text { ASTM C } 150 \text { \& C } 618\end{array}$ & Type 1 & Armstrong Cement & 564 & 2.87 \\
\hline $\begin{array}{c}\text { Aggregates } \\
\text { ASTM C } 33 \text { \& ASTM C } 330\end{array}$ & $\begin{array}{l}\text { Greer } 57 \text { Limestone } \\
\text { Stocker Sand } \\
\text { Greer } 67 \text { Limestone }\end{array}$ & $\begin{array}{c}\text { Greer } \\
\text { Stocker \& Gravel } \\
\text { Greer } \\
\end{array}$ & $\begin{array}{c}950 \\
1147 \\
950 \\
\end{array}$ & $\begin{array}{l}5.64 \\
6.99 \\
5.64 \\
\end{array}$ \\
\hline Percent Air & & & $6 \%$ & 1.62 \\
\hline Water & & & 265 & 4.25 \\
\hline & MB AE 90 & $\begin{array}{c}\text { TOTAL } \\
\text { Master Builders }\end{array}$ & 3876 & $\frac{27}{2.82 \mathrm{oz} / \mathrm{yd}}$ \\
\hline $\begin{array}{l}\text { ASTM C } 260 \\
\end{array}$ & IVID AE 90 & & & \\
\hline $\begin{array}{l}\text { Other Admixtures } \\
\text { ASTM C } 494\end{array}$ & Polyheed 997 & Master Builders & & $39.48 \mathrm{oz} / \mathrm{yd}$ \\
\hline
\end{tabular}

Table 3.4 - Mechanical properties of steel dowel

\begin{tabular}{|c|c|c|c|}
\hline DESCRIPTION & Yield stress & Tensile stress & $\begin{array}{c}\text { Elongation } \\
\% \text { In 8” }\end{array}$ \\
\hline KSI & KSI & 14.0 \\
\hline $\begin{array}{c}\text { (ASTM A615M-96A) } \\
\text { Grade 60 }\end{array}$ & $\begin{array}{c}73.8 \\
(508.9 \mathrm{Mpa})\end{array}$ & $\begin{array}{c}99.8 \\
\text { (687.8 Mpa) }\end{array}$ & \\
\hline
\end{tabular}

Table 3.5 - Mechanical properties of polymer concrete material

\begin{tabular}{|c|c|c|c|c|c|}
\hline Concrete property & 1 hr. & 2 hrs. & 8 hrs. & 4 days & 7 days \\
\hline $\begin{array}{c}\text { Compressive Strength, psi (ASTM C-109, } \\
\text { Mod.) }\end{array}$ & 8,000 & 8,500 & 9,000 & 11,000 & 12,000 \\
\hline Tensile Strength, psi (ASTM C-190) & 1,400 & 1,600 & 1,650 & 1,750 & 1,800 \\
\hline Flexural Strength, psi (ASTM C-348) & 3,400 & & 3,470 & & \\
\hline
\end{tabular}


Table 3.6 - Strain readings around bars subjected to static loading

\begin{tabular}{|c|c|c|c|c|c|}
\hline Type of bar & $\begin{array}{c}\text { Specimen } \\
\text { number }\end{array}$ & $\begin{array}{c}\text { Joint } \\
\text { number }\end{array}$ & $\begin{array}{c}\text { Bottom } \\
\text { strain }(\mu s)\end{array}$ & $\begin{array}{c}\text { Tension-1 } \\
(\mu s) \\
\end{array}$ & $\begin{array}{c}\text { Tension-2 } \\
(\mu s)\end{array}$ \\
\hline \multirow{6}{*}{ 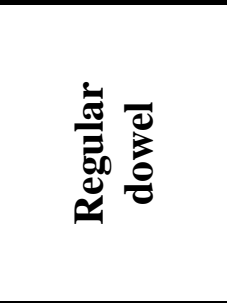 } & \multirow{2}{*}{1} & 1 & -145 & 212 & 35 \\
\hline & & 2 & -579 & 136 & -- \\
\hline & \multirow{2}{*}{2} & 1 & -420 & -- & 17 \\
\hline & & 2 & -820 & 108 & 42 \\
\hline & \multirow{2}{*}{3} & 1 & -115 & 150 & 24 \\
\hline & & 2 & -487 & -- & 56 \\
\hline \multicolumn{3}{|c|}{ Mean value } & -427.667 & 151.5 & 34.8 \\
\hline
\end{tabular}

\begin{tabular}{|c|c|c|c|c|c|}
\hline Type of bar & $\begin{array}{c}\text { Specimen } \\
\text { number }\end{array}$ & $\begin{array}{c}\text { Joint } \\
\text { number }\end{array}$ & $\begin{array}{c}\text { Bottom } \\
\text { strain }(\mu s)\end{array}$ & $\begin{array}{c}\text { Tension-1 } \\
(\mu s)\end{array}$ & $\begin{array}{c}\text { Tension-2 } \\
(\mu s)\end{array}$ \\
\hline \multirow{6}{*}{  } & \multirow{2}{*}{1} & 1 & -121 & -- & -- \\
\hline & & 2 & -383 & 41 & 23 \\
\hline & \multirow{2}{*}{2} & 1 & -215 & 24 & 14 \\
\hline & & 2 & -284 & -- & 42 \\
\hline & \multirow{2}{*}{3} & 1 & -506 & -- & 12 \\
\hline & & 2 & -255 & 42 & -- \\
\hline & Mean valu & & -294 & 35.7 & 22.75 \\
\hline
\end{tabular}

\begin{tabular}{|c|c|c|c|c|c|}
\hline Type of bar & $\begin{array}{c}\text { Specimen } \\
\text { number }\end{array}$ & $\begin{array}{c}\text { Joint } \\
\text { number }\end{array}$ & $\begin{array}{c}\text { Bottom } \\
\text { strain }(\mu s)\end{array}$ & $\begin{array}{c}\text { Tension-1 } \\
(\mu s)\end{array}$ & $\begin{array}{c}\text { Tension-2 } \\
(\mu s)\end{array}$ \\
\hline \multirow{6}{*}{ 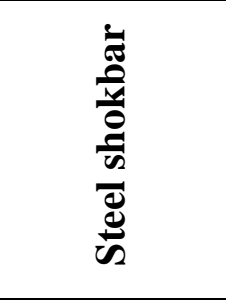 } & \multirow{2}{*}{1} & 1 & -138 & 35 & 14 \\
\hline & & 2 & -717 & 37 & 15 \\
\hline & \multirow{2}{*}{2} & 1 & -103 & -- & 17 \\
\hline & & 2 & -262 & 25 & -- \\
\hline & \multirow{2}{*}{3} & 1 & -142 & 39 & 12 \\
\hline & & 2 & -330 & 12 & 12 \\
\hline & \multicolumn{2}{|c|}{ Mean value } & -282 & 29.6 & 14 \\
\hline
\end{tabular}

Note: strain 1 refers to tensile strains at bar/concrete interface; strain 2 refers to tensile strains at about 0.7 in from the bar/concrete interface (see Figure 3.16) 
Table 3.7 - Maximum relative displacement across joints

\begin{tabular}{|c|c|c|c|}
\hline Type of bar & $\begin{array}{c}\begin{array}{c}\text { Specimen } \\
\text { number }\end{array} \\
\end{array}$ & $\begin{array}{c}\text { Joint } \\
\text { number }\end{array}$ & Relative displacement (in) \\
\hline \multirow{6}{*}{ 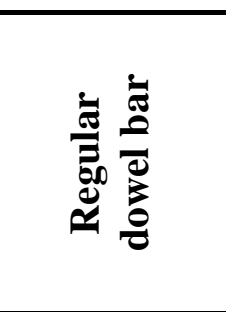 } & \multirow[b]{2}{*}{1} & 1 & $5.80 \mathrm{E}-03$ \\
\hline & & 2 & $3.20 \mathrm{E}-03$ \\
\hline & \multirow{2}{*}{2} & 1 & $4.90 \mathrm{E}-03$ \\
\hline & & 2 & $3.20 \mathrm{E}-03$ \\
\hline & \multirow{2}{*}{3} & 1 & $1.20 \mathrm{E}-03$ \\
\hline & & 2 & $1.60 \mathrm{E}-03$ \\
\hline \multicolumn{3}{|c|}{ Mean value } & $3.31 \mathrm{E}-03$ \\
\hline
\end{tabular}

\begin{tabular}{|c|c|c|c|}
\hline Type of bar & $\begin{array}{c}\text { Specimen } \\
\text { number }\end{array}$ & $\begin{array}{c}\text { Joint } \\
\text { number }\end{array}$ & Relative displacement (in) \\
\hline \multirow{6}{*}{ 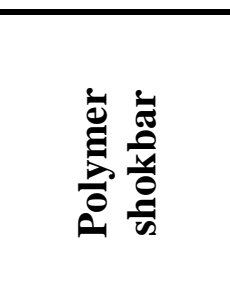 } & \multirow{2}{*}{1} & 1 & $2.4 \mathrm{E}-03$ \\
\hline & & 2 & $2.20 \mathrm{E}-03$ \\
\hline & \multirow{2}{*}{2} & 1 & $6.30 \mathrm{E}-03$ \\
\hline & & 2 & $2.20 \mathrm{E}-03$ \\
\hline & \multirow{2}{*}{3} & 1 & $3.20 \mathrm{E}-03$ \\
\hline & & 2 & $3.60 \mathrm{E}-03$ \\
\hline & ean value & & 3.31E-03 \\
\hline
\end{tabular}

\begin{tabular}{|c|c|c|c|}
\hline Type of bar & $\begin{array}{c}\text { Specimen } \\
\text { number }\end{array}$ & $\begin{array}{c}\text { Joint } \\
\text { number }\end{array}$ & Relative displacement (in) \\
\hline \multirow{6}{*}{ 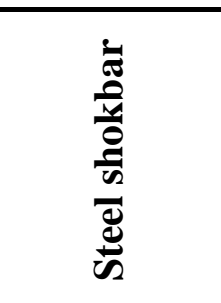 } & \multirow{2}{*}{1} & 1 & $1.50 \mathrm{E}-03$ \\
\hline & & 2 & $4.00 \mathrm{E}-03$ \\
\hline & \multirow{2}{*}{2} & 1 & $4.00 \mathrm{E}-03$ \\
\hline & & 2 & $5.40 \mathrm{E}-03$ \\
\hline & \multirow{2}{*}{3} & 1 & $2.00 \mathrm{E}-03$ \\
\hline & & 2 & $4.30 \mathrm{E}-03$ \\
\hline & Mean value & & 3.53E-03 \\
\hline
\end{tabular}


Table 3.8 - Bending moment, Shear force and bearing stresses at bar/concrete interface

\begin{tabular}{|c|c|c|c|c|c|c|c|}
\hline $\begin{array}{c}\text { Type of } \\
\text { bar }\end{array}$ & $\begin{array}{c}\text { Specimen } \\
\text { number }\end{array}$ & $\begin{array}{c}\text { Bending } \\
\text { moment } \\
(\text { lb.in })\end{array}$ & $\begin{array}{c}\text { Shearing } \\
\text { force } \\
(l b)\end{array}$ & $\begin{array}{l}\text { Modulus } \\
\text { of dowel } \\
\text { support }\end{array}$ & $\begin{array}{c}\text { Bar } \\
\text { relative } \\
\text { stiffness } \\
\left(l b / i n^{3}\right)\end{array}$ & $\begin{array}{c}\text { Bearing } \\
\text { stress } \\
\left(l b / i n^{2}\right)\end{array}$ & $\begin{array}{c}\text { Average } \\
\text { Bearing } \\
\text { stress } \\
\left(l b / \text { in }^{2}\right)\end{array}$ \\
\hline \multirow{3}{*}{  } & 1 & 199.88 & 1439.3 & $2.65 E+05$ & 0.389536 & $8.49 \mathrm{E}+02$ & \multirow{3}{*}{  } \\
\hline & 2 & 864.65 & 650.286 & $5.50 \mathrm{E}+04$ & 0.262922 & $1.78 \mathrm{E}+02$ & \\
\hline & 3 & 713.58 & 1144.5 & $3.50 \mathrm{E}+05$ & 0.417593 & $5.66 \mathrm{E}+02$ & \\
\hline \multirow{3}{*}{ 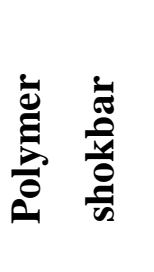 } & 1 & 40.76 & 606.934 & $1.44 \mathrm{E}+05$ & 0.334446 & $3.17 \mathrm{E}+02$ & \multirow{3}{*}{ 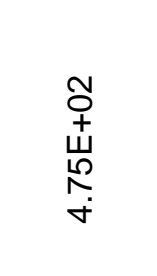 } \\
\hline & 2 & 10.83 & 761.26 & $2.00 \mathrm{E}+05$ & 0.363073 & $4.40 \mathrm{E}+02$ & \\
\hline & 3 & 422.97 & 1321.38 & $1.88 \mathrm{E}+05$ & 0.357262 & $6.69 \mathrm{E}+02$ & \\
\hline \multirow{3}{*}{ 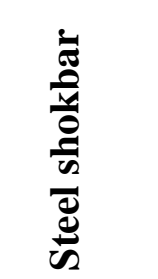 } & 1 & 701.12 & 1165.31 & $1.20 \mathrm{E}+05$ & 0.319544 & $4.81 \mathrm{E}+02$ & \multirow{3}{*}{ 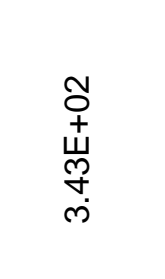 } \\
\hline & 2 & 308.83 & 353.75 & $1.70 \mathrm{E}+04$ & 0.196042 & $9.20 \mathrm{E}+01$ & \\
\hline & 3 & 451.26 & 1061.27 & $1.05 \mathrm{E}+05$ & 0.309053 & $4.56 \mathrm{E}+02$ & \\
\hline
\end{tabular}




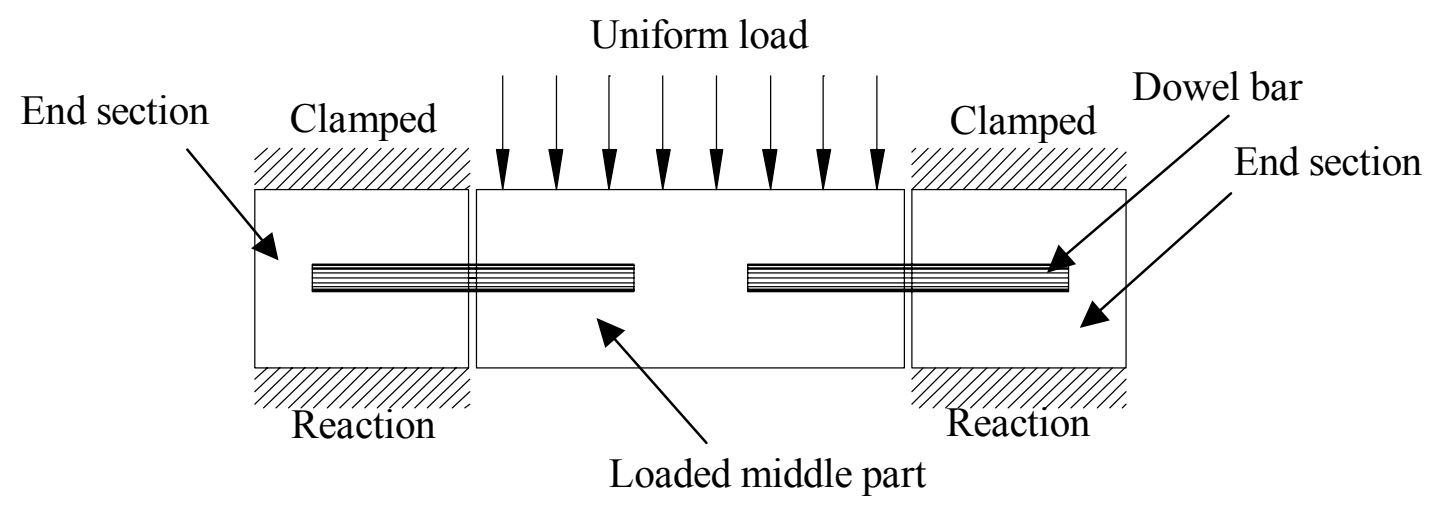

Figure 3.1 - Load deflection test specimens

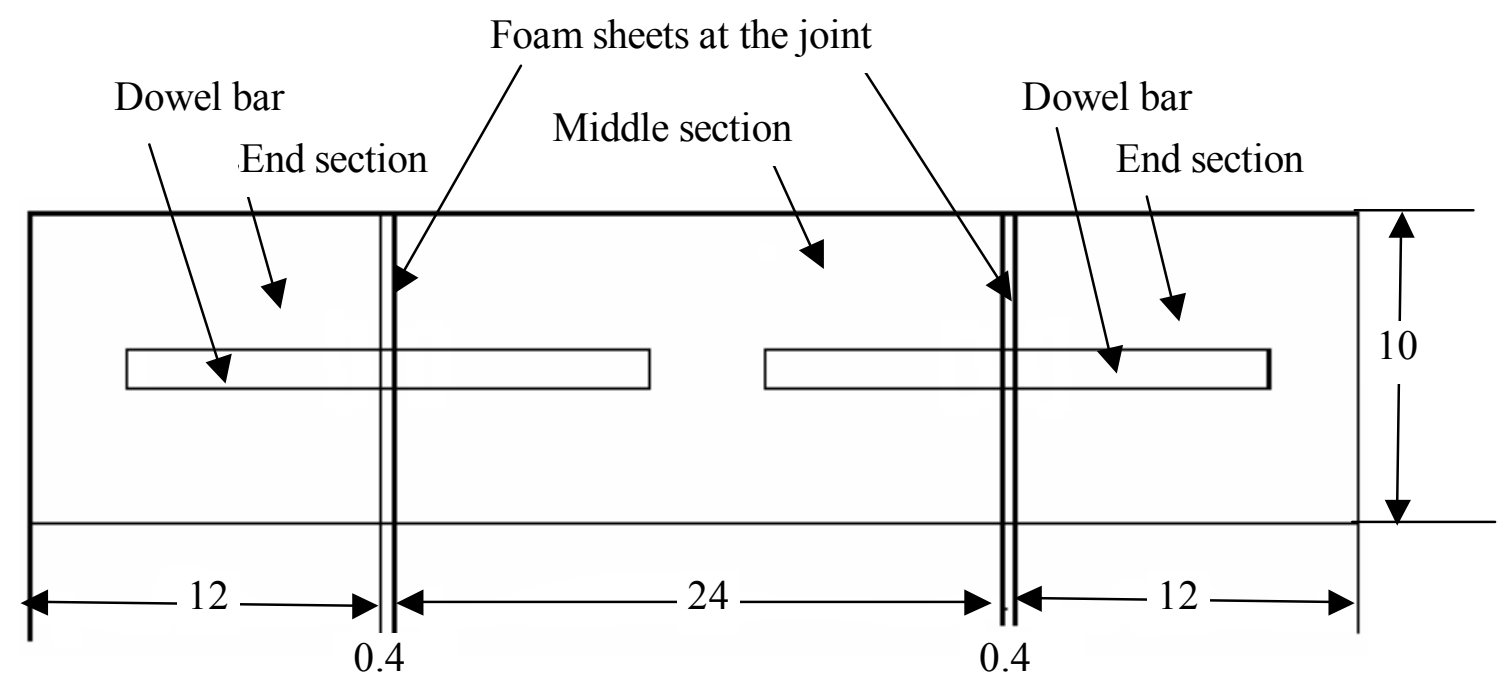

Note: all dimensions are in inches.

Figure 3.2 - Longitudinal view of test specimen 


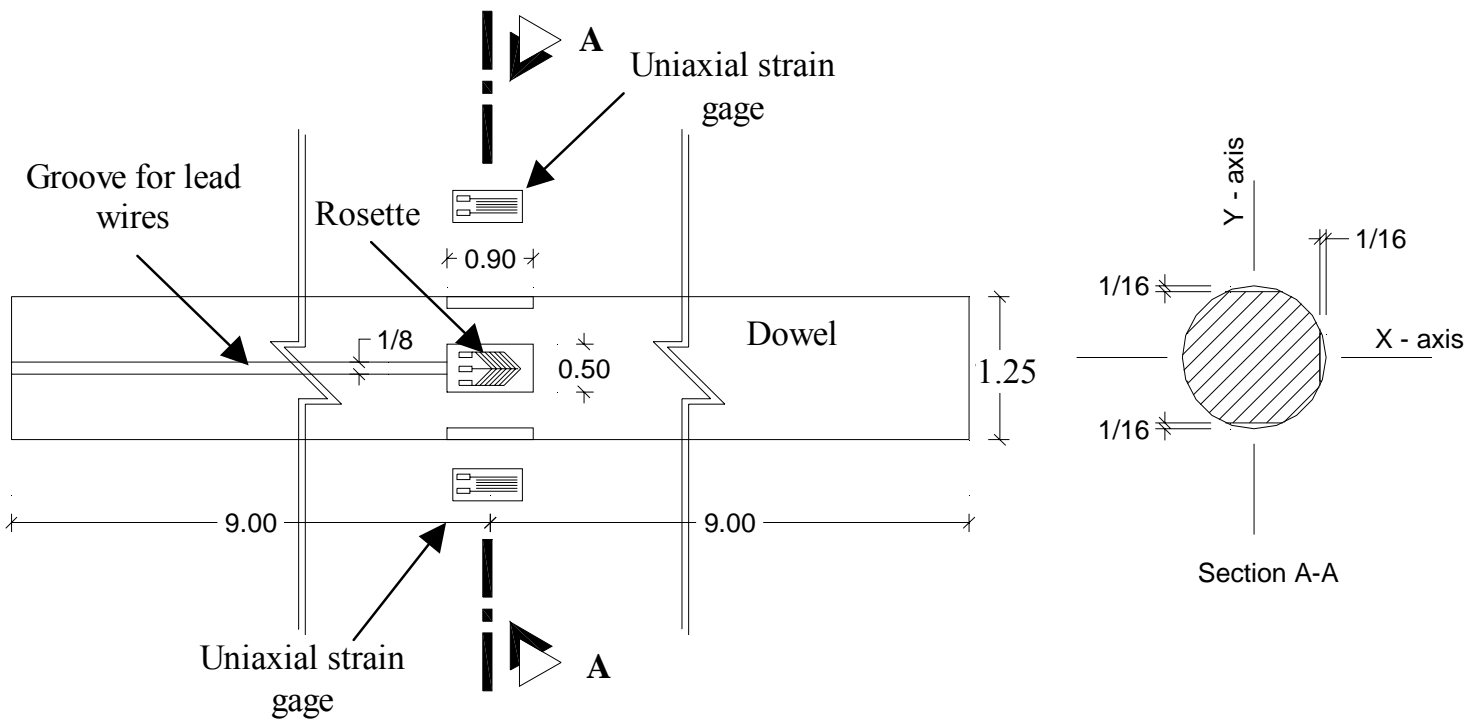

Note: All dimensions are in inches

Figure 3.3 - Preparation plan for the instrumentation of dowel bar 


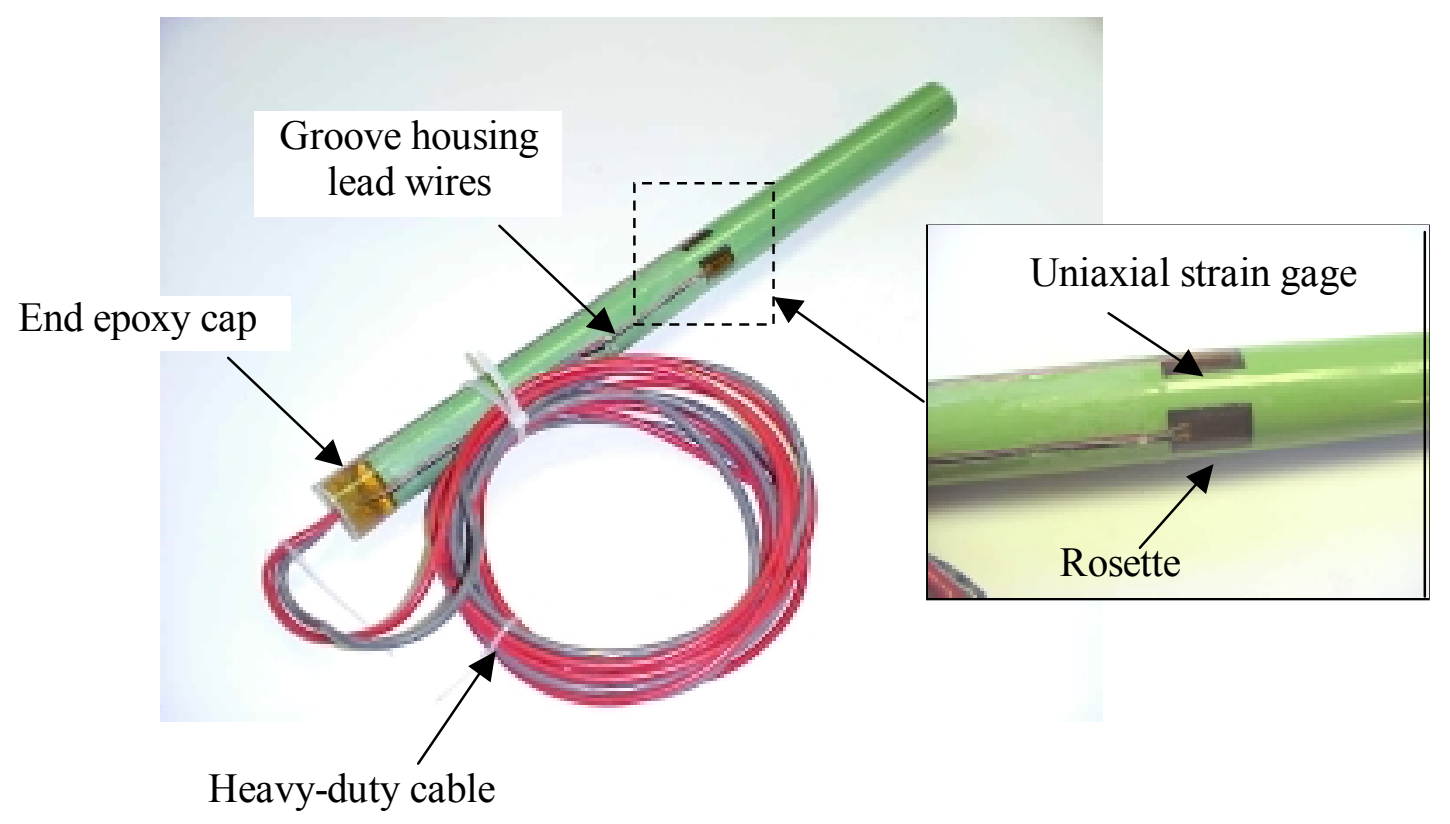

a) Instrumented dowel

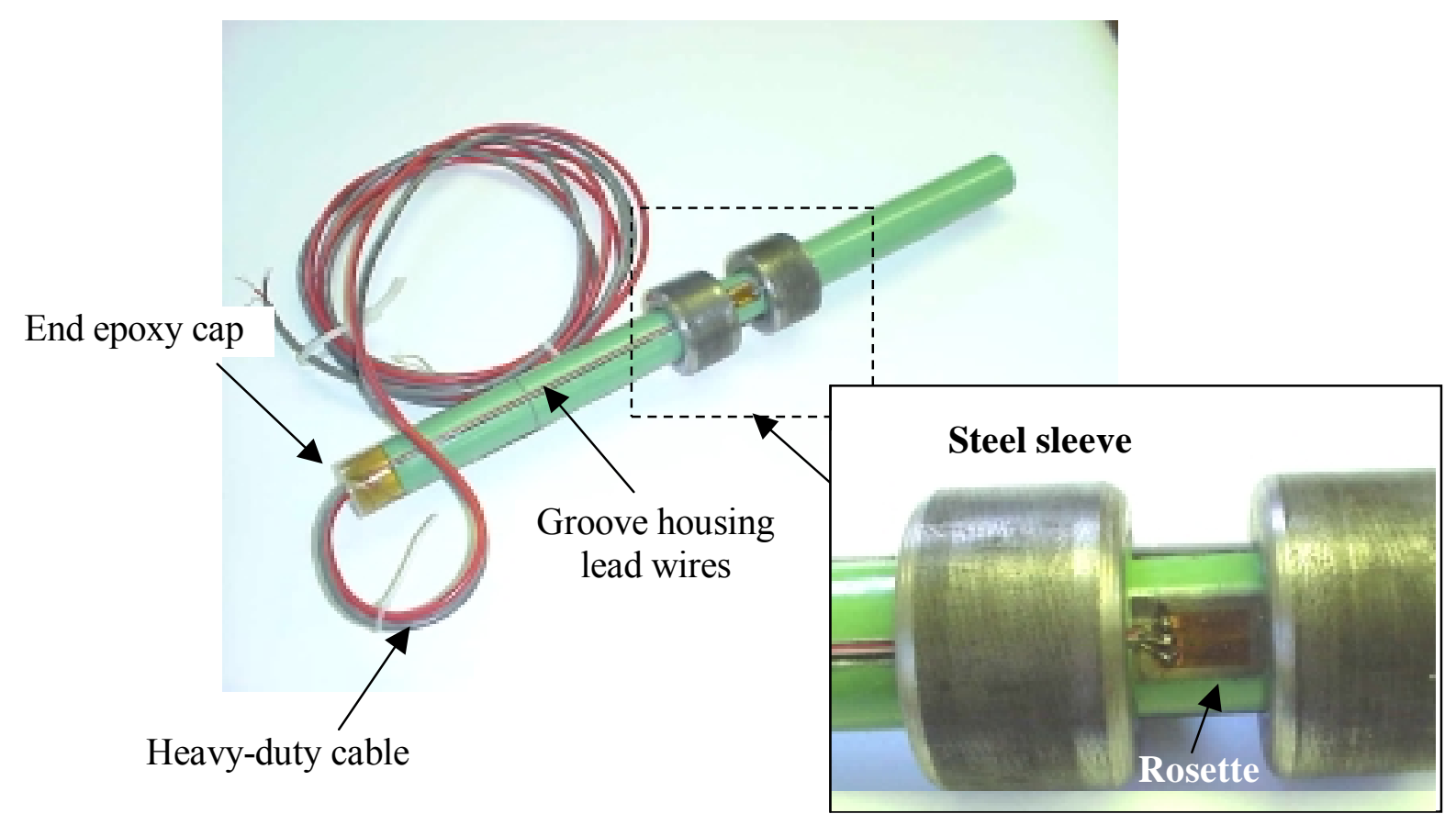

b) Instrumented steel shokbar

Figure 3.4 - Instrumented dowel and Shokbar 


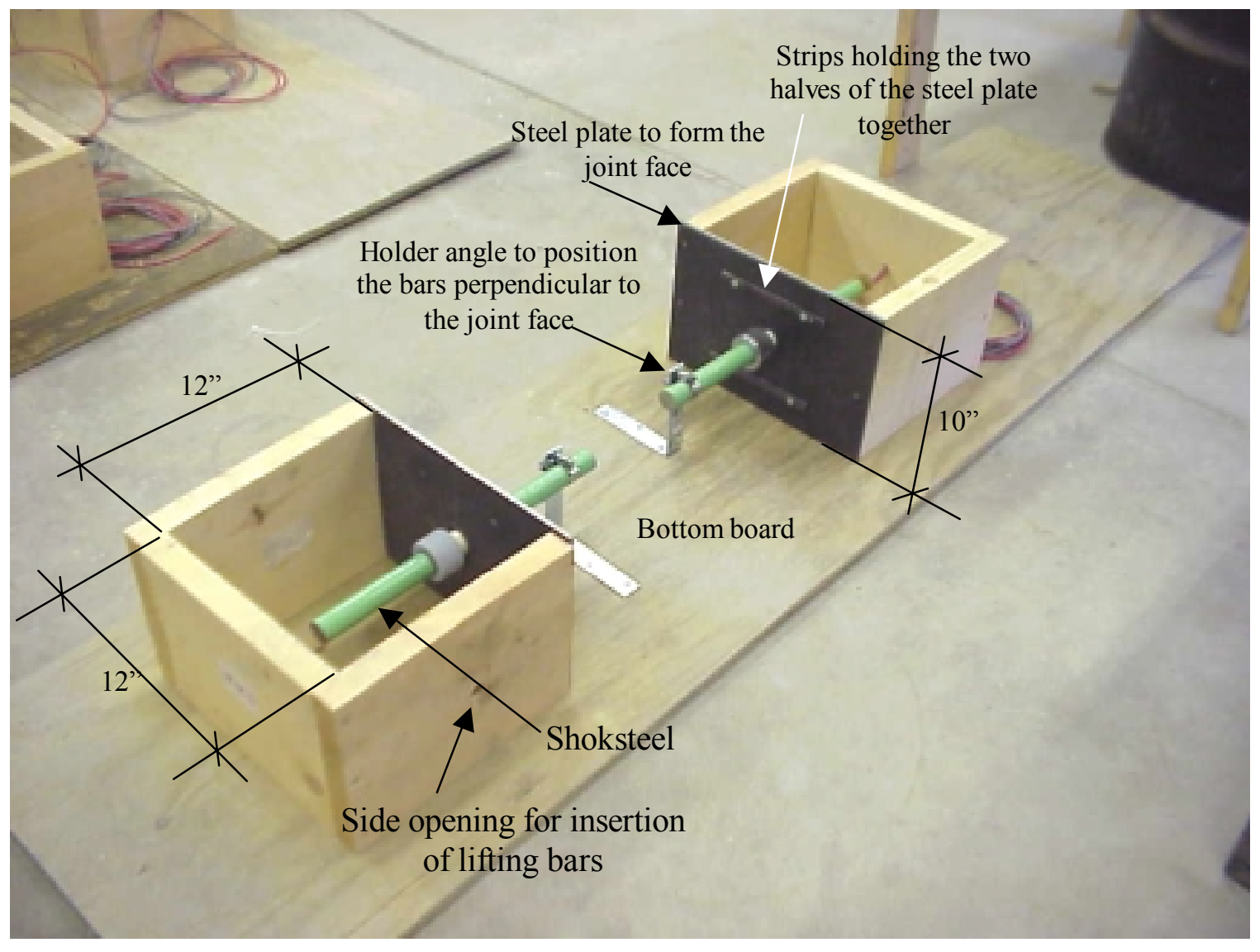

Figure 3.5 - Preparation of molds for casting end sections of specimens

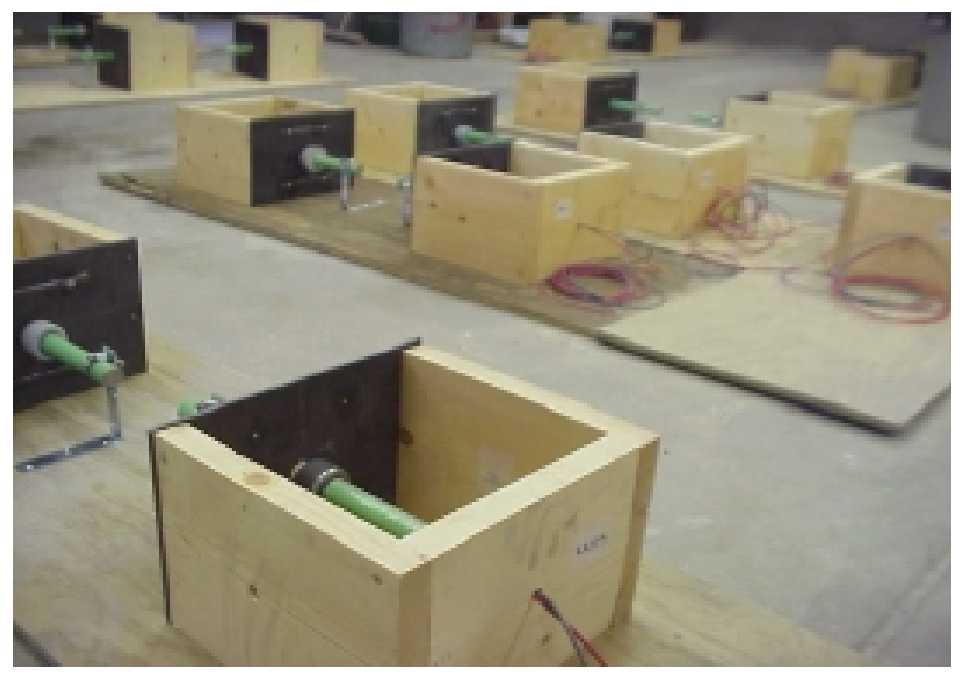

Figure 3.6 - A number of prepared molds ready to cast end sections 


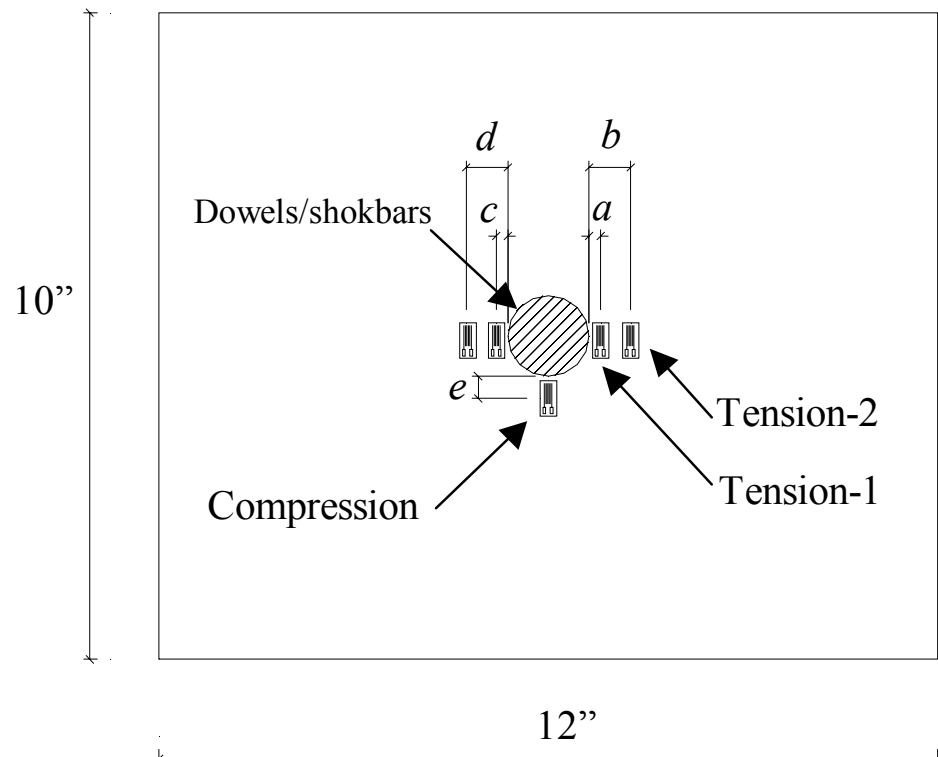

Figure 3.7 - Locations of strain gages on joint face 


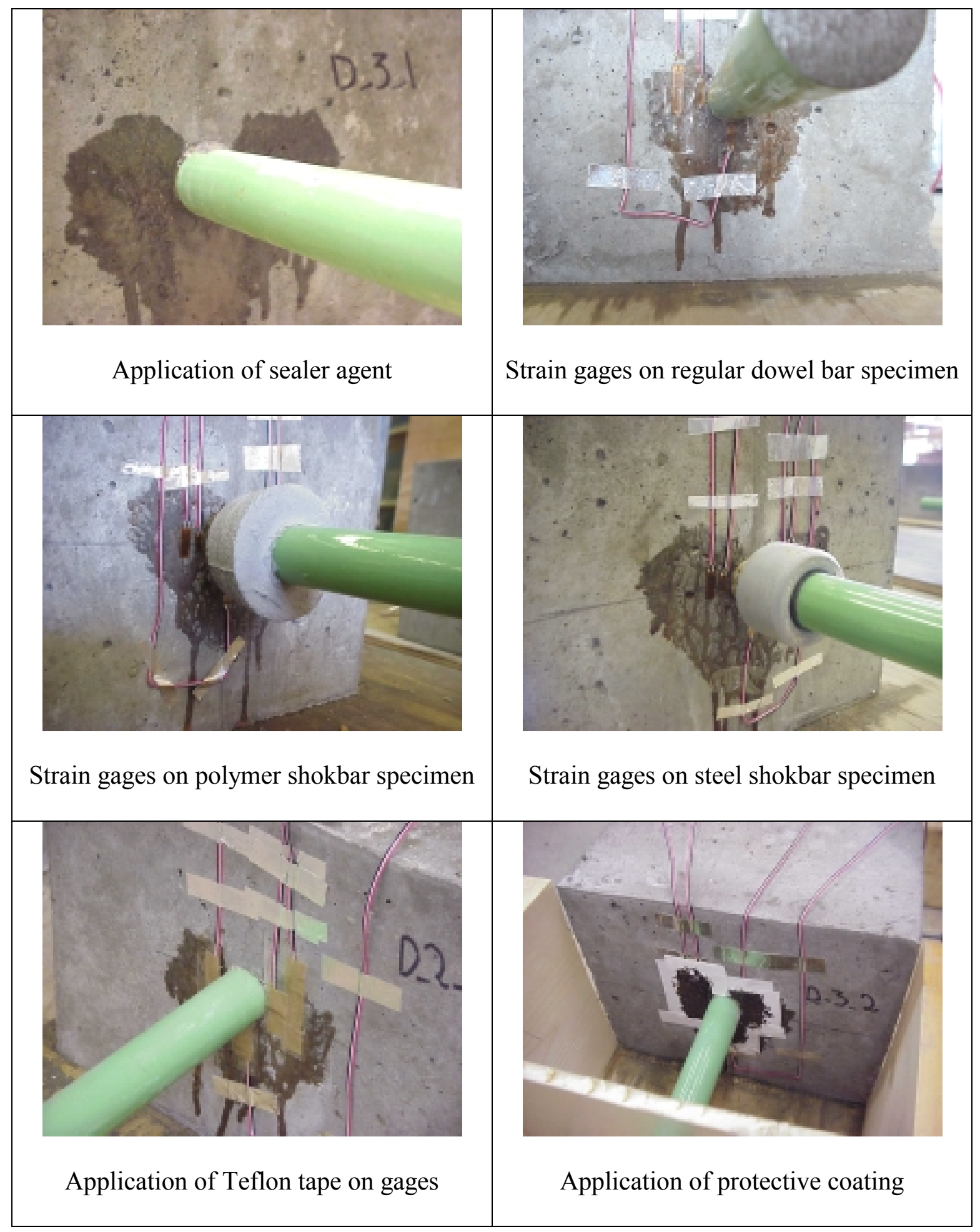

Figure 3.8 - Different stages in application of strain gages on joints faces 


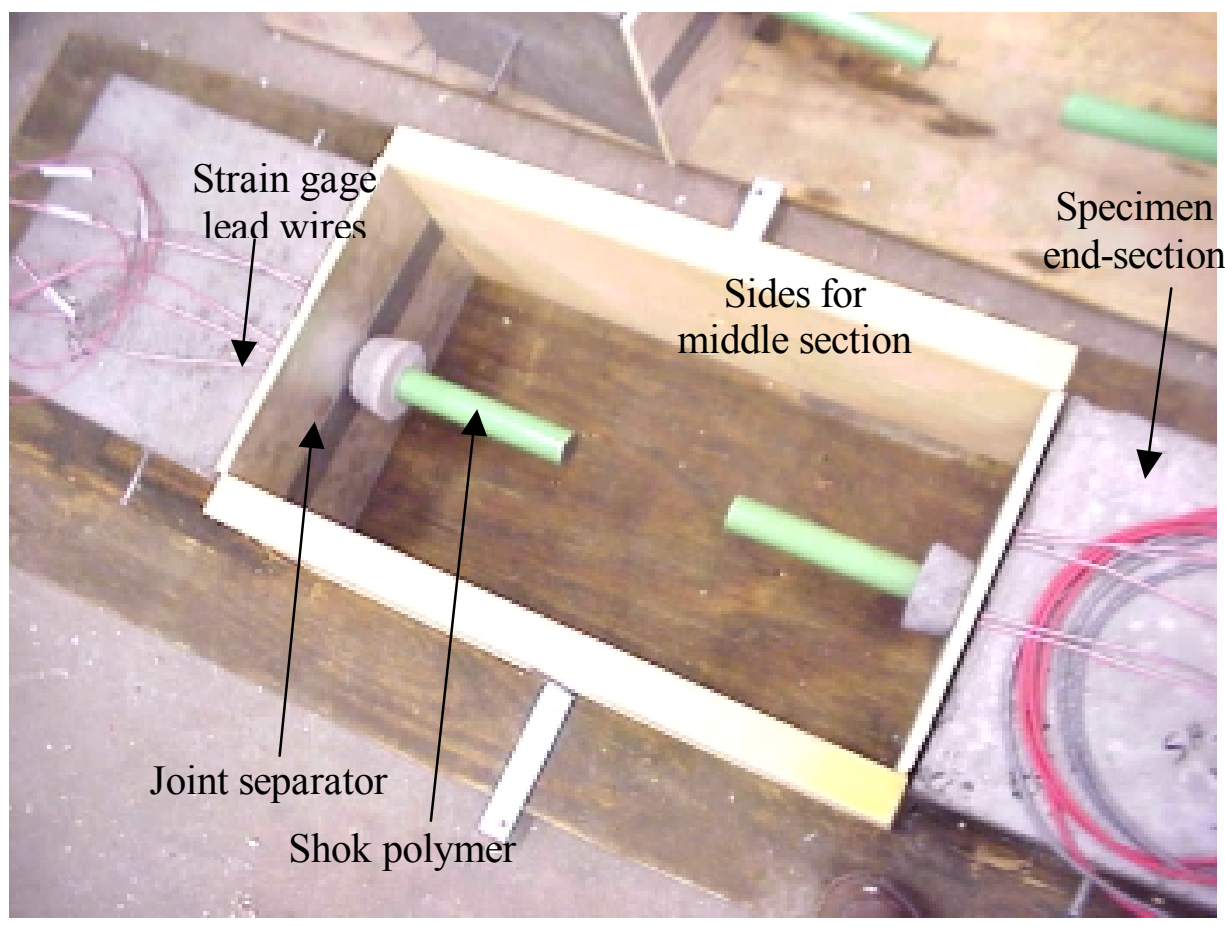

Figure 3.9 - Specimen ready for casting the middle section

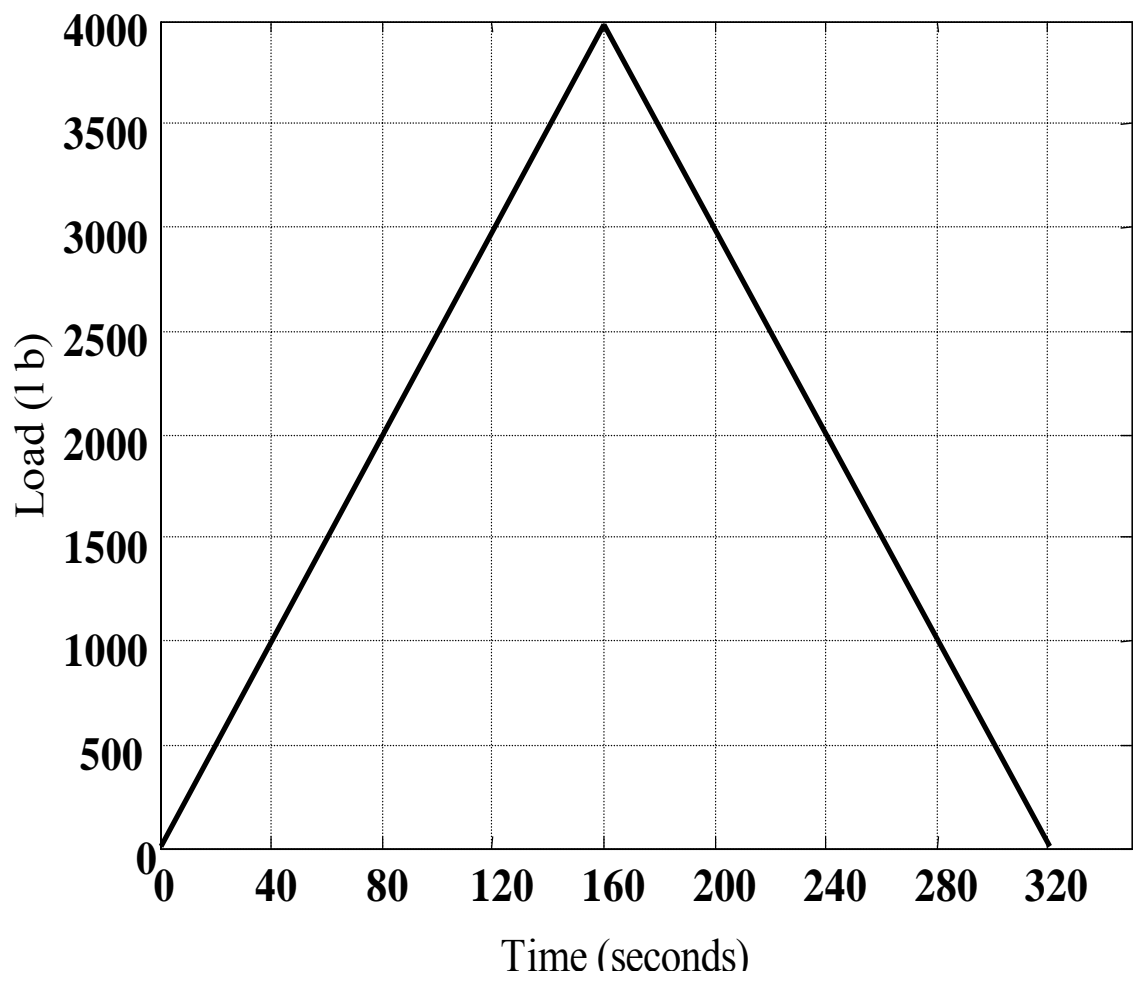

Figure 3.10 - Load curve for Static Loading 


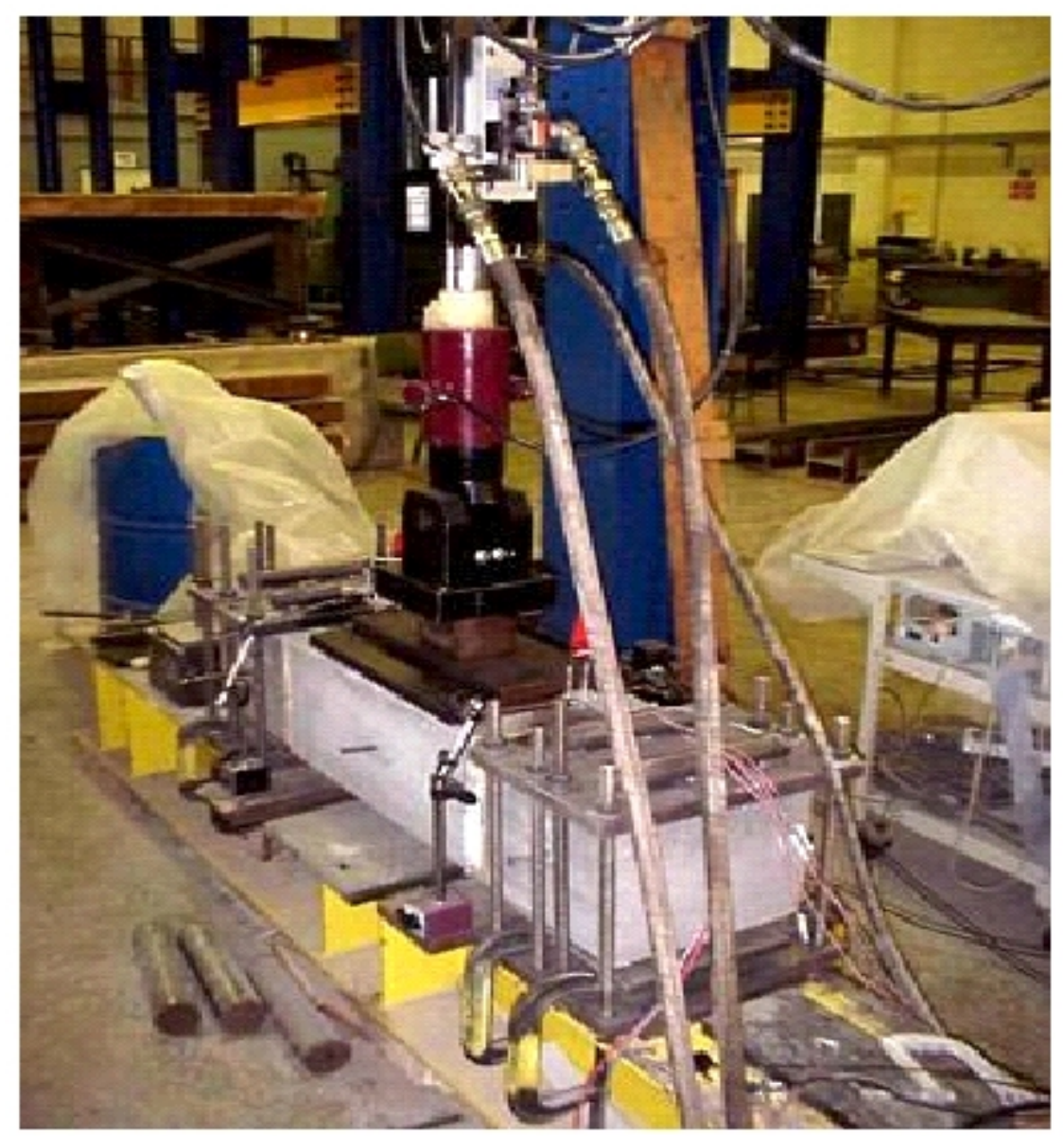

Figure 3.11 - Test rig 

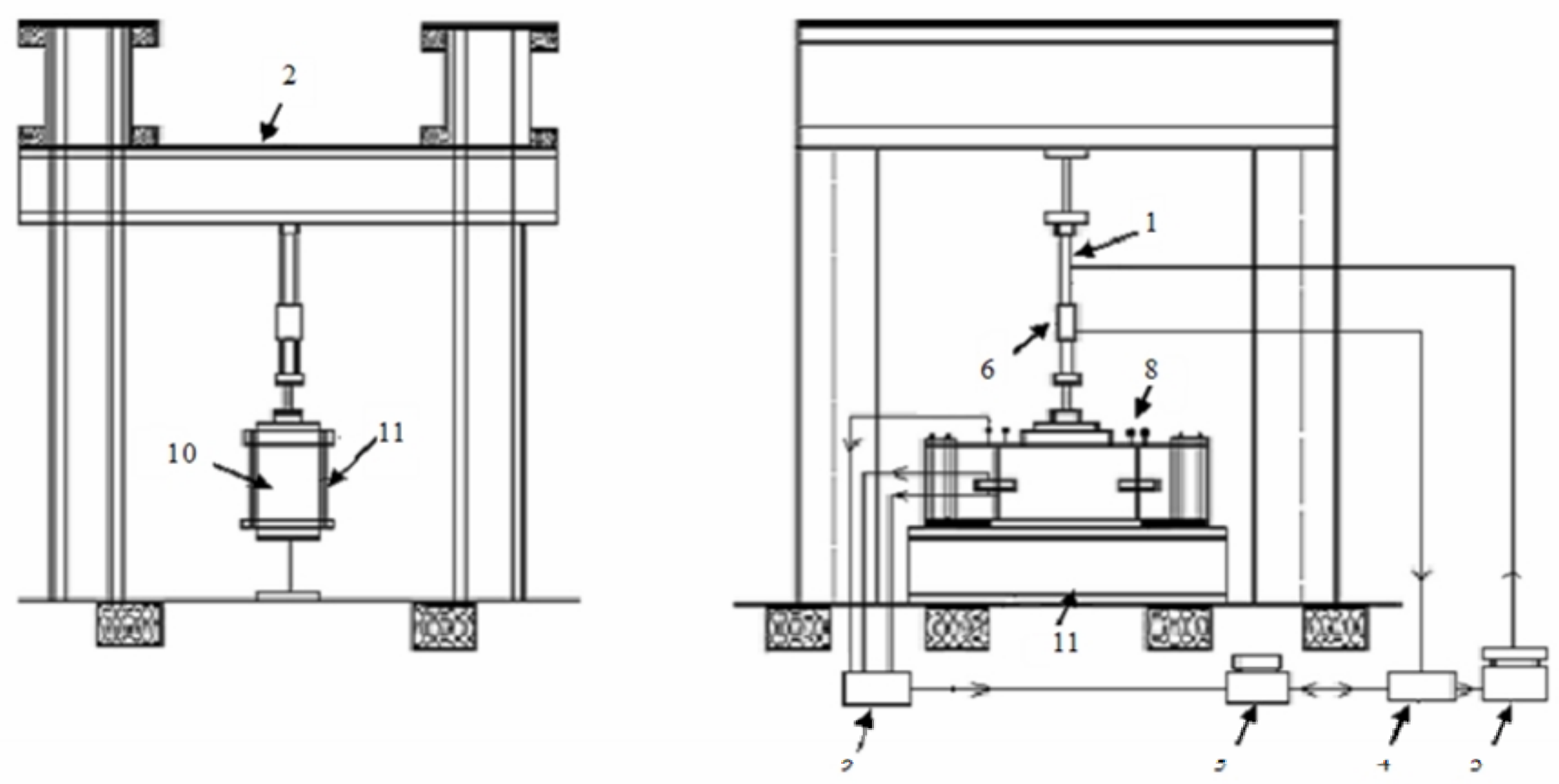

Side view

Front view

Figure 3.12 - Test rig mounted with test specimen 


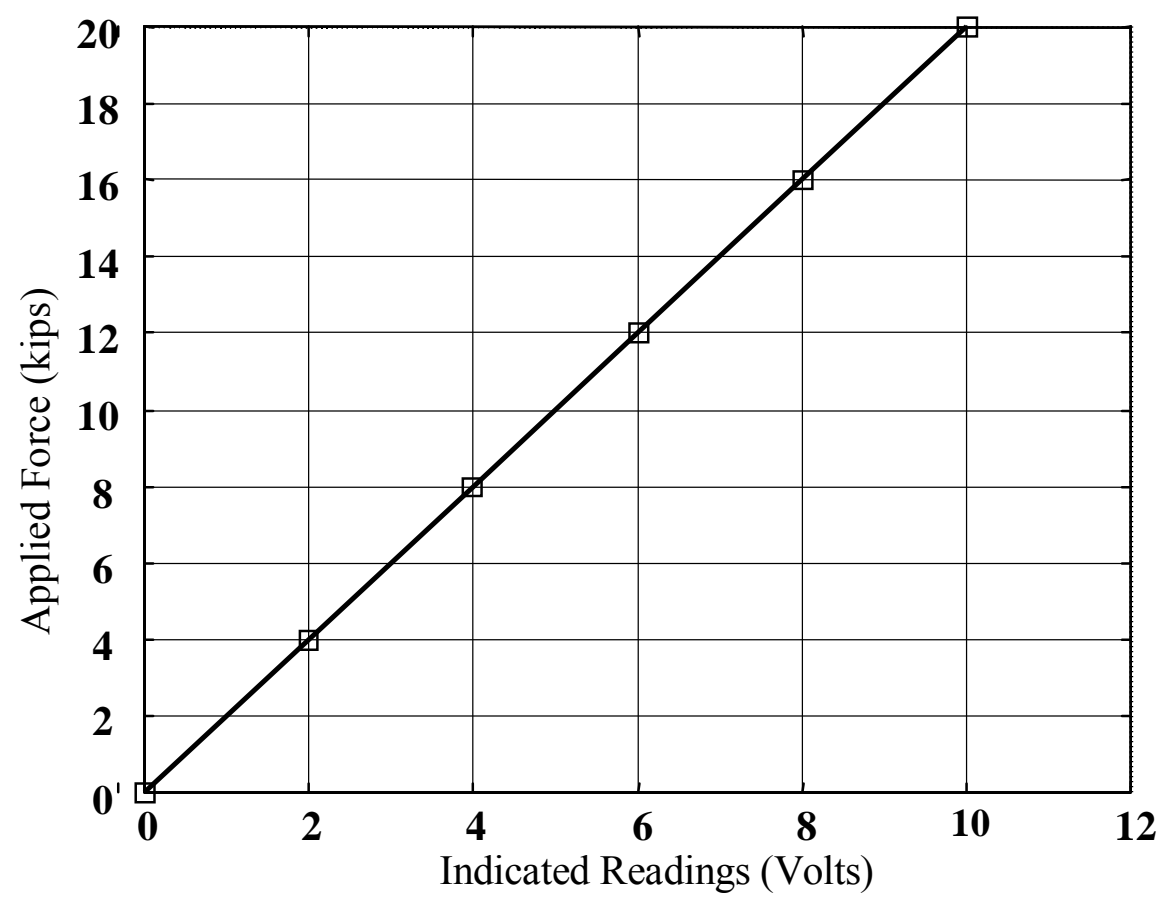

Figure 3.13 -Calibration curve for MTS load cell

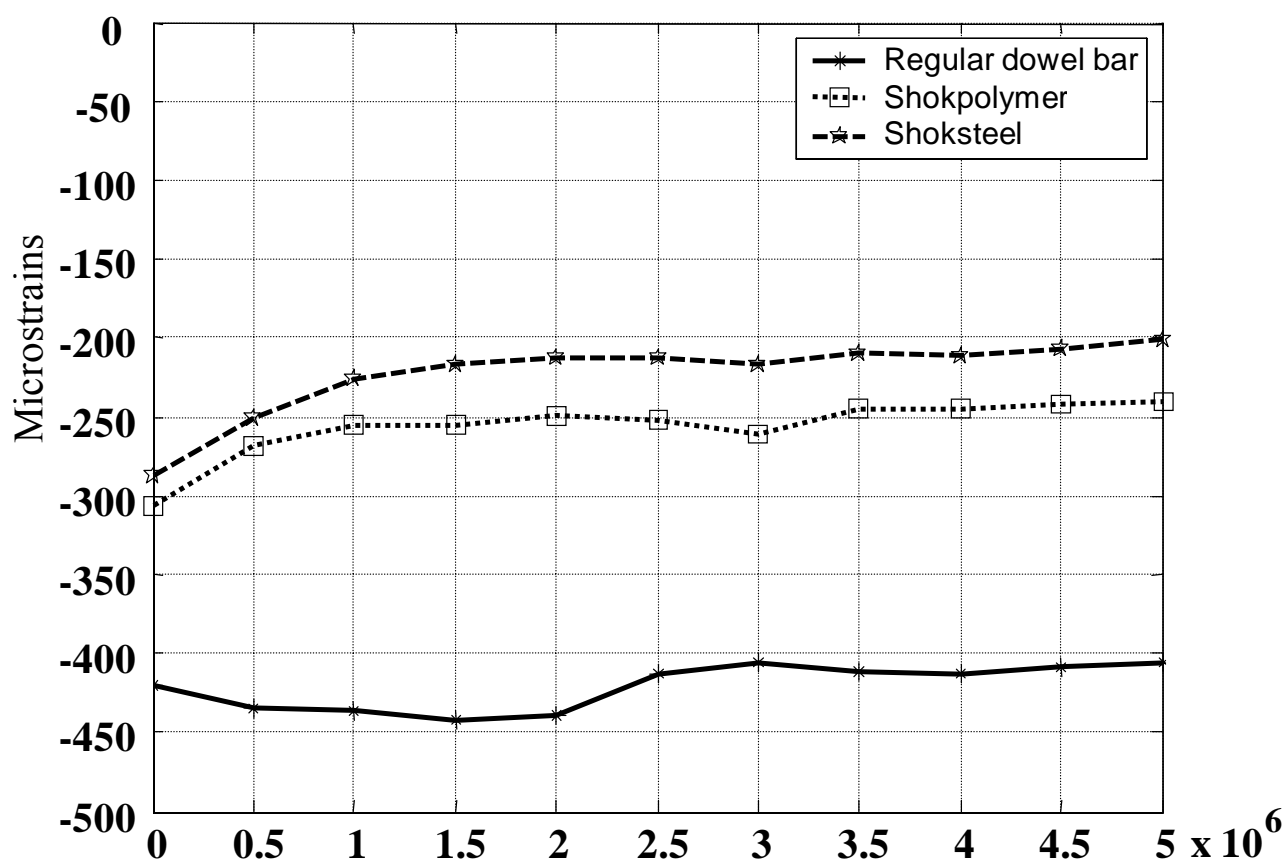

Figure 3.14 - Compressive strains at bar/concrete interface 


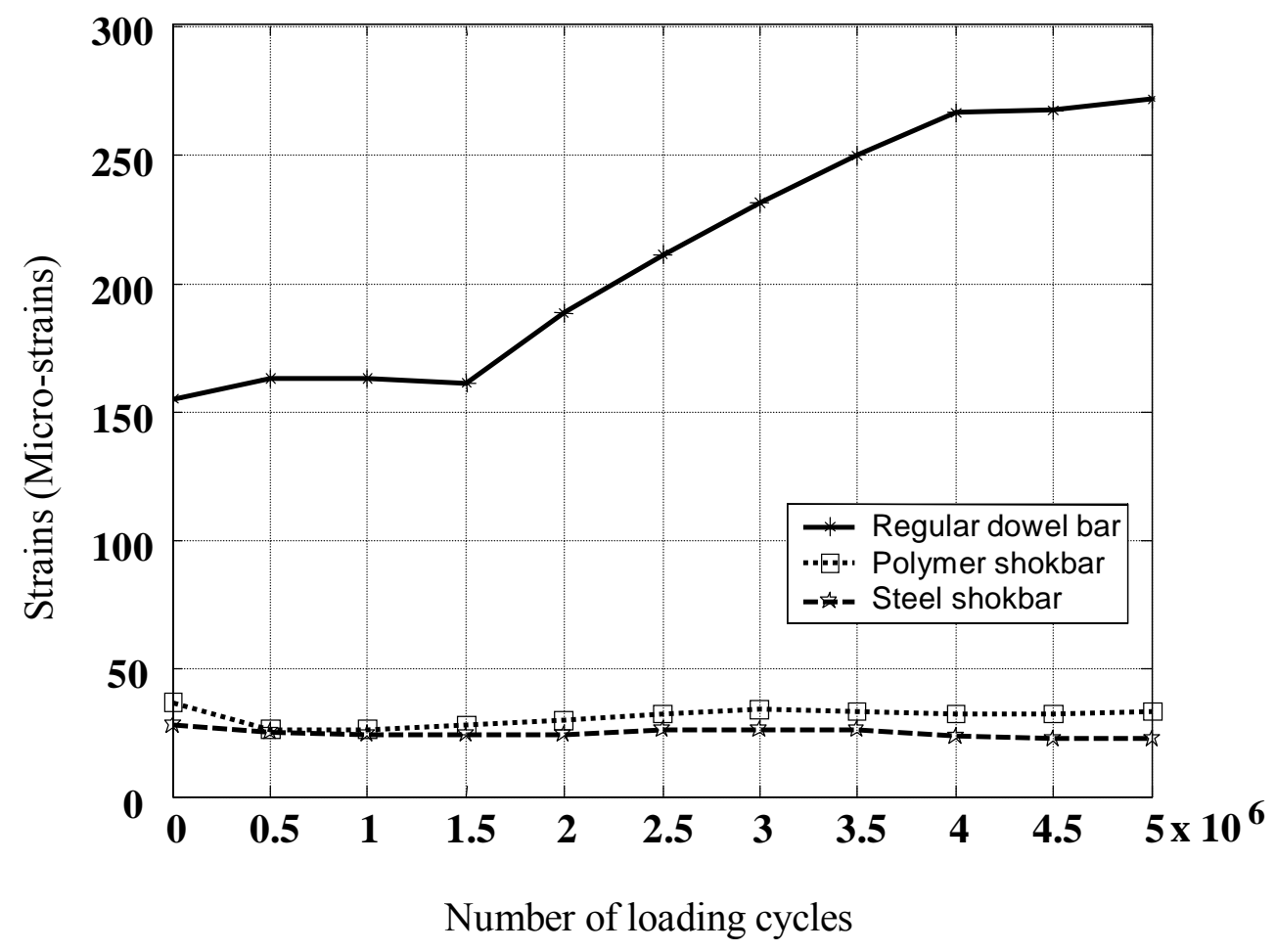

Figure 3.15 -Tensile strains at bar/concrete interface (Tension-1)

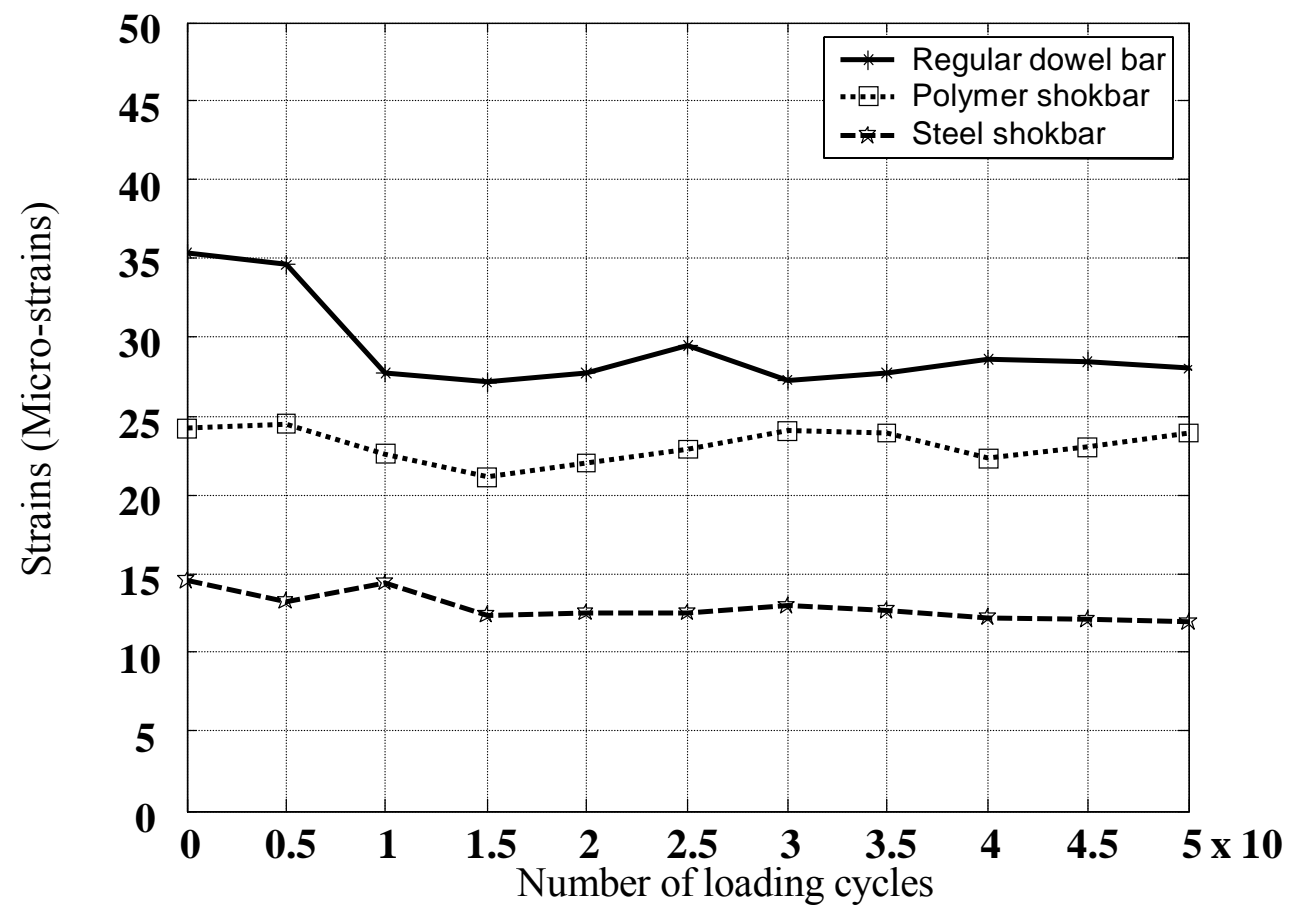

Figure 3.16 -Tensile strains at about 0.7 inches from bar/concrete interface (Tension- 2) 




Figure 3.17 -Vertical relative displacements across joints

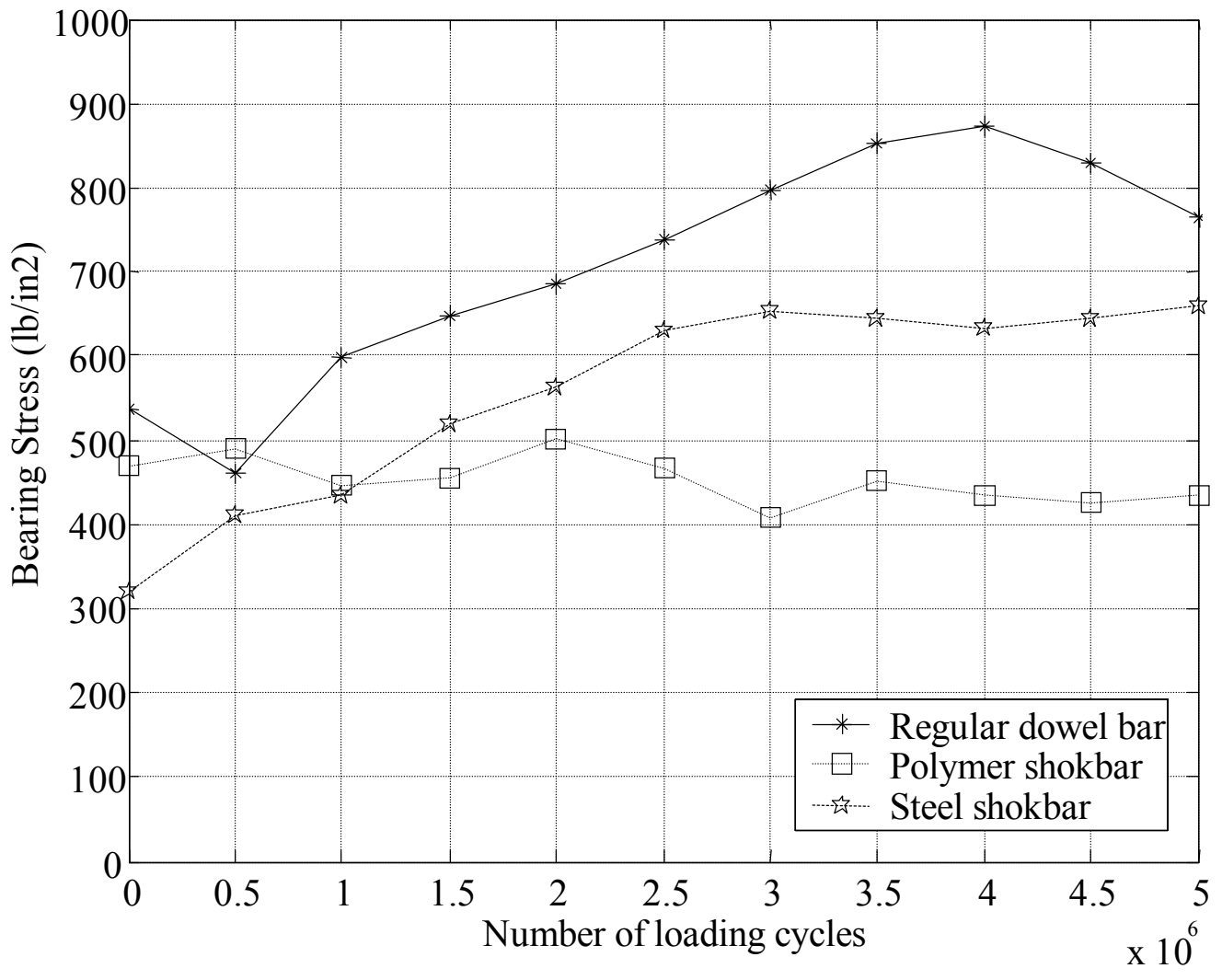

Figure 3.18 - Bearing Stresses in Stationary section 


\section{CHAPTER FOUR \\ FINITE ELEMENT MODELLING}

\subsection{INTRODUCTION}

The primary objective of this research work is to compare the performance of shokbar and regular dowel in double-jointed concrete specimens subjected to static and fatigue loading. The Finite element method is a powerful tool for solving problems that are too difficult to tackle with analytical methods. Three dimensional Finite element modeling is applied to explore the behavior of dowel bar and shokbar in double-jointed concrete specimens. For this purpose, three dimensional finite element models are developed with regular dowel, steel shokbars and polymer shokbars. Those models simulate the experimental tests presented in Chapter 4.

The double-jointed models mainly consist of three concrete blocks joined together by the dowel/shok bars. The end blocks are fixed and no external constraints are applied on the middle block where the load is applied. In this study LS-Dyna was used to perform the finite element modeling and analysis.

\subsection{FINITE ELEMENT MODEL}

\subsubsection{Meshing}

Figure 4.1 shows the finite element model (FEM) of a double-jointed concrete specimen. Modeling and mesh generation is developed using same techniques for all models. A small gap of 0.4 inches is given between the middle block and end blocks and consequently, the connecting dowel/shok bars are the only means of load transfer. Figure 4.2 shows the finite element model of the specimen with regular dowel bars, Figure 4.3, the model with polymer shokbars and Figure 4.4, the one with steel shokbars. For all models, the x-axis is along the length of the block, the y-axis is along width of the block and the z-axis is along the thickness of the block. Dowel bars, polymer shokbars, and steel shokbars of diameter 1.25-in and length 18 -in are modeled using mesh of solid brick elements as shown in Figures 4.5.

Regions of high stress intensity such as the transverse joints and the region surrounding the dowel bars require a fine mesh. Figure 4.6 shows the mesh at the joint 
face, which is very fine at the center and coarser toward the exterior edges of the blocks. The fine mesh enables accurate assessment of the contact stresses that develop around the dowels. The dowel-concrete interface at the joint is the primary area of concern and the developed contact stresses may cause concrete failure. To accurately mesh the circular geometry of the bar, large number of nodes on the bar surface is specified. In this model, 32 nodes are present around the circumference of the circle. Eight-noded brick elements, with six degrees of freedom at each node, are used for discretizing the concrete blocks, bars and loading plate.

\subsubsection{Interface}

Dowel-Concrete Interface

The essential function of a dowel bar is to transfer the load between adjacent joints with out constraining the axial movement of the slab. To fulfill this requirement, concrete construction contractors try to ensure proper dowel alignment and minimize dowel-concrete bonding through coating the dowels with bond breaking agents such as oil, tar, or types of wax that resist the heat of hydration of concrete without melting. The bond breaking agents are commonly applied on top of a layer of epoxy coating to provide corrosion protection for the steel dowels and to reduce the friction with concrete. In this study, epoxy coated dowels covered with in a layer of bond breaker were assumed to introduce a uniform dowel clearance of 0.0025 inch. The dowel-concrete coefficient of friction is assumed as 0.005 (no data is available in the literature). Contact stresses between the dowel and concrete develop when the slab deflects due to applied load.

A sliding interface that allows partial contact between the dowel and concrete surface is implemented in this finite element study. This type of interface, implemented in the general-purpose finite element software "LS-DYNA" is suitable for the simulation of different possibilities of dowel concrete contact. Dowel contact possibilities may range from localized contacts that can form at two or more locations along the interface (due to dowel bending and concrete surface deformation) to full contact of the cylindrical interface. In either case, the contacting surfaces may slide against each other when the dowel pulling force exceeds the frictional shear stress at the interface. Since the dowels are modeled as solid round bars, the localized contact areas can grow in size at any 
circumferential direction along the interfaces under one or both of the following conditions.

1. Localized elastic deformation of the contacting materials.

2. Localized cracking of the concrete material at the contact spots if the contact stress reaches the modulus of rupture of concrete.

The solution of the contact problem in "LS-DYNA" finite element software is based on satisfying two conditions: the first is that the contacting surfaces may coalesce or separate during the motion of the two bodies and the second is the impenetrability of the two bodies. To satisfy the latter condition: a) the contacting points (nodal points) of the master and slave surfaces move with the same displacement and velocity in the direction normal to the contact interface, b) the momentum is balanced on the contact interface, and c) no tensile traction forces are allowed on the contact interface.

Interface between the loading plate and the concrete

A sliding interface that allows partial contact between the loading plate and concrete surface was implemented in this investigation.

\subsubsection{Material properties:}

An anisotropic brittle damage material model developed specially for plain concrete is used in this study to describe the material behavior of the concrete blocks. In this model, tensile failure of concrete is represented by a smeared crack that develops normal to direction of the maximum principle stress at any point in the material where the maximum principle stress reaches the modulus of rupture $f_{n}$ of concrete. Once a smeared crack is detected, the magnitudes of the tensile and shear tractions $\left(\Phi_{n}, \Phi_{s}\right)$ that can be transmitted across the crack start to decay exponentially with increasing deformation. The rate of decay is numerically evaluated for each integration point as a function of the fracture toughness of the concrete material and the characteristic crack length. The limits set on the tensile and shear tractions are:

$$
\begin{aligned}
& \Phi_{n}=f_{n}(1-\varepsilon)\left(1-e^{H \alpha}\right) \text { and } \\
& \Phi_{s}=f_{s}(1-\beta)\left(1-e^{H \alpha}\right)
\end{aligned}
$$

Where $f_{n}$ and $f_{s}$ are the tensile and shear strengths, respectively, $\varepsilon$ and $\beta$ are small constants that give the material residual tensile and shear stress, respectively. $H$ is a softening decay constant numerically evaluated as a function of the concrete fracture 
toughness and the crack length and $\alpha$ is a constant that measures the crack field intensity. The "LS-DYNA" implementation of the material model includes a check on the compressive failure of the material using Von-Mises yield criterion that ensures that the effective stress at the point is less than or equal to $(1 / 3)^{1 / 2} f_{c}$,

Where $f_{c}$ is the compressive strength of concrete. If violated at any point, a "return mapping" takes place in the form of magnitude adjustment of the effective stress at that point to a value which corresponds to the plastic strain on the stress-strain relation. The software requires the user to define Young's modulus, Poisson's ratio, tensile strength, shear strength, and fracture toughness of the material.

The dowel bar material is represented using a linear elastic material model. The material constants used for concrete and dowel bars are listed in the table.

\subsubsection{Loading:}

The loading/unloading profile shown in Figure 4.7 is applied to the model. The loading plate serves as a medium that uniformly distributes the pressure on the loaded area. Figure 4.8 illustrates the deformation of the model at the maximum load.

\subsubsection{Boundary conditions:}

The end blocks are constrained in translation and rotation in all directions. The middle block is free from external constraints. The load is applied on the middle block and is transferred to the end blocks by the dowel/shok bars.

\subsection{RESULTS AND DISCUSSION}

\subsubsection{Location of maximum stress around the dowel bar}

Modeling of concrete blocks and the embedded dowel bars as threedimensional solid elements allow the study of the various types of stresses induced at any location inside the structure. This was not available when using two-dimensional modeling techniques, or when using beam and spring elements to represent the dowel bars as done in earlier studies. As the main purpose for developing the $3 \mathrm{D}$ finite element model is to characterize the stress concentration at the dowel/concrete interface, it is 
important to localize the regions where maximum stresses take place. In the search of the locations where the maximum stresses are induced in the concrete material around the selected dowel, it is concluded from Friberg's study that this would be expected at the joint face, where the maximum deflection of the dowel bar takes place.

Figure 4.9 shows the vertical stress along the dowel bar from FEM in comparison with Friberg's formulation.

According to Friberg, $\sigma=K y$

Where: $\sigma=$ The stress in the concrete.

$K=$ the modulus of dowel support $=3,000,000 \mathrm{pci}$

$y=$ deflection of the dowel

$$
y=\frac{e^{-\beta x}}{2 \beta^{3} E I}\left[P_{t} \cos \beta x-\beta M_{o}(\cos \beta x-\sin \beta x)\right]
$$

$P_{t}=$ Load carried by the dowel $=2000 \mathrm{lb}$.

$M_{o}=$ Bending moment on dowel at face of concrete $=0.5 \mathrm{w} P_{t}$.

$w=$ width of joint opening $=0.4 \mathrm{in}$.

$\beta=\sqrt[4]{\frac{K d}{4 E_{d} I_{d}}}=$ relative stiffness of an elastic bar embedded in an elastic media.

$d=$ the diameter of the dowel $=1.25 \mathrm{in}$.

$E_{d}=$ young's modulus of the dowel $=29 \mathrm{e}+06$ psi.

$I=$ Moment of inertia of the dowel $=\pi \mathrm{d}^{4} / 64$.

It is noticed that the FEM results indicate that the high compressive stresses occur at the face of the joint, and diminish sharply at about 1.5-in from the joint face. Friberg's solution gives a longer distance for the dissipation of the stress magnitudes, which is about 4.5 inches from the joint face. The reason for this lies in the assumption made by Friberg, of a uniform modulus of dowel concrete support all along the dowel bar to satisfy the wave shape assumed for its deformation.

The concrete surrounding the dowel is subjected to compressive, tensile and shear components either individually or in combination depending upon the position and angle of the element considered. Hence there exists a multiaxial state of stress, which makes it 
difficult to explain which component is responsible for failure. The principle stress is a uniaxial stress, which gives the same effect when a body is subjected to multiaxial stress components. Failure is initiated by maximum principle stress.

The next set of figures show the stress distribution at the dowel/concrete interface as a function of the angular position around the dowel bar. For example $0^{0} / 360^{0}$ represents the bottom of the dowel and $180^{\circ}$ represents the top of the dowel. The profile of maximum principle stress, maximum shear stress and vertical stress at the dowelconcrete interface at the face of the joint for both loaded and unloaded blocks are shown in Figures 4.10-4.15. Figures 4.16 to 4.21 show the fringes of maximum principle stress, maximum shear stress and vertical stress at the dowel-concrete interface at the face of the joint for both loaded and unloaded blocks.

\subsubsection{Maximum stresses at the face of the unloaded block}

The maximum compressive stress is observed to be at the bottom of the dowel/shokbar. The maximum tensile stress is observed at the sides of the dowel/shokbar. The maximum shear stress is observed at the bottom of dowel/shokbar. The maximum principle stress is observed at the sides of dowel/shokbar.

Figures 4.12 to 4.13 indicate that the bearing stress induced in the concrete at joint interface is accompanied by high magnitudes of shear stresses, which increase the possibility of concrete failure around the dowel bar.

According to the ACI, the compressive bearing stress of concrete $\left(f_{b}\right)$ has the

form:

$$
f_{b}=\left(\frac{4-d}{3}\right) f_{c}
$$

Where: $d=$ the dowel diameter,

$$
f_{c}{ }^{\prime}=\text { the concrete compressive strength }=5600 \text { psi. }
$$

The allowable bearing stress calculated is 5133 psi. Obviously, the maximum compressive stress at the concrete dowel interface at both loaded and unloaded faces is found to be less than the allowable bearing stress. The details of maximum compressive stress, maximum tensile stress, maximum shear stress and maximum principle stresses at the dowel concrete interface of loaded and unloaded faces are given in Tables 4.2 and 4.3. Maximum compressive stresses at the bottom zones under each bar show that for the 
case of regular dowel bar, this measured $20 \%$ and $130 \%$ higher than values measured for polymer shokbar and steel shokbar, respectively.

Results of maximum tensile stresses at the bar/concrete interface show that polymer shokbar and steel shokbar were able to reduce this value by $51 \%$ and $77 \%$, respectively compared to those measured at the regular dowel. Maximum principle stresses at the bar/concrete interface show that polymer shokbar and steel shokbar were able to reduce this value by $33 \%$ and $69 \%$, respectively compared to those measured at the regular dowel.

\subsection{CONCLUSIONS}

From the results, it is concluded that the shokbars are very effective in reducing the stress concentration at bar/concrete interface. Polymer shokbar and steel shokbar are able to reduce the tensile stresses at bar/concrete interface by 2 to 4 times compared to dowel bars. Failure is initiated due to maximum principle stress. The maximum principle stress observed in the concrete at regular dowel/concrete interface is nearly equal to the limit set in the finite element program and is an indication of susceptibility of tensile crack formation with in this zone. Where as the maximum principle stress observed in the concrete around polymer shokbar and steel shokbar are $37 \%$ and $72 \%$, respectively, less than the limit value. This indicates that the shokbar strengthens the concrete surrounding the bar and reduces the possibility of crack formation in this zone.

The superior behavior of Shokbars versus regular dowel bars is well observed in finite element models. The techniques used proved reliable to measure performance parameters that formulate the behavior of the load transferring devices. 
Table 4.1 - Material Properties

\begin{tabular}{|c|c|c|c|}
\hline Item & Material model & Parameter & Value \\
\hline \multirow{5}{*}{ Concrete } & \multirow{4}{*}{ Anisotropic brittle damage } & Compressive strength (psi) & 5600 \\
& & Young's modulus (psi) & $4.500 \mathrm{E}+6$ \\
& & Poisson's ratio & 0.18 \\
& & Density (lb/ft $\left.\mathrm{ft}^{3}\right)$ & 150 \\
& & Tension limit (psi) & 650 \\
& & Shear limit (psi) & 2250 \\
& & Fracture toughness (lb/in) & 0.8 \\
\hline \multirow{3}{*}{ Dowel bars } & \multirow{3}{*}{ Linear elastic } & Young's modulus (psi) & $29.00 \mathrm{e}+06$ \\
& & Poisson's ratio & 0.30 \\
& & Density (lb//in $\left.{ }^{3}\right)$ & $7.324 \mathrm{e}-04$ \\
\hline
\end{tabular}


Table 4.2 - Stresses at the unloaded dowel- concrete interface:

\begin{tabular}{|c|c|c|c|c|}
\hline & $\begin{array}{c}\text { Maximum } \\
\text { Compressive } \\
\text { Stress "psi" }\end{array}$ & $\begin{array}{c}\text { Maximum } \\
\text { Tensile } \\
\text { Stress } \\
\text { "psi" }\end{array}$ & $\begin{array}{c}\text { Maximum } \\
\text { Shear Stress } \\
\text { "psi”" }\end{array}$ & $\begin{array}{c}\text { Maximum } \\
\text { Principle Stress } \\
\text { "psi" }\end{array}$ \\
\hline Regular dowel & 2280 & 426 & 1430 & 623 \\
\hline Polymer shokbar & 1930 & 300 & 1140 & 423 \\
\hline Steel shokbar & 974 & 150 & 594 & 180 \\
\hline
\end{tabular}

Table 4.3 - Stresses at the loaded dowel- concrete interface:

\begin{tabular}{|l|c|c|c|c|}
\hline & $\begin{array}{c}\text { Maximum } \\
\text { Compressive } \\
\text { Stress “psi”" }\end{array}$ & $\begin{array}{c}\text { Maximum } \\
\text { Tensile } \\
\text { Stress } \\
\text { “psi”" }\end{array}$ & $\begin{array}{c}\text { Maximum } \\
\text { Shear Stress } \\
\text { “psi”" }\end{array}$ & $\begin{array}{c}\text { Maximum } \\
\text { Principle Stress } \\
\text { "psi”" }\end{array}$ \\
\hline Regular dowel & 2220 & 621 & 1410 & 618 \\
\hline Polymer shokbar & 1890 & 306 & 1110 & 412 \\
\hline Steel shokbar & 967 & 145 & 593 & 193 \\
\hline
\end{tabular}




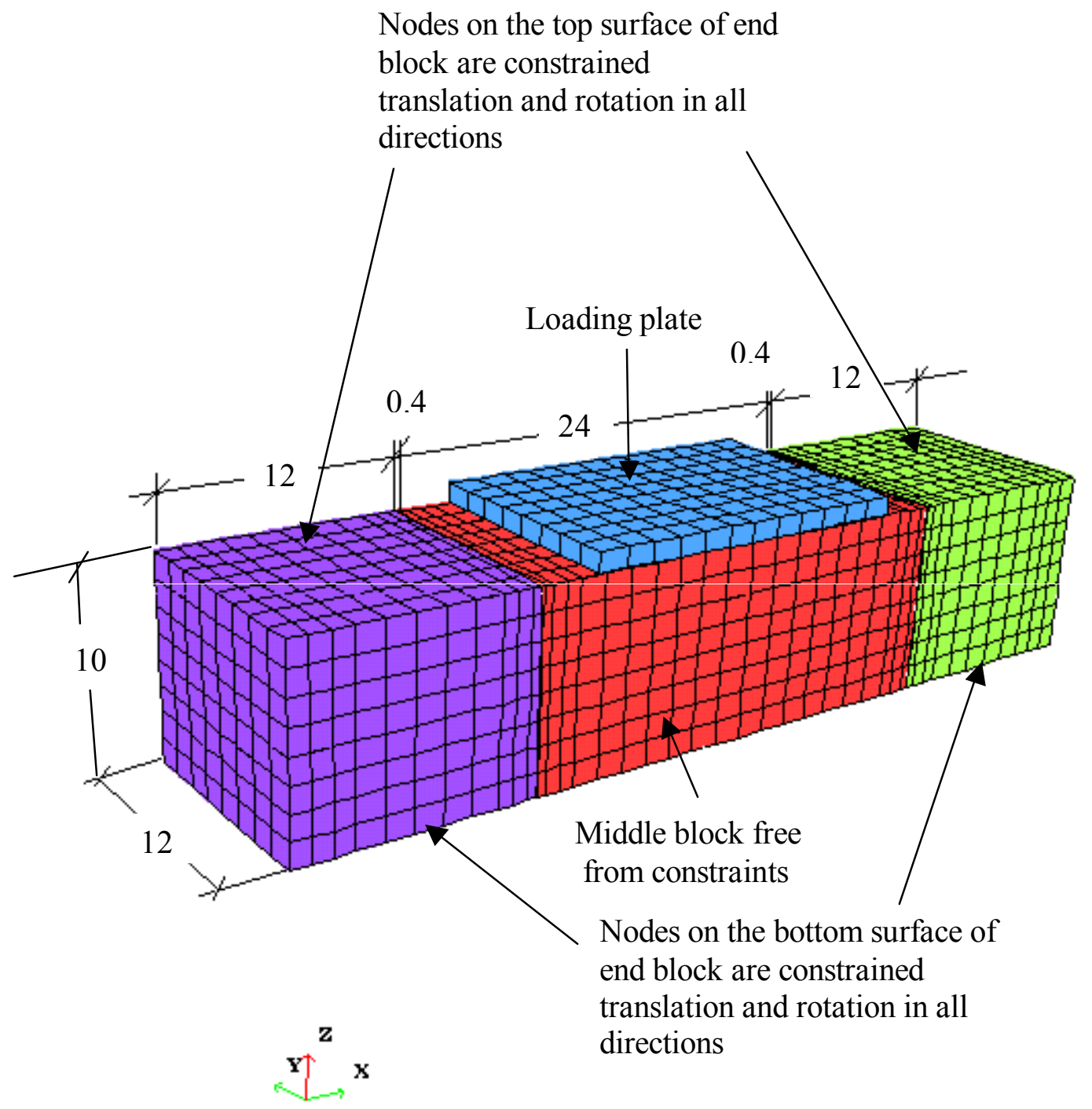

Note: all dimensions are in inches

Figure 4.1 - Finite element model of a double-jointed concrete specimen 


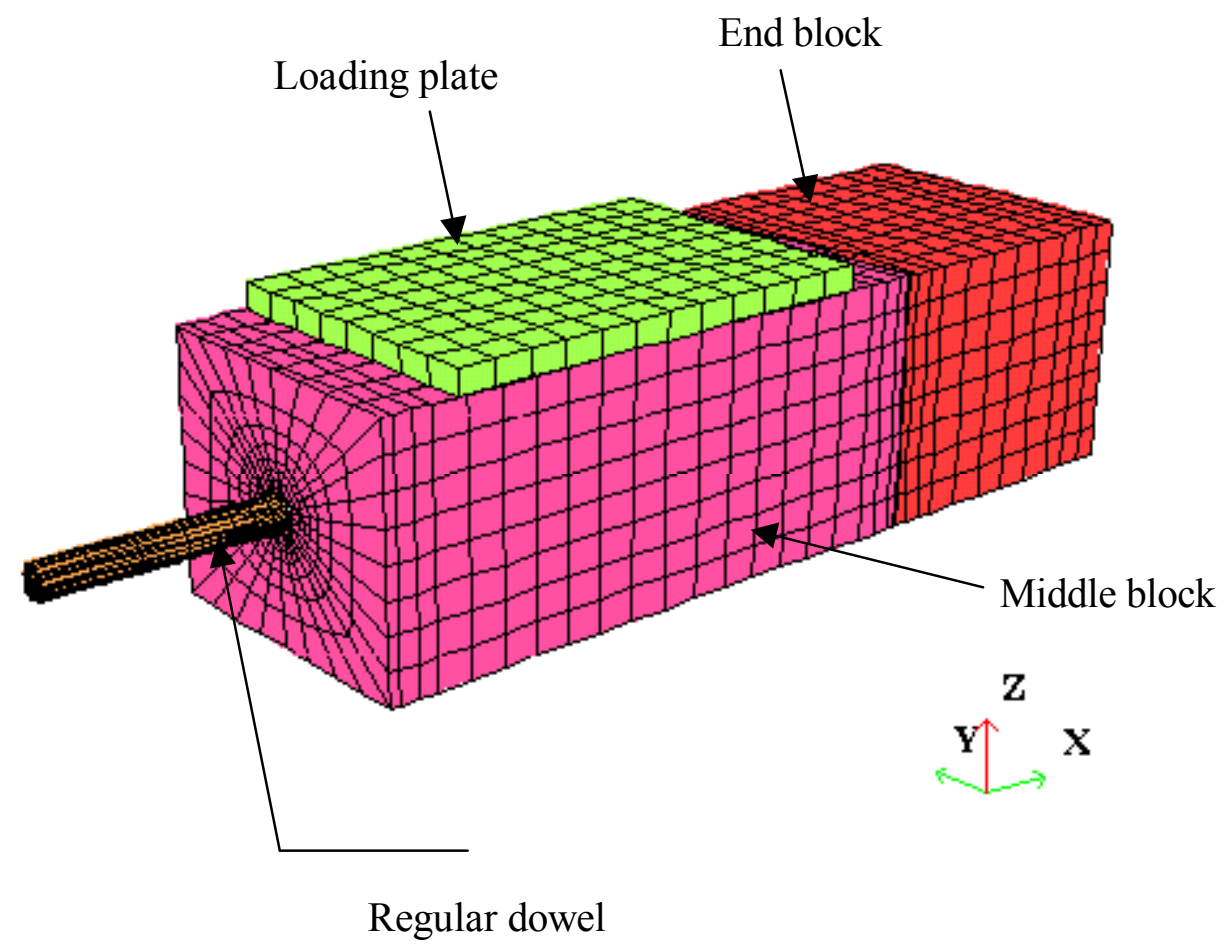

Figure 4.2 - Finite element model of double-jointed concrete specimen with dowel bars; one end block removed 


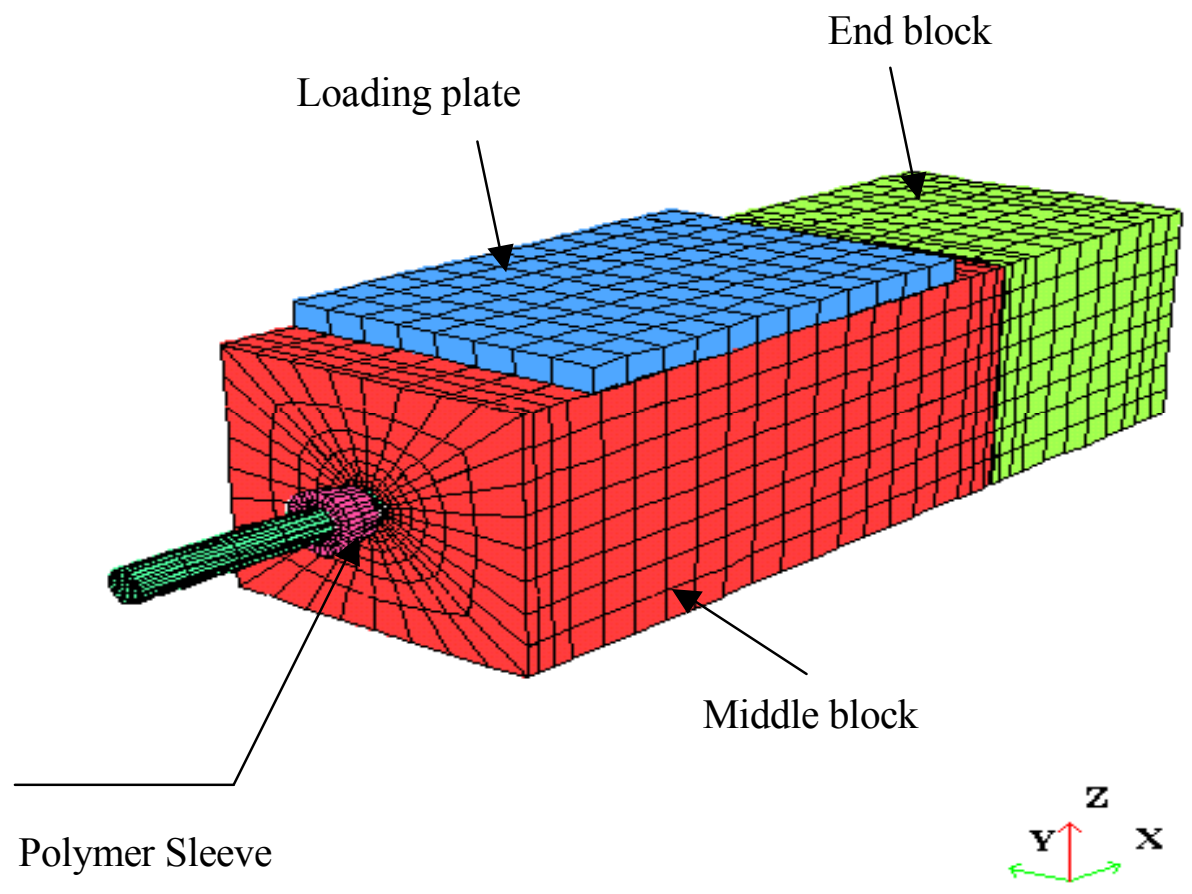

Figure 4.3 - Finite element model of double-jointed concrete specimen with polymer shokbars; one end block removed 


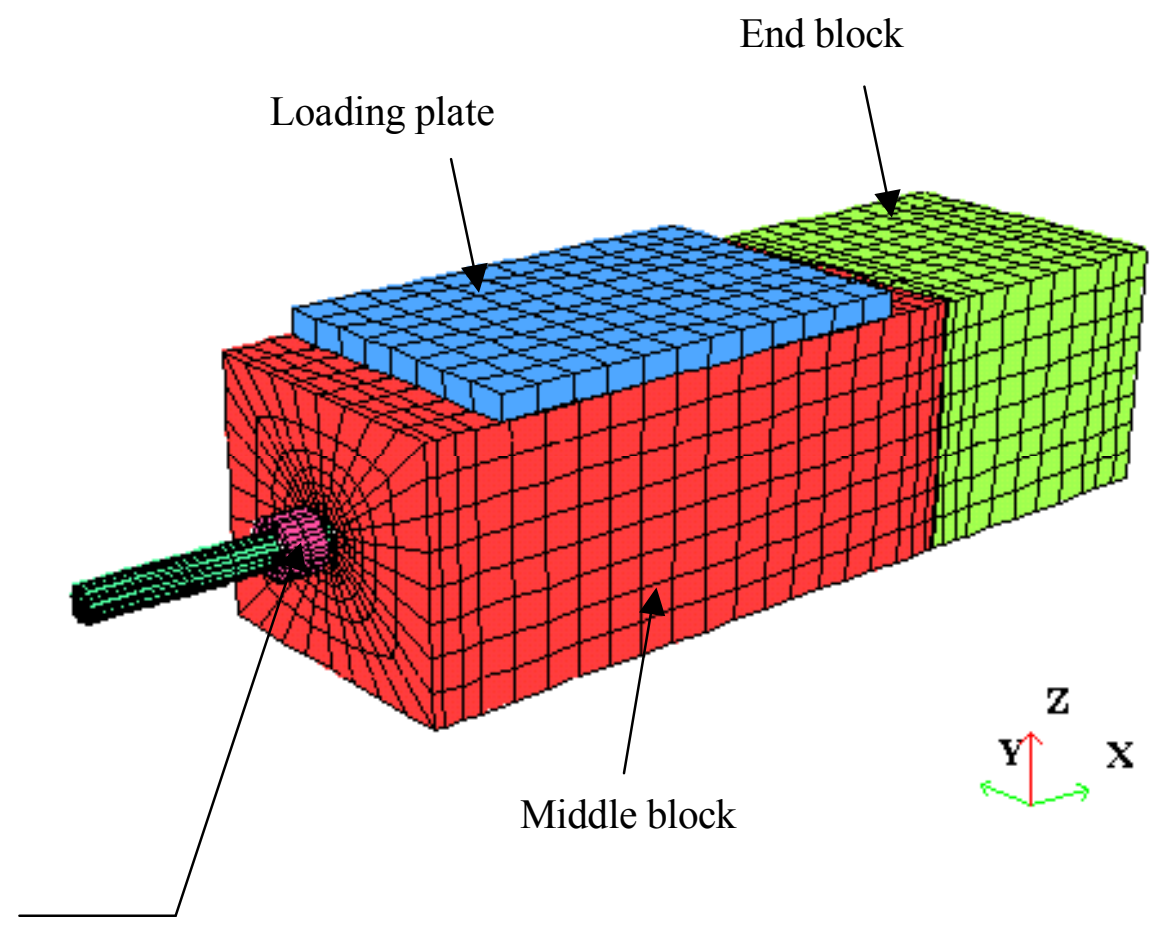

Steel Sleeve

Figure 4.4 Finite element model of double-jointed concrete specimen with steel shokbars; one end block removed 



$\overbrace{}^{\mathbf{y}} \mathbf{z}$

Steel shokbar

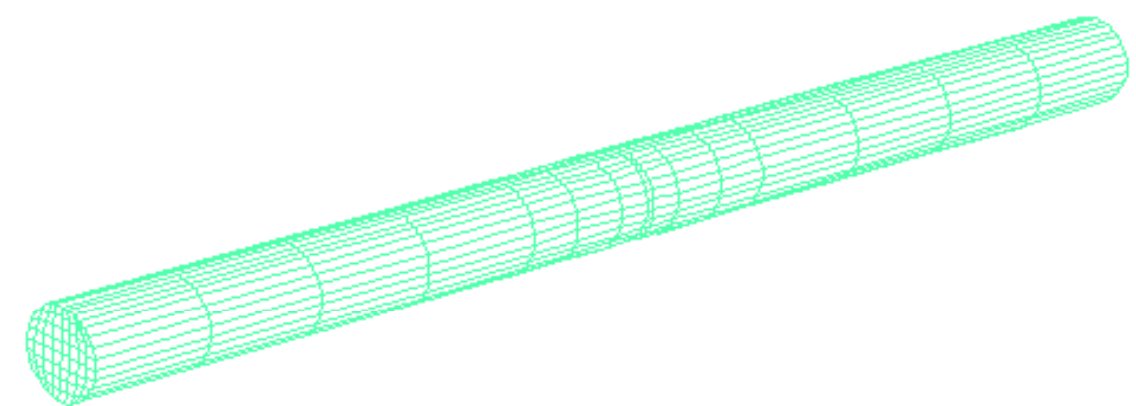

Regular dowel

$\overbrace{}^{\mathbf{Y}} \mathbf{x}$

Figure 4.5 - Meshing of polymer shokbar, steel shokbar and regular dowel 


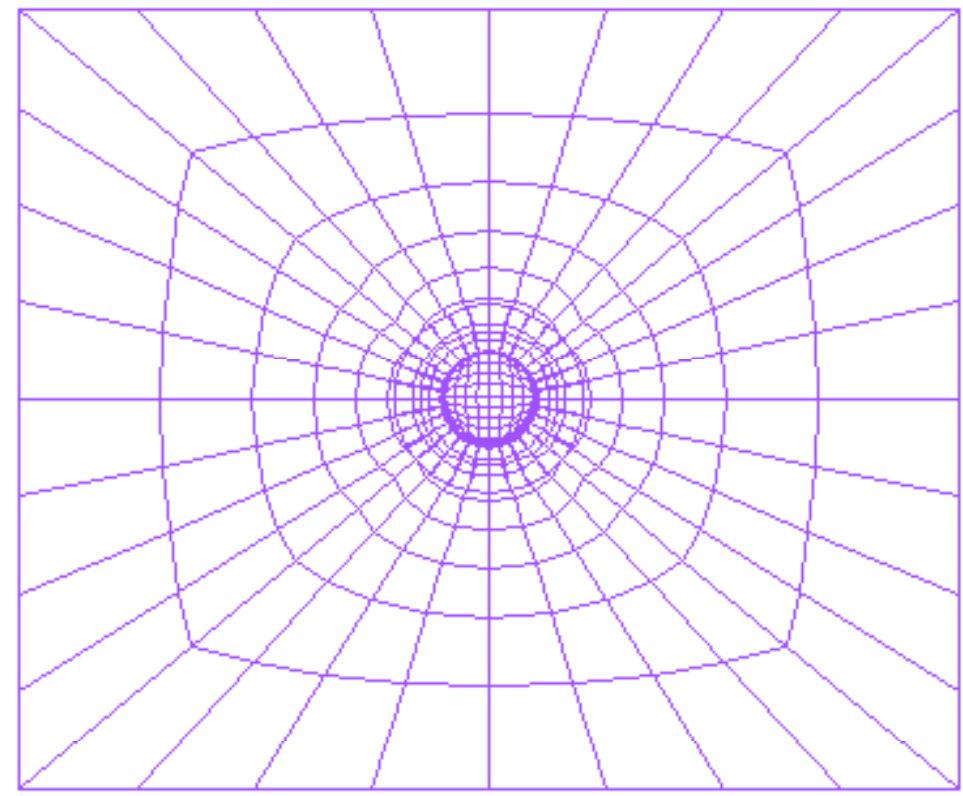

Z

$\stackrel{X}{\longrightarrow} \mathbf{Y}$

Figure 4.6 Finite element mesh at joint face 


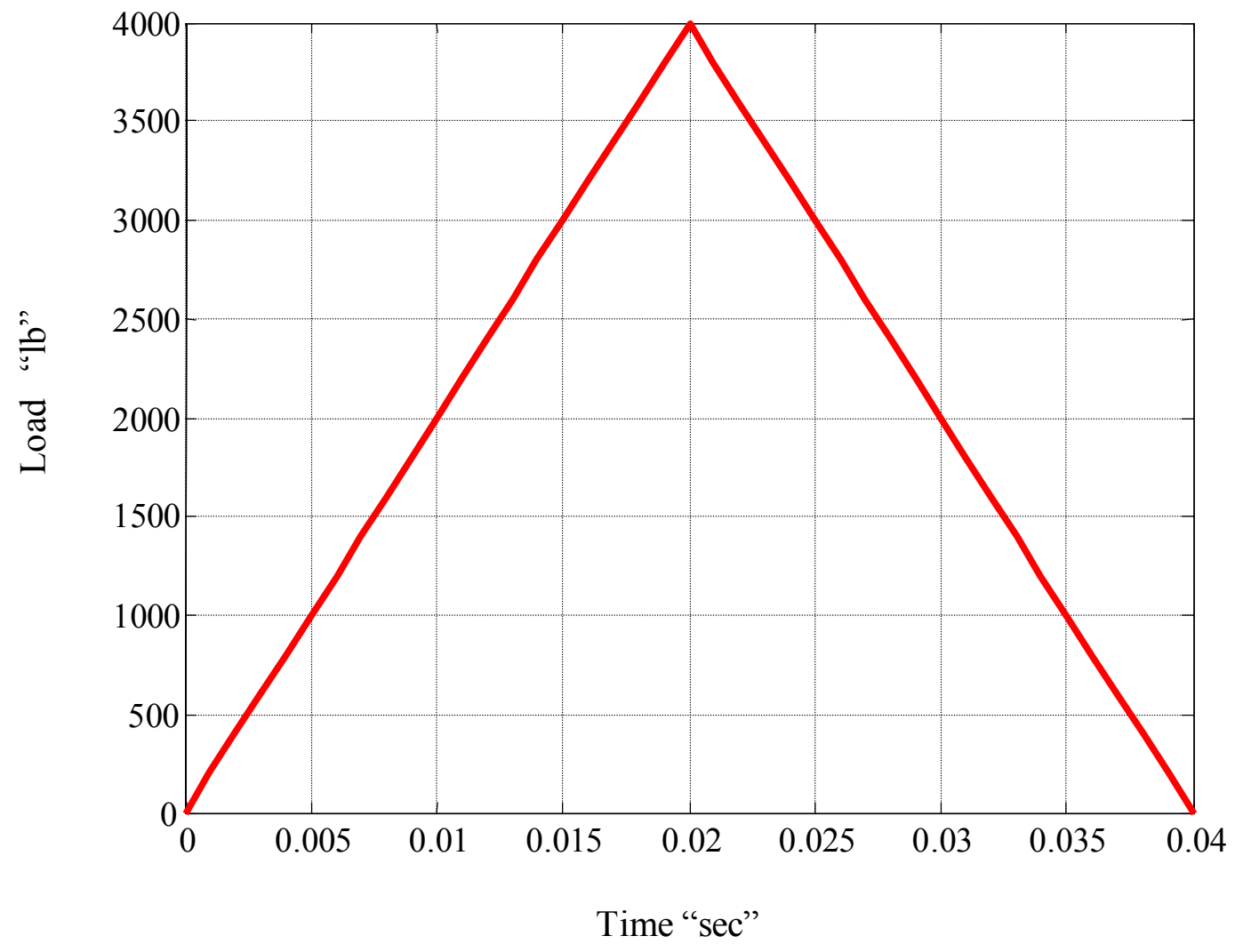

Figure 4.7 - Load Profile

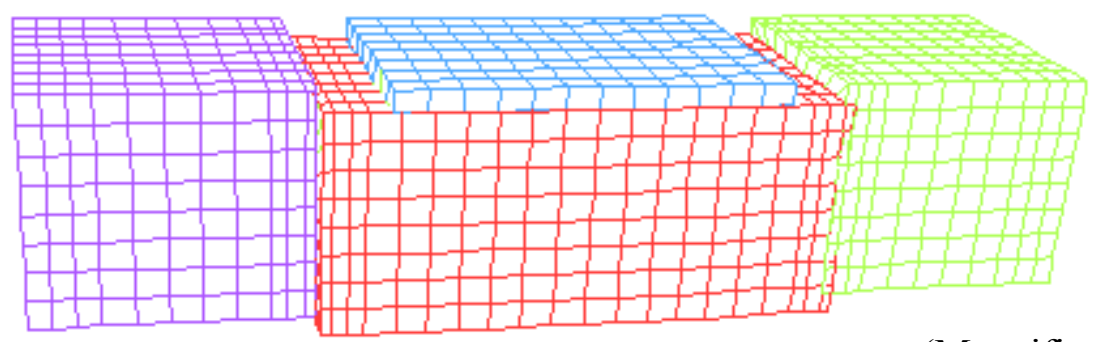

(Magnification factor 300) $\stackrel{y}{z}^{z}$

Figure 4.8 - Deformation of double joint specimen at maximum load. 




Figure 4.9 - Vertical Stress along the dowel bar 


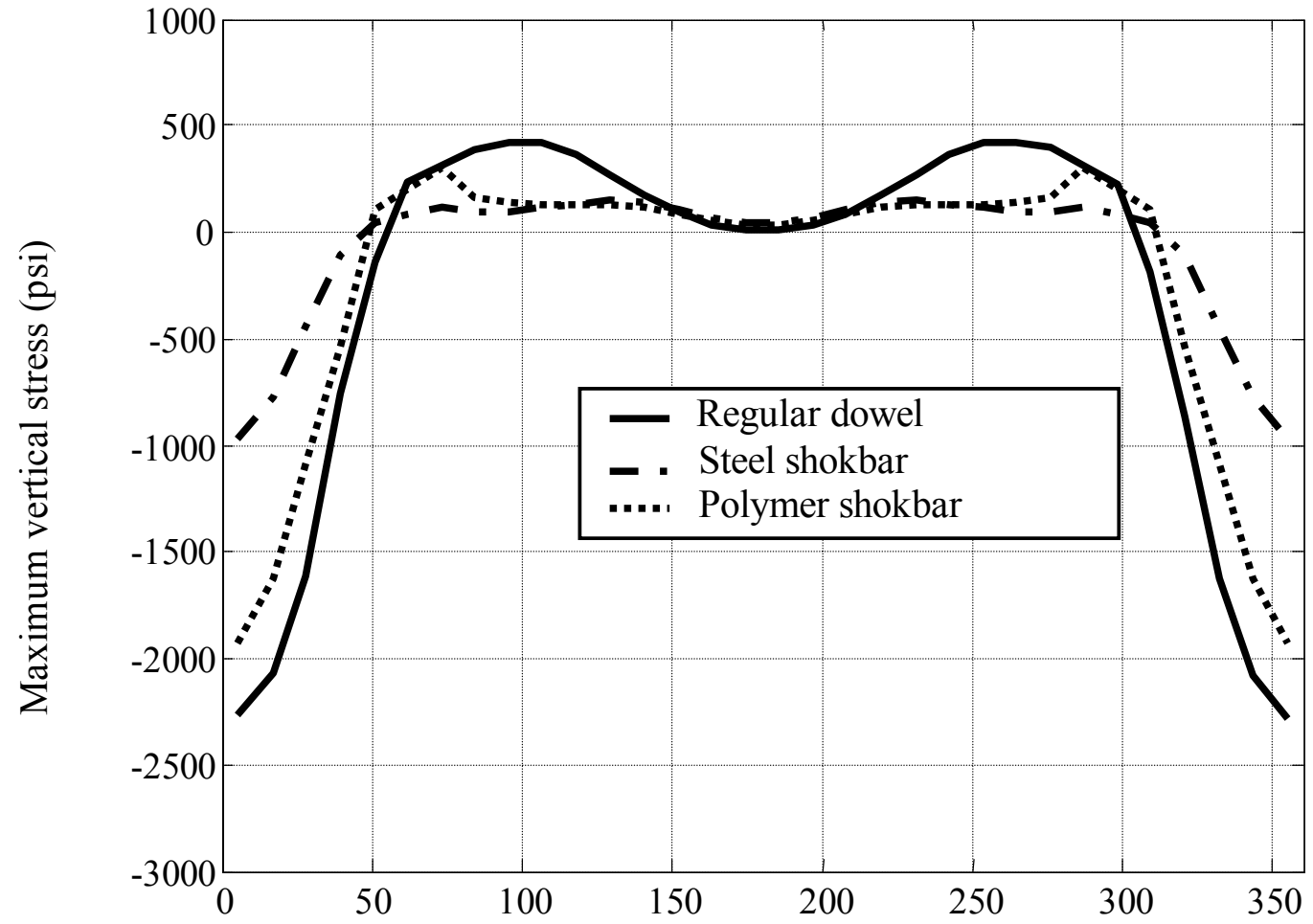

Position around dowel (degrees)

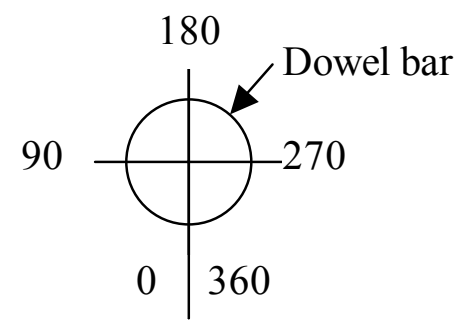

Angular position

Figure 4.10 - Vertical stress at dowel concrete interface of unloaded block 


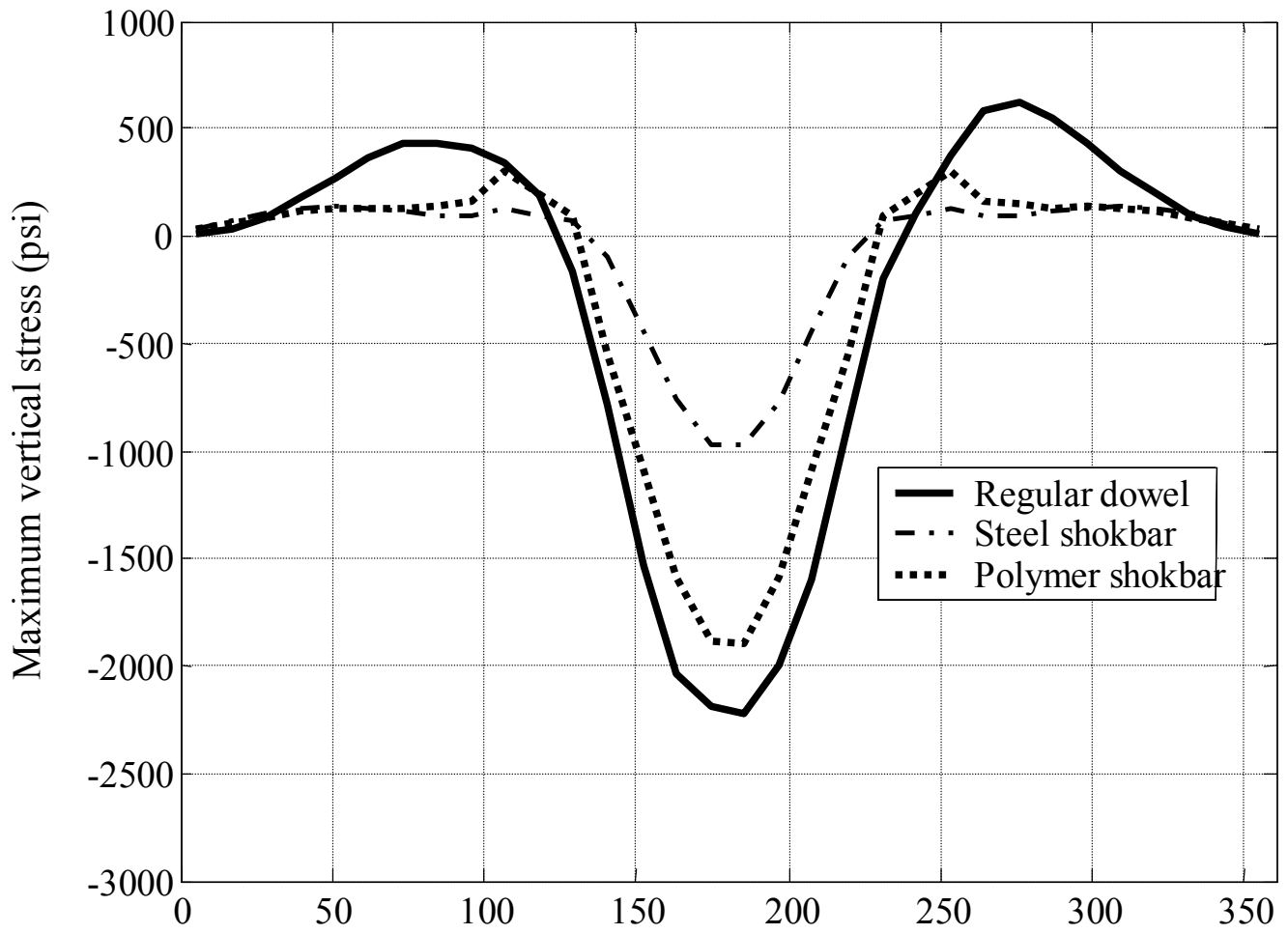

Position around dowel (degrees)

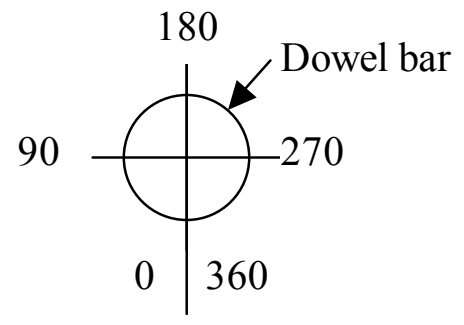

Angular position

Figure 4.11 -Vertical stress at dowel concrete interface of loaded block. 


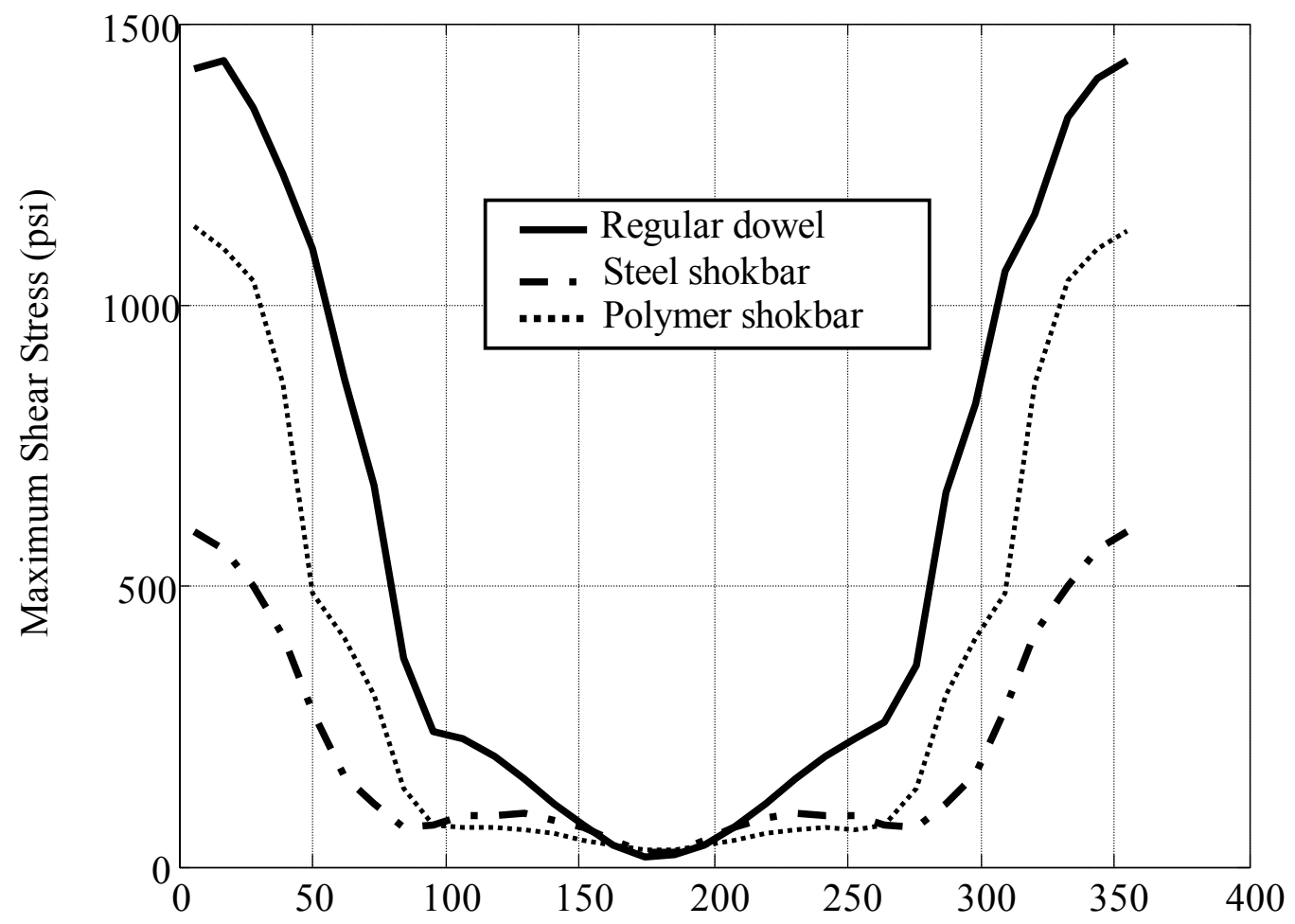

Position around dowel (degrees)

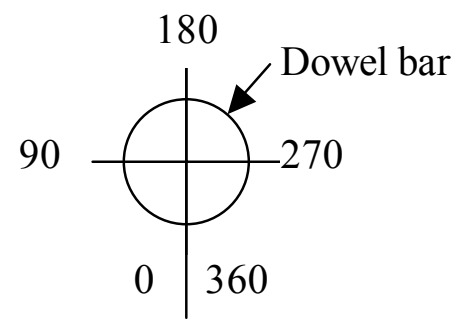

Angular position

Figure 4.12 -Maximum Shear Stress at dowel concrete interface of unloaded block 


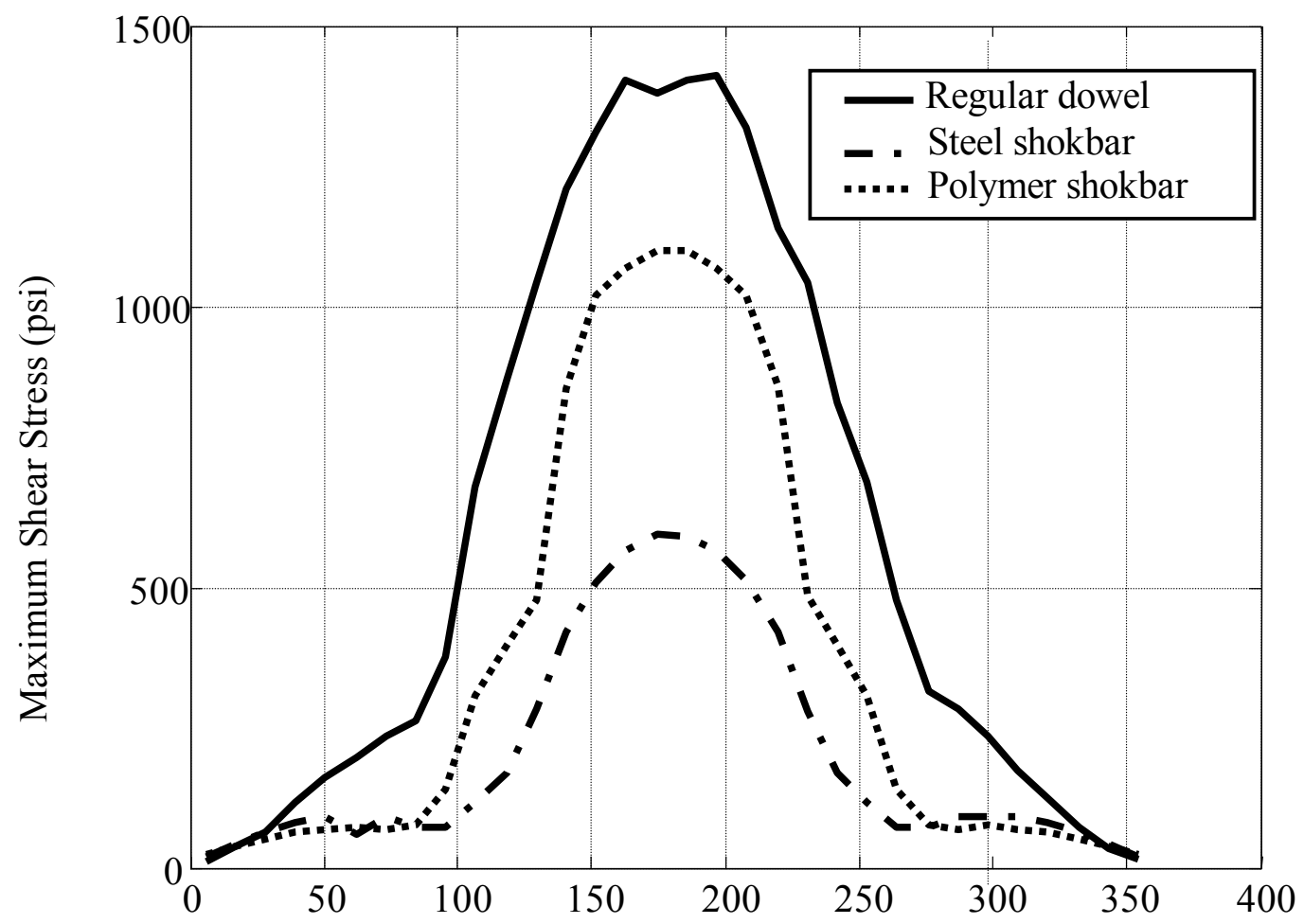

Position around dowel (degrees)

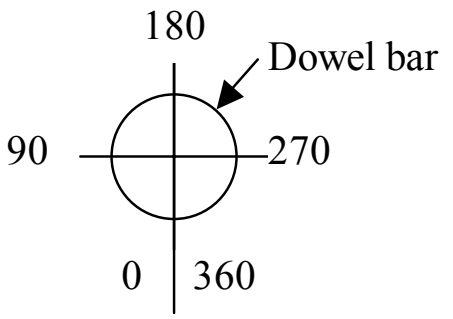

Angular position

Figure 4.13- Maximum Shear Stress at dowel concrete interface of loaded block 


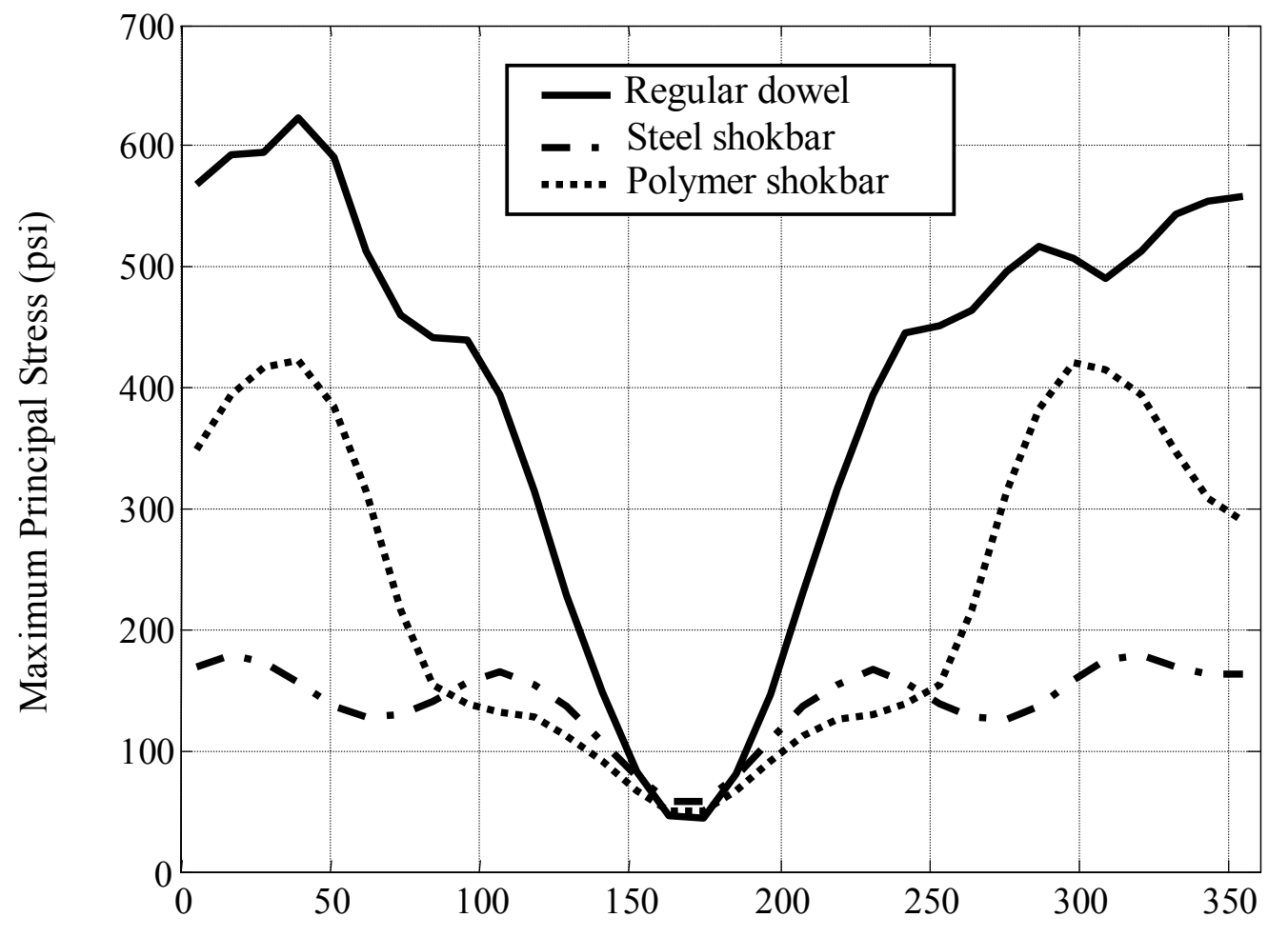

Position around dowel (degrees)

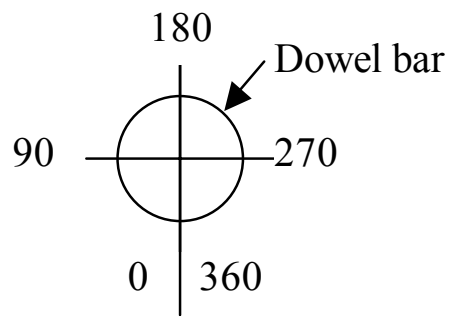

Angular position

Figure 4.14 - Maximum Principal Stress at dowel concrete interface of unloaded block 


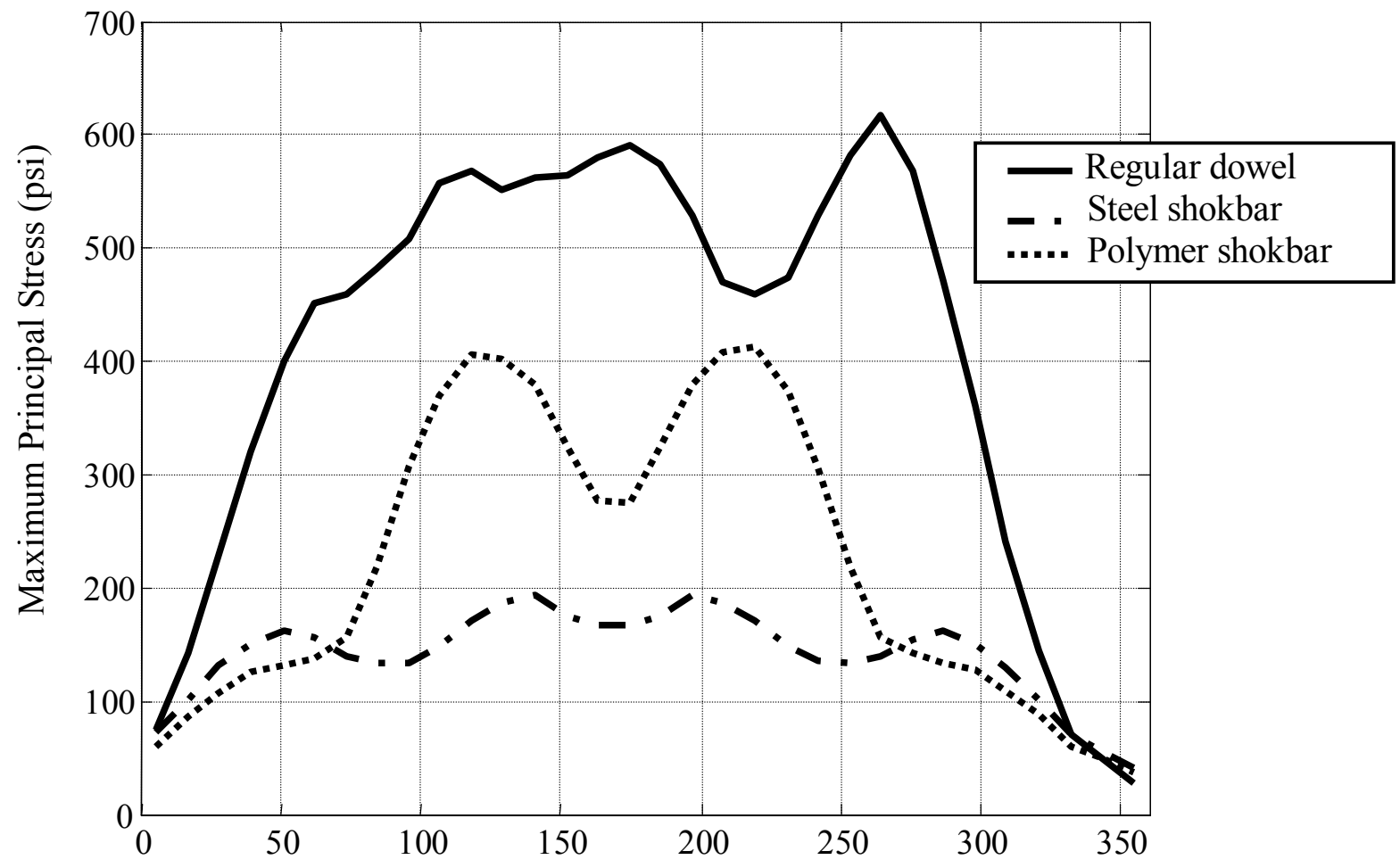

Position around dowel (degrees)

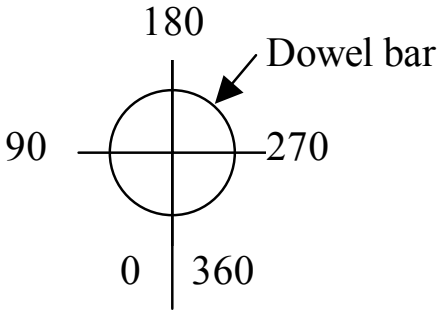

Angular position

Figure 4.15 - Maximum Principal Stress at dowel concrete interface of loaded block 

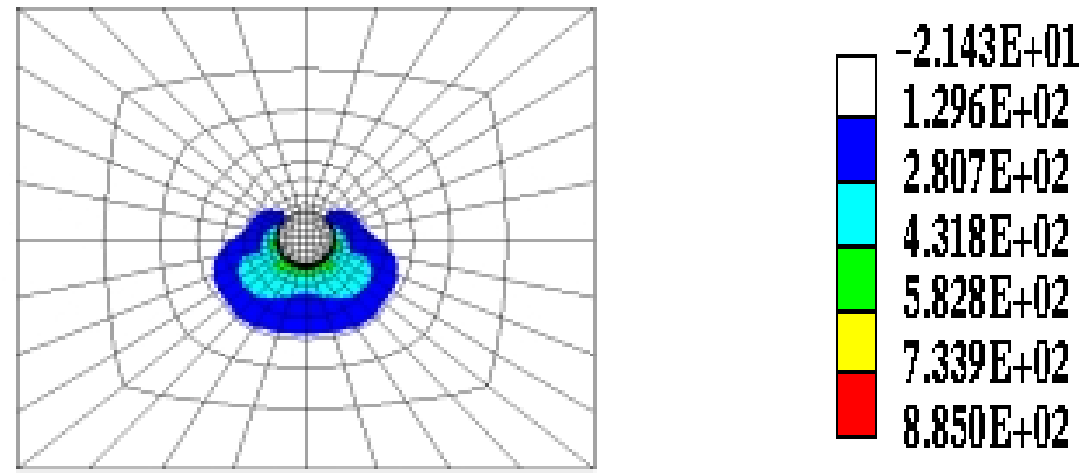

Maximum Principle Stress

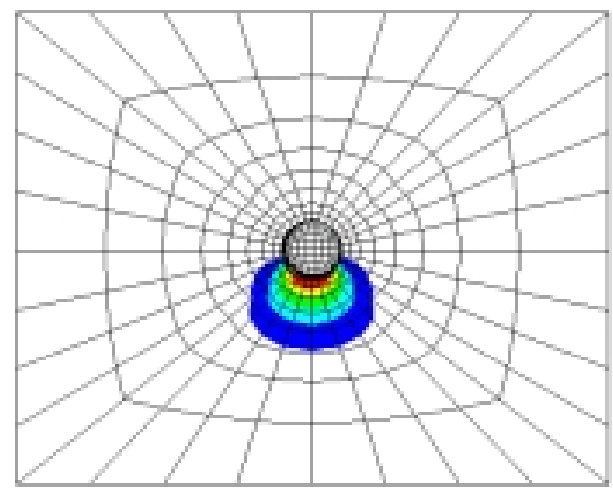

$2.046 \mathrm{E}-01$

$3.433 \mathrm{E}+02$

$6.863 \mathrm{E}+02$

$1.029 \mathrm{E}+103$

$1.372 \mathrm{E}+13$

$1.715 \mathrm{E}+13$

$2.059 \mathrm{E}+13$

Maximum Shear Stress
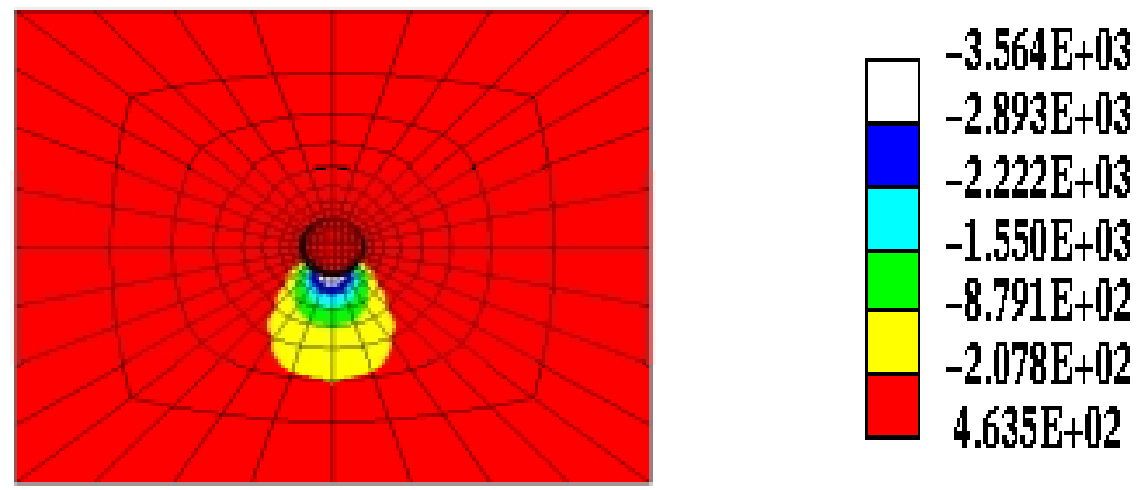

Vertical Stress

Figure 4.16 - Fringes of Maximum Principle Stress, Maximum Shear Stress and Vertical Stress around unloaded Polymer shokbar 

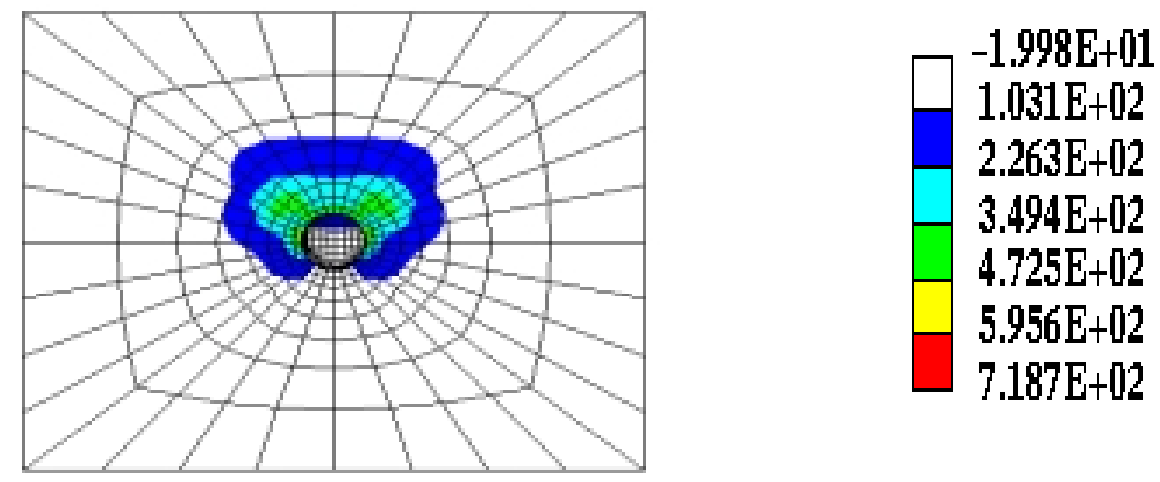

Maximum Principal Stress
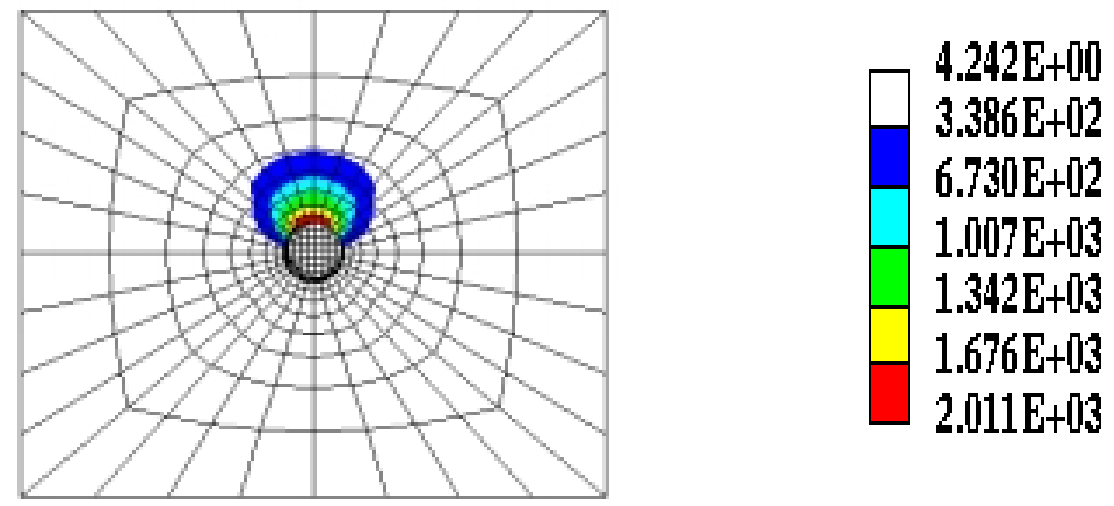

Maximum Shear Stress
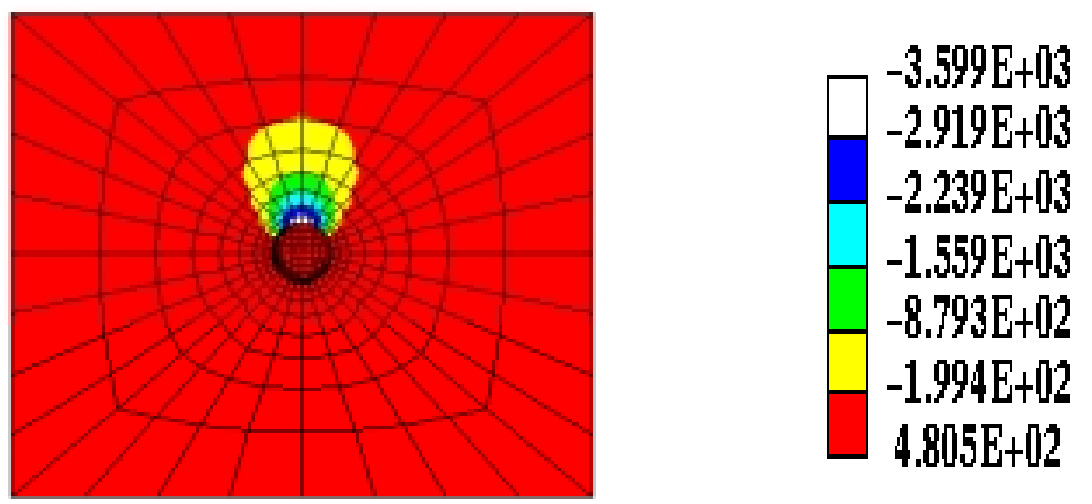

Vertical Stress

Figure 4.17 - Fringes of Maximum Principle Stress, Maximum Shear Stress and Vertical Stress around loaded Polymer shokbar 

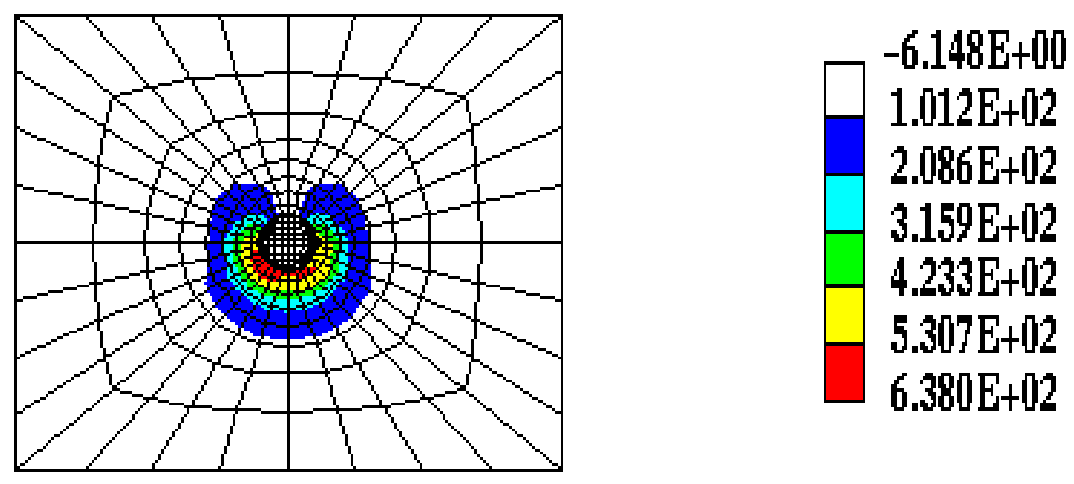

Maximum Principal Stress
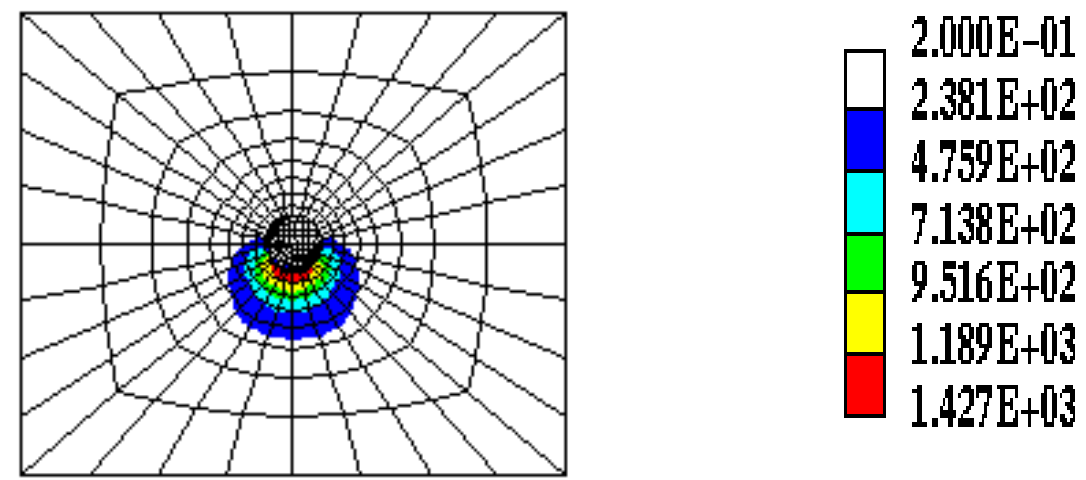

Maximum Shear Stress
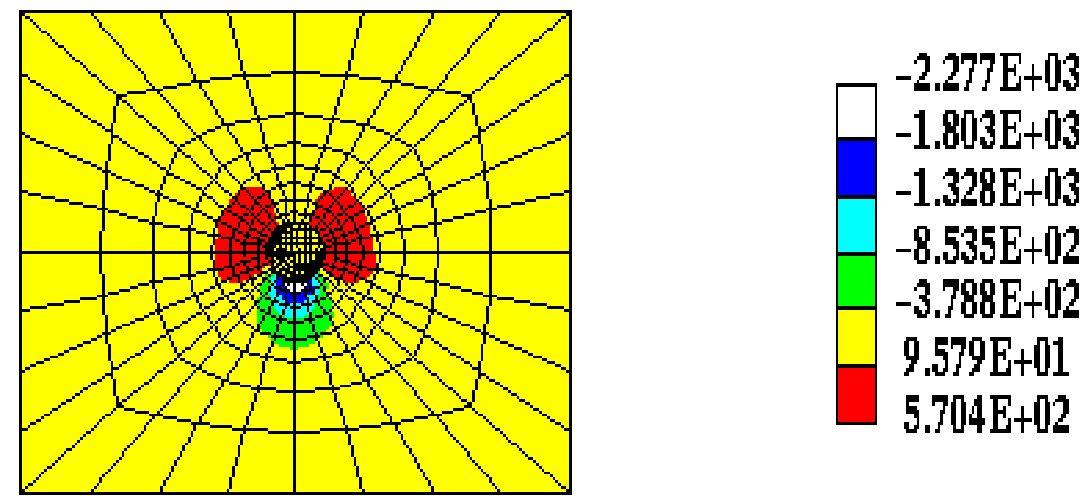

Vertical Stress

Figure 4.18 - Fringes of Maximum Principle Stress, Maximum Shear Stress Vertical Stress around unloaded regular dowel 



Maximum Principal Stress
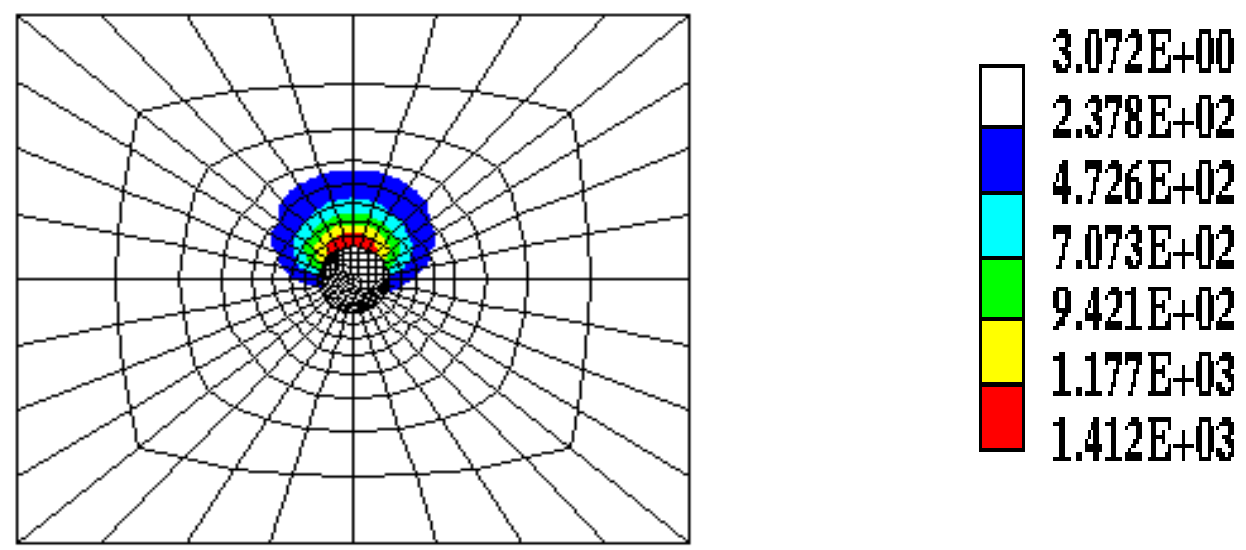

Maximum Shear Stress
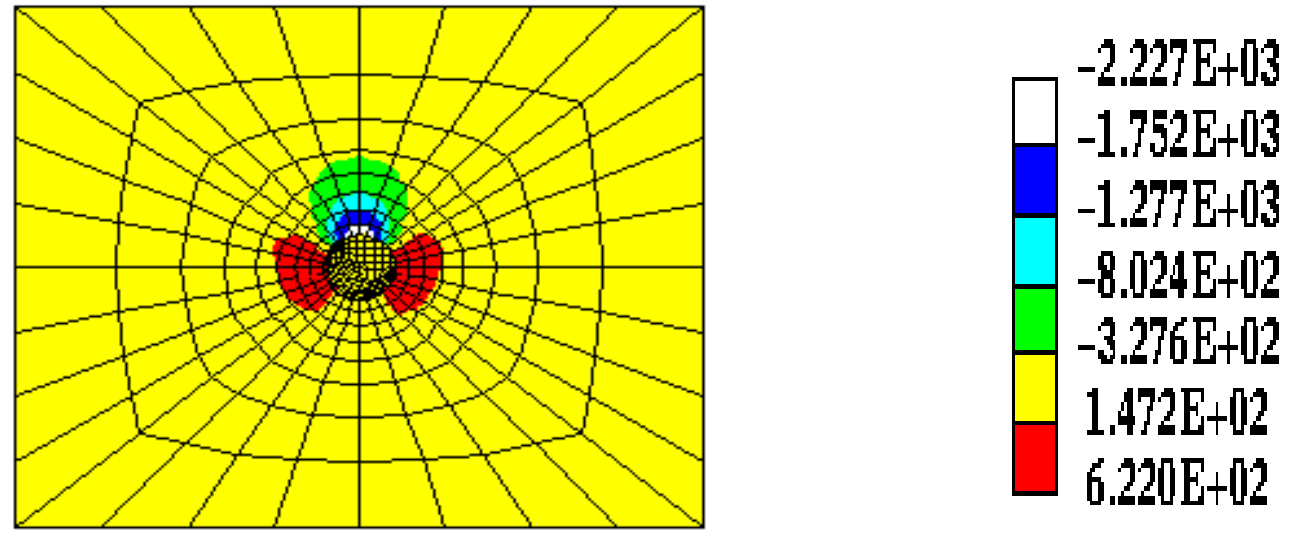

Vertical Stress

Figure 4.19 - Fringes of Maximum Principle Stress, Maximum Shear Stress Vertical Stress around loaded regular dowel 

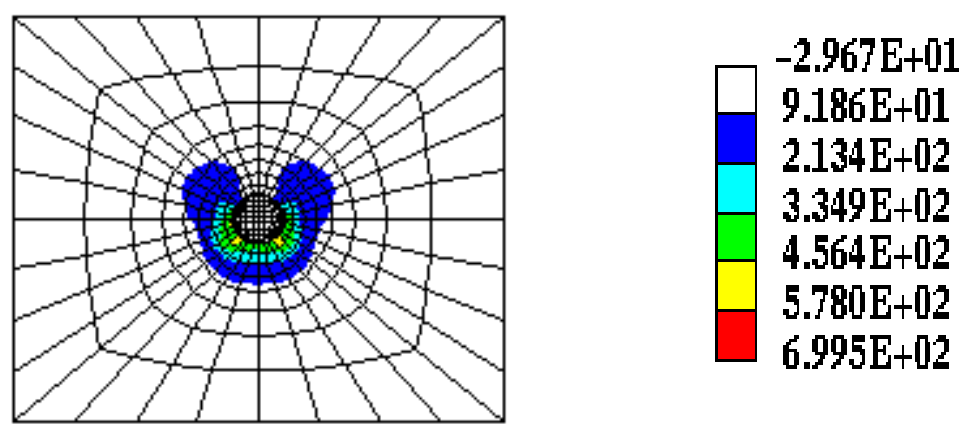

Maximum Principal Stress
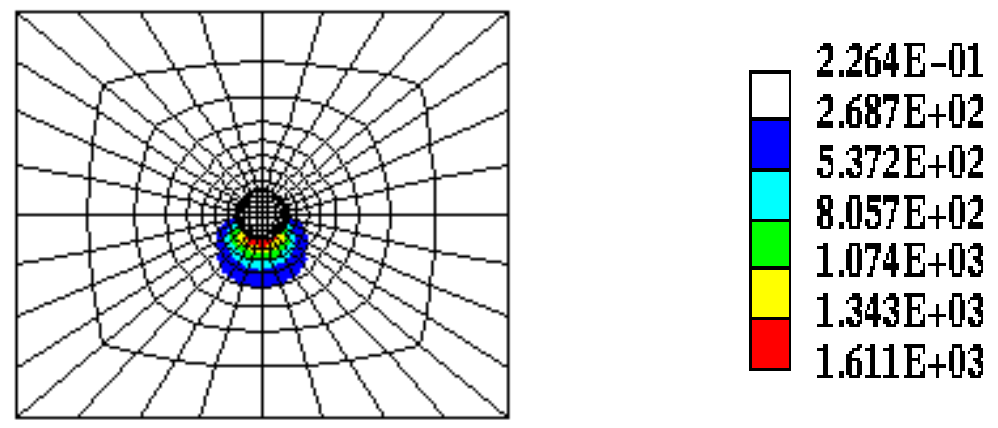

Maximum Shear Stress
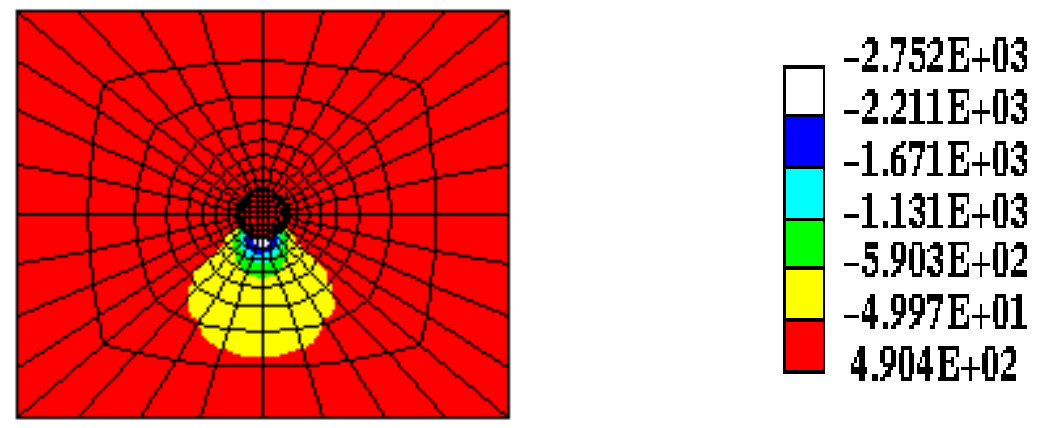

Vertical Stress

Figure 4.20 - Fringes of Maximum Principle Stress, Maximum Shear Stress Vertical Stress around unloaded Steel shokbar 


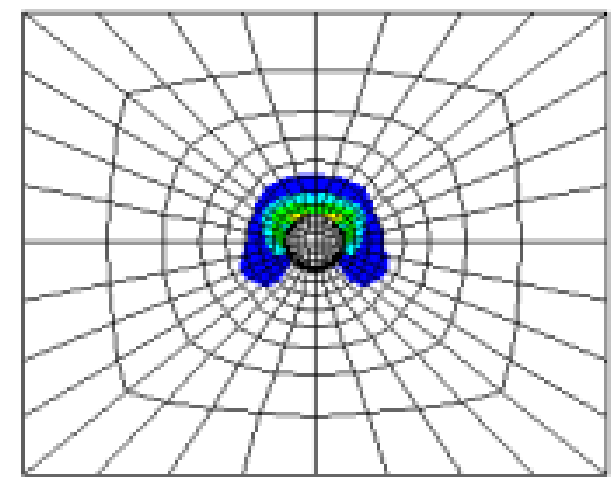

Maximum Princioal Stress



Maximum Shear Stress
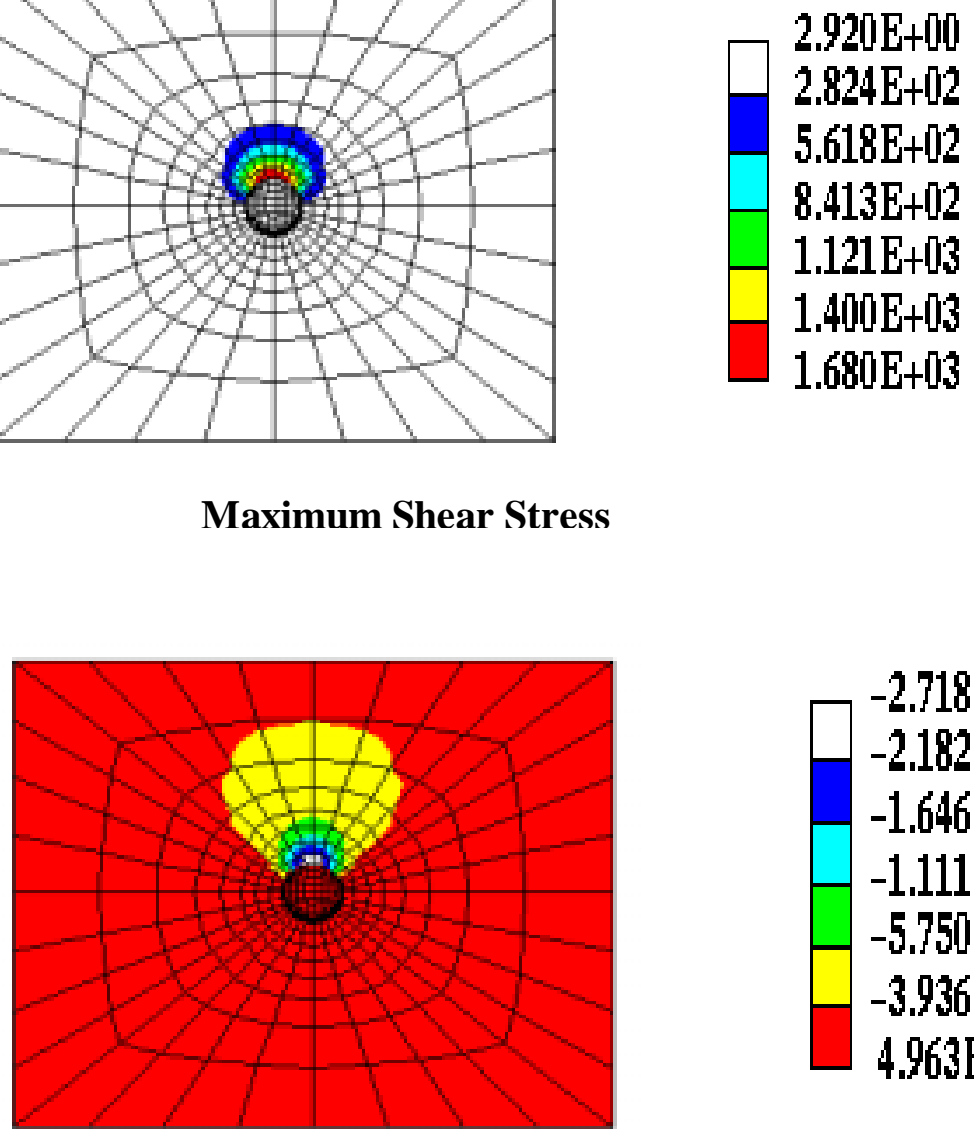

Vertical Stress

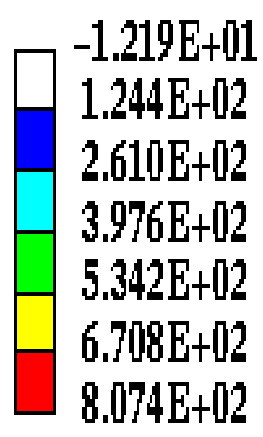

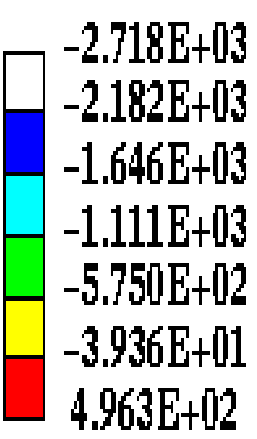

Figure 4.21 - Fringes of Maximum Principle Stress, Maximum Shear Stress Vertical Stress around loaded Steel shokbar 


\section{CHAPTER FIVE FINITE ELEMENT MODEL VERIFICATION}

The results obtained from the finite element model are compared with the results from the experimental results to validate the finite element model. A close match between several response parameters measured from the experiments, and those calculated from the finite element models would provide many benefits. On one hand, this could lend legitimacy to the collected data. On the other hand, the use of finite element modeling makes it more economical in terms of material cost, equipments, and time consumption than the statistical approach, which requires conducting tests on a large number of specimens.

\subsection{STRAINS AT BAR/CONCRETE INTERFACE}

Strains measured from the finite element models are compared to the strains measured from the experimental specimens.

\subsubsection{Compressive strains at bar/concrete interface:}

Figures 5.1-5.3 show the history of compressive strains at bar/concrete interface from finite element model and experiments when subjected to the static test. The maximum strain measured in the concrete at the bottom of the dowel bar is -427.667 microstrains and the corresponding value calculated from the finite element model is -502 microstrains. The finite element model over predicts the maximum compressive strain by about $17 \%$. The maximum strain measured in the concrete at the bottom of the polymer shokbar is -294 microstrains and the corresponding value calculated from the finite element model is -301 microstrains. The finite element model over predicts the maximum compressive strain by about $2 \%$.

The value of the maximum strains measured in the concrete at the bottom of the steel shokbar is -282 microstrains and the corresponding value calculated from the finite element model is -248 microstrains. The finite element model less predicts the maximum compressive strain by about $12 \%$. 


\subsubsection{Tensile strains at bar/concrete interface:}

Figures 5.4-5.6 show the history of tensile strains at bar/concrete interface from finite element model and experiments when subjected to the static test.

The maximum tensile strain at dowel/concrete measured at the side of dowel bar is 151.5 microstrains and the corresponding value of the strain from the finite element model is 118 microstrains. The numerical maximum tensile strain differs from that of the experiments by about $22 \%$.

The maximum tensile strain measured at polymer shokbar/concrete interface is 35.7 microstrains and the corresponding value from the finite element model is 38.66 microstrains. The numerical maximum tensile strain differs from that of the experiments by about $7 \%$.

The maximum tensile strain measured at steel shokbar/concrete interface is 28.8 microstrains and the corresponding strain from the finite element model is 45 mircostrains. The numerical maximum tensile strain differs from that of the experiments by about $36 \%$.

\subsubsection{Tensile strains at about 0.7 inches from bar/concrete interface:}

The time history of strains when subjected static test are illustrated in Figures 5.7 -5.9. The maximum tensile strain measured at about 0.7 inches from the side of dowel bar is 34.8 microstrains and the corresponding strain from the finite element model is 33.2 microstrains. The numerical maximum tensile strain differs from that of the experiments by about $4 \%$.

The maximum tensile strain measured at about 0.7 inches from the side of polymer shokbar is 22.75 microstrains and the corresponding value from the finite element model is 18 microstrains. The numerical maximum tensile strain differs from that of the experiments by about $20 \%$.

The maximum tensile strain measured at about 0.7 inches from the side of dowel bar is 14 microstrains and the corresponding value from the finite element model is 15 microstrains. The numerical maximum tensile strain differs from that of the experiments by about $6 \%$. 


\subsection{LOAD -DEFLECTION}

The relative displacements measured at the joints of experimental specimen were compared with those measured from the finite element model.

Figure 5.10 illustrates the history of relative displacements at the joints of regular dowel specimen from the experiments and the corresponding results from finite element model with respect to the load. The difference in their maximum values is about $19 \%$.

Figure 5.11 illustrates the history of relative displacements measured at the joints of polymer shokbar specimen from the experiments and the corresponding finite element results. The difference in their maximum values is $42 \%$. It is observed that the slope of the experimental relative deflection curve is the same as the finite element relative displacement curve. The reason for the difference in their maximum relative displacements could be due to the difference in the initial conditions i.e. the dowel looseness assumed in the finite element program could be different from the actual dowel looseness in the test specimen.

Figure 5.12 illustrates the history of relative displacements measured at the joints of steel shokbar specimen from the experiments and the corresponding finite element results of a static test. The percentage error between the FEM and experiments is less than $1 \%$.

\subsection{DISCUSSION}

A good match for strains at bar/concrete interface, tensile strains measured far from the bar/concrete interface, and relative displacements at joints are obtained between experiments and finite element models.

Although some discrepancies appeared between some experimental and finite element results, the overall agreement was very good. The discrepancies could be attributed to several experimental difficulties. The configuration of the joints with the bars being the only means of connecting the three concrete sections make the bar/concrete interface vulnerable to stresses while moving the specimens. The looseness of dowel assumed in the finite element model may not be the same as in the test specimen. Although special care was taken to place the LVDT's at the exact locations to measure the vertical displacements of the loaded and unloaded blocks, error in their 
placement could occur due to the surface irregularities and small asymmetry in the test dimensions. A small change in the placement of LVDT would give varying displacement results.

\subsection{CONCLUSIONS}

The experimentally measured strains at bar/concrete interface and the corresponding results from finite element models were in good agreement with each other. The relative displacements at the joints measured from the experiments and finite element models were also in good agreement.

This indicates that the techniques used in the finite element models are capable of producing promising results and it could be used to explore more about the behavior of dowel/shokbar in transverse joints. It can be concluded that the use of techniques of these finite element models in the simulation of pavement structures would produce accurate results. 


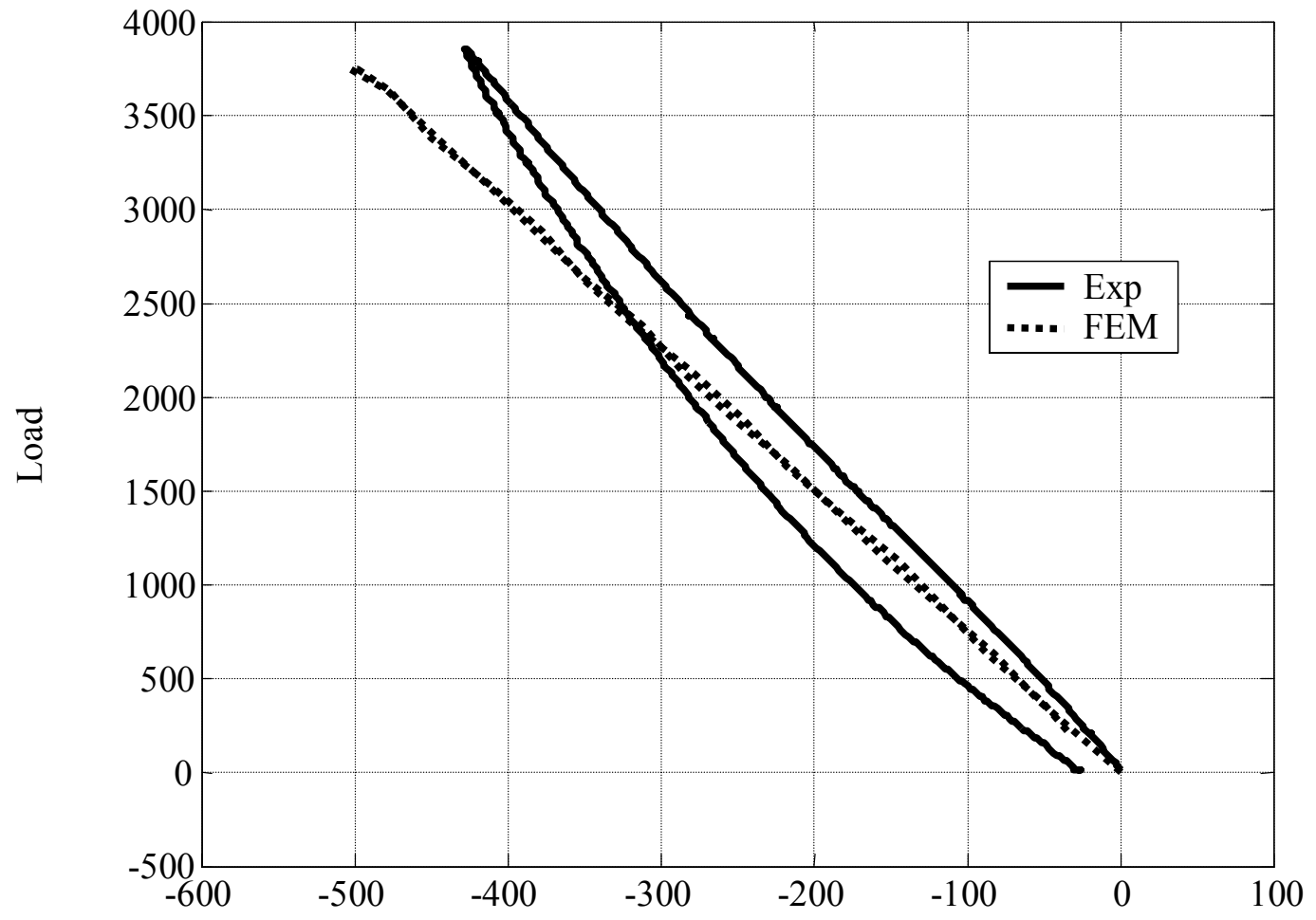

Microstrains

Figure 5.1 - Compressive strain at regular dowel/concrete interface from experiment and finite element model 


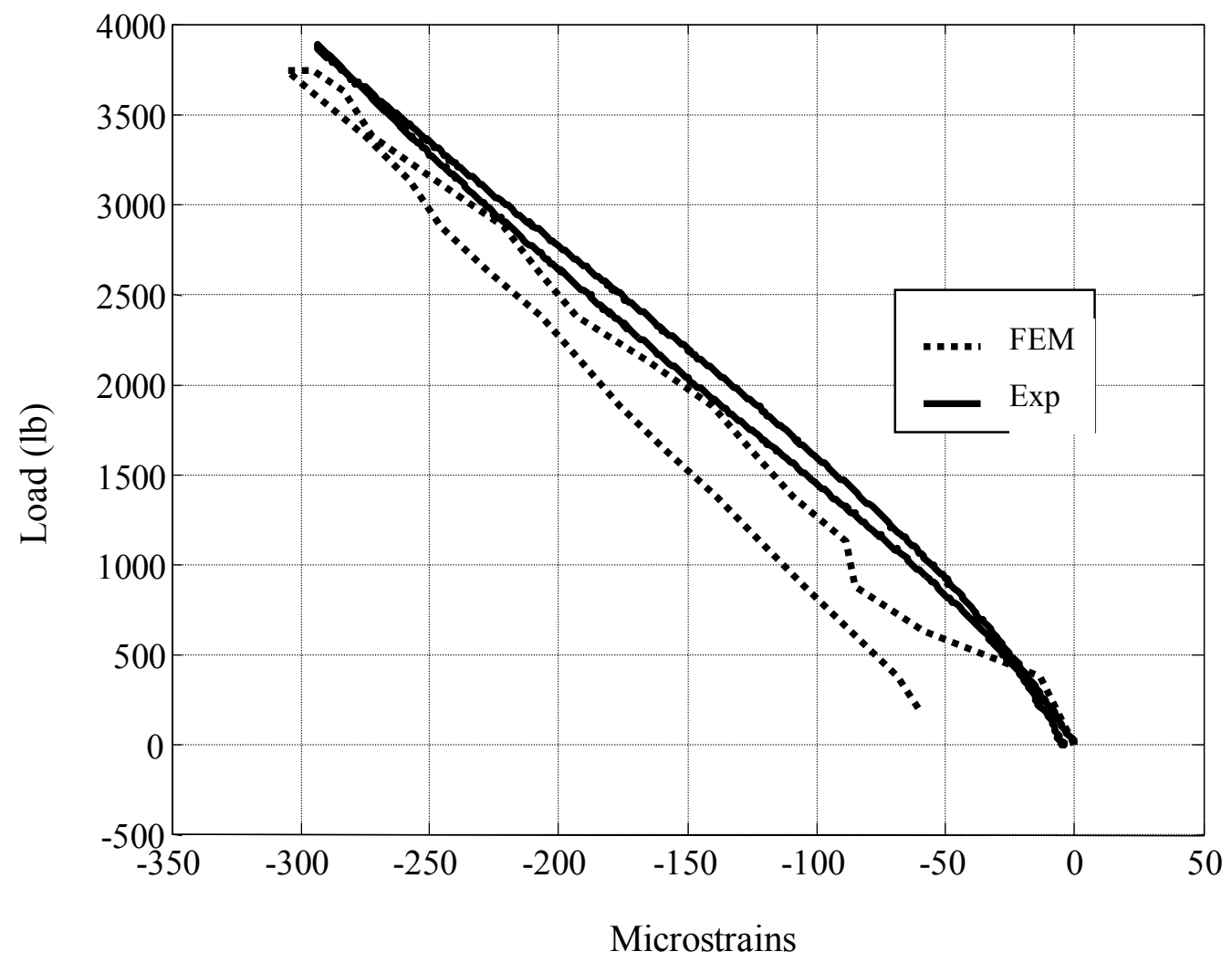

Figure 5.2 - Compressive strain at polymer shokbar/concrete interface from experiment and finite element model 


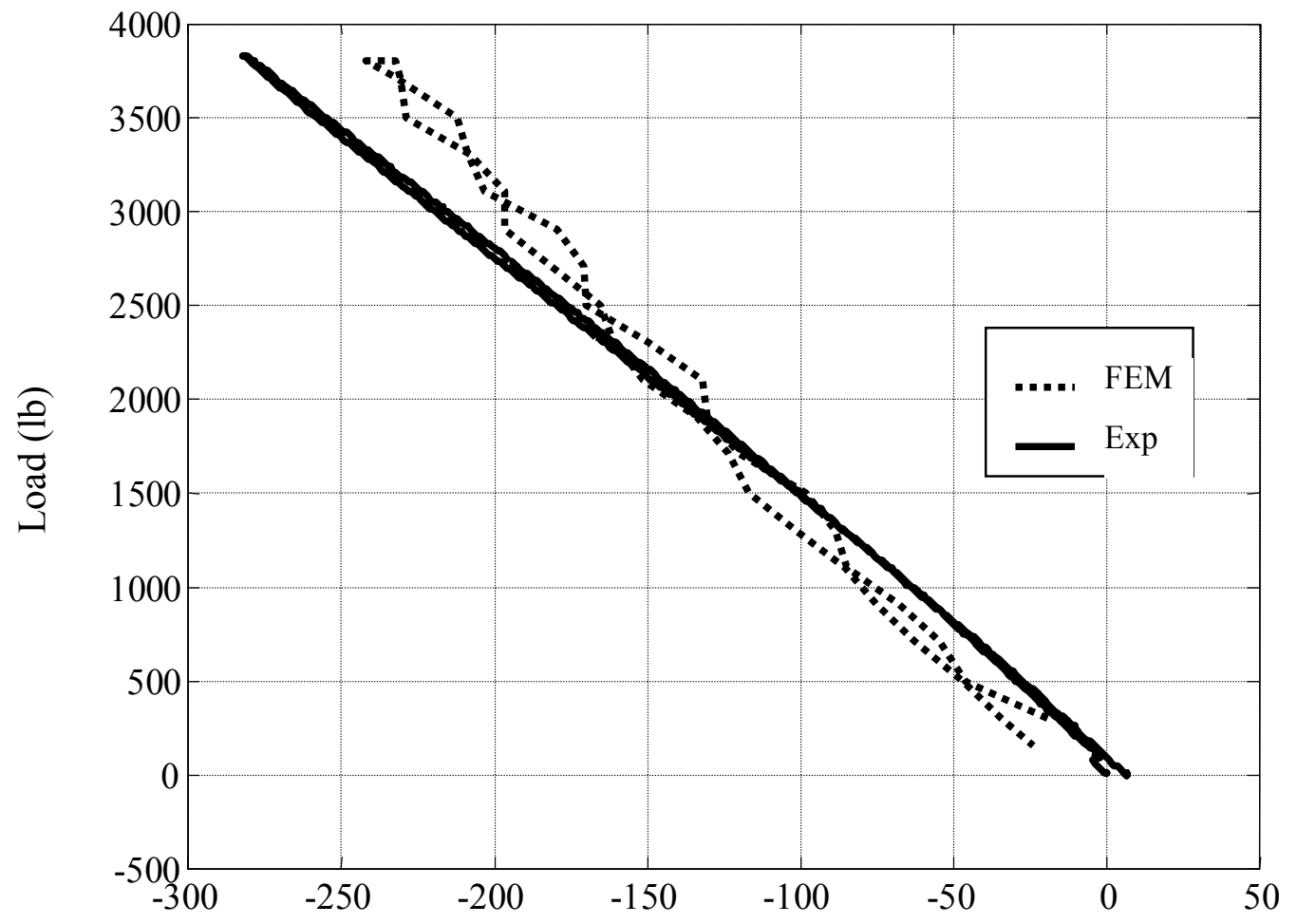

Microstrains

Figure 5.3 - Compressive strain at steel shokbar/concrete interface from experiment and finite element model 




Microstrains

Figure 5.4 - Tensile strain at regular dowel/concrete interface from experiment and finite element model 


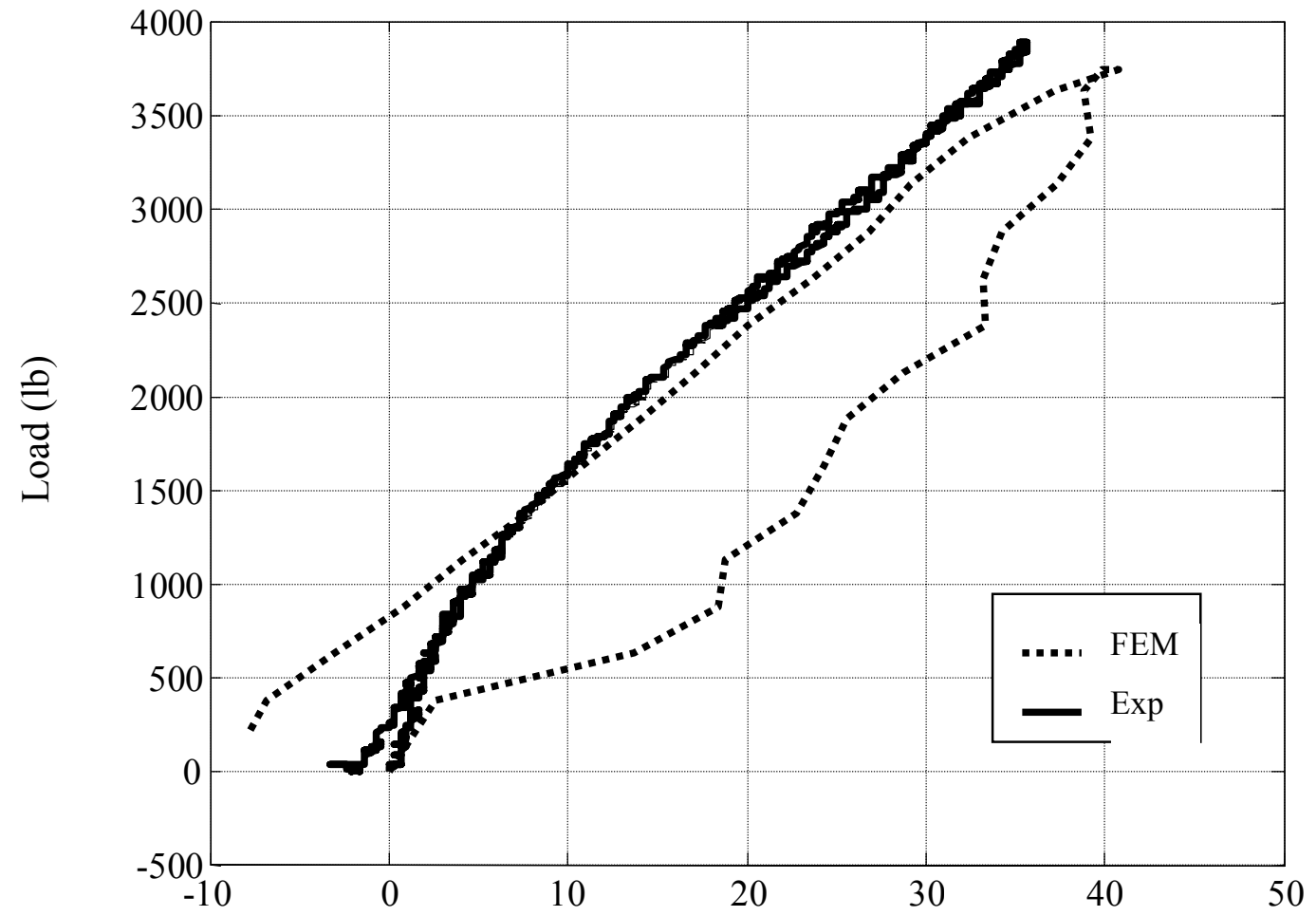

Microstrains

Figure 5.5 - Tensile strain at polymer shokbar/concrete interface from experiment and finite element model 


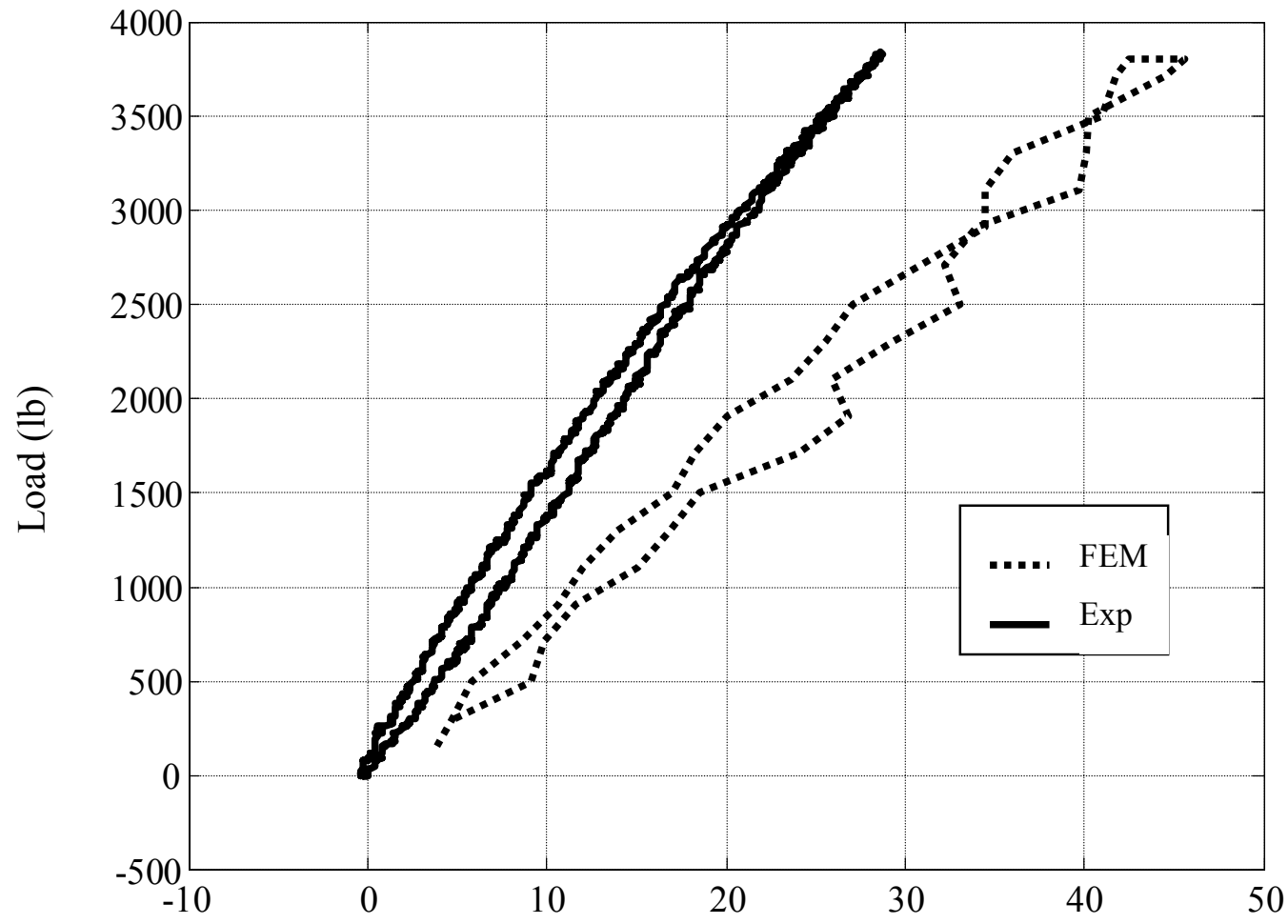

Microstrains

Figure 5.6 - Tensile strain at steel shokbar/concrete interface from experiment and finite element model 


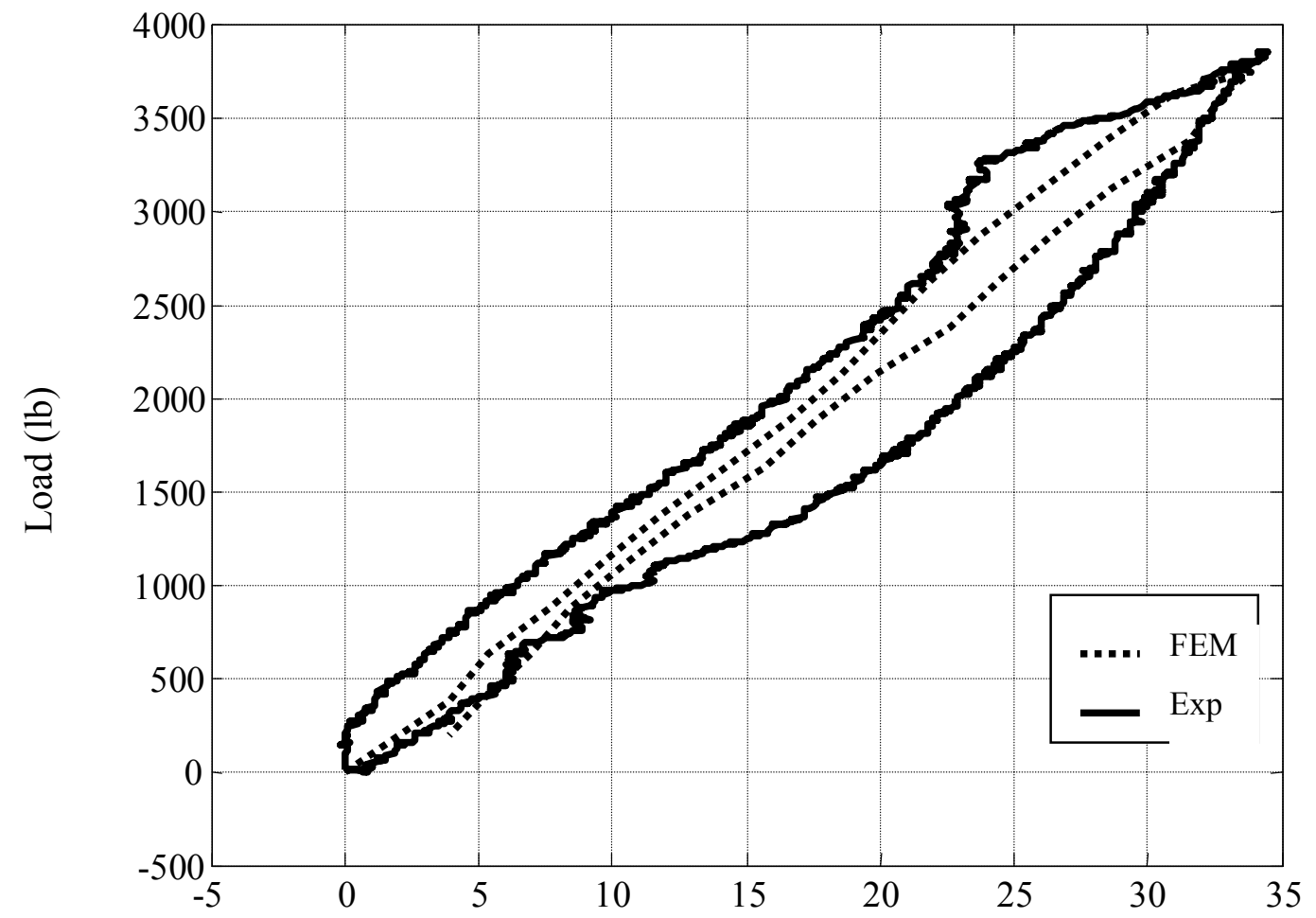

Microstrains

Figure 5.7 - Tensile strain at about 0.7-in from regular dowel/concrete interface from experiment and finite element model 


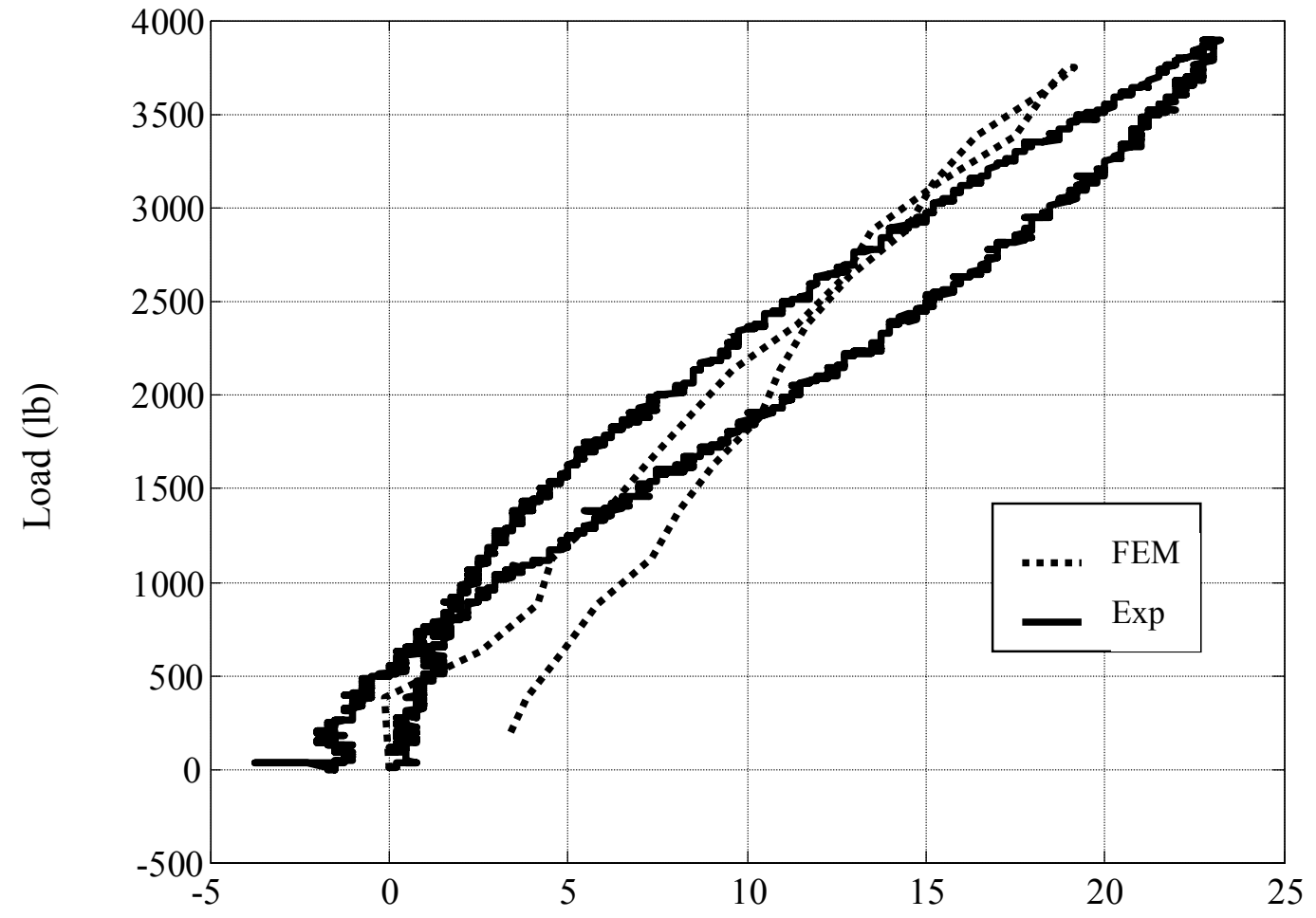

Microstrains

Figure 5.8 - Tensile strain at about 0.7-in from polymer shokbar/concrete interface from experiment and finite element model 


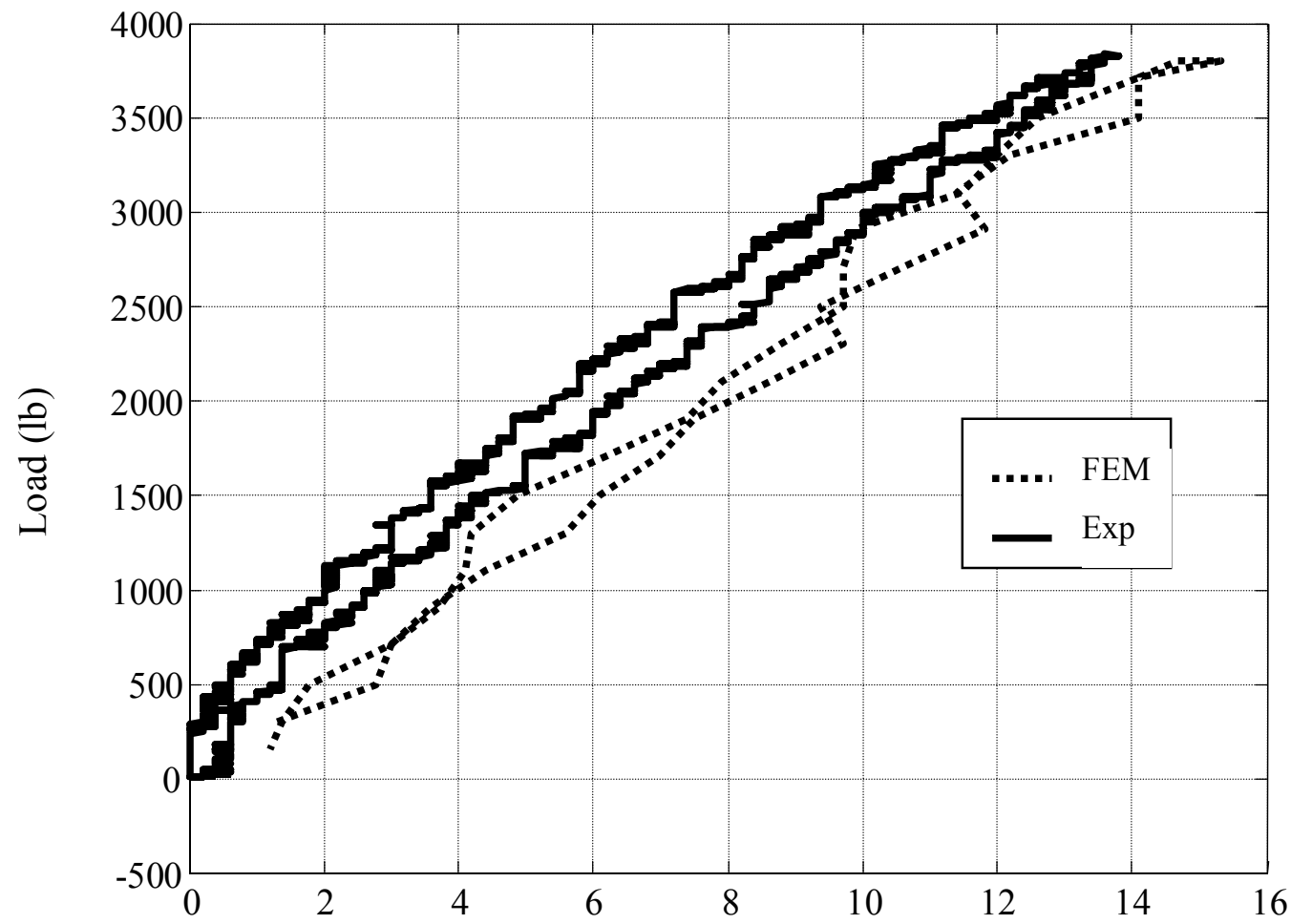

Microstrains

Figure 5.9 - Tensile Strain at about 0.7-in from steel shokbar/concrete interface from experiment and finite element model 


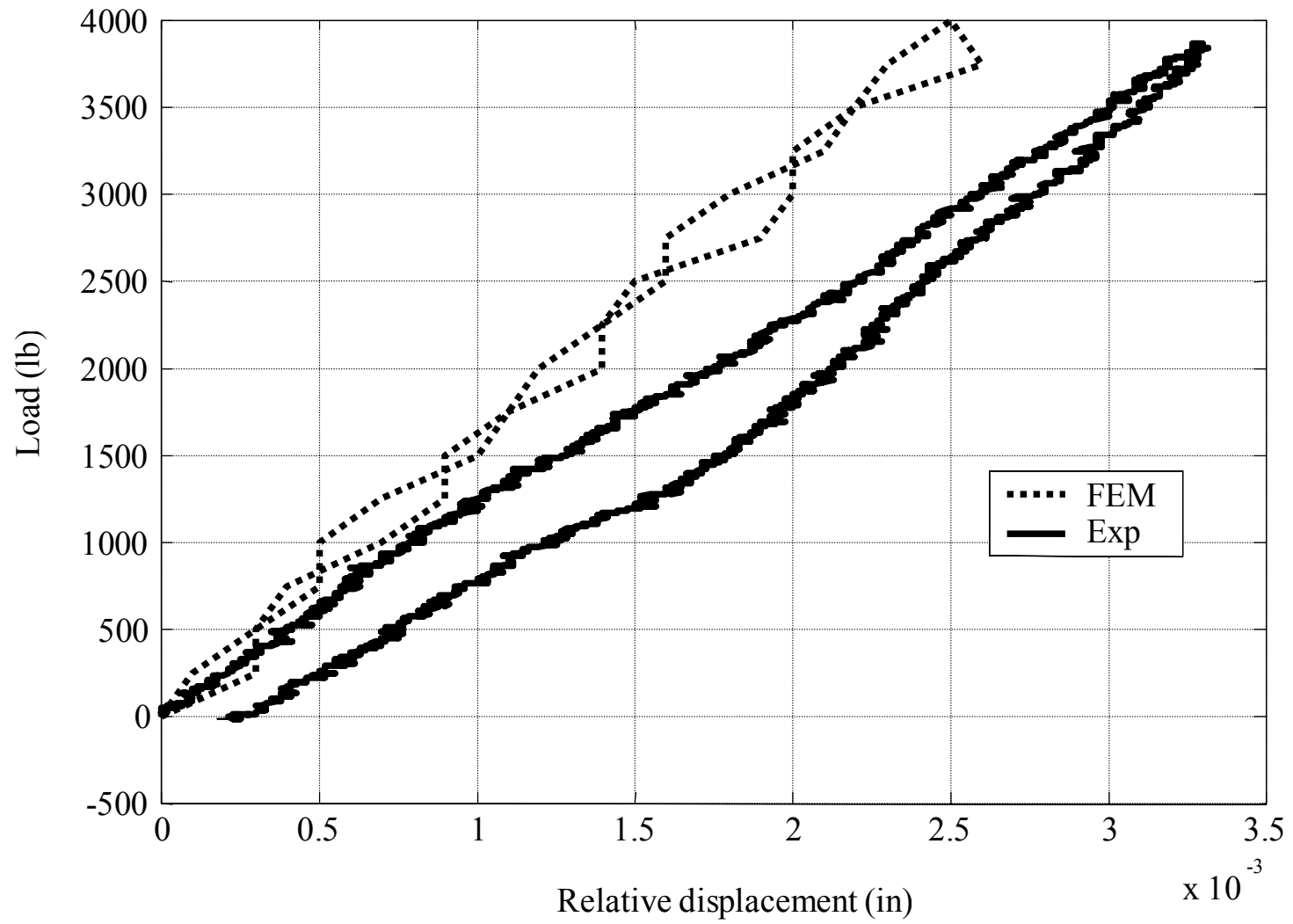

Figure 5.10 - Relative displacement at the joints of regular dowel specimen from experiment and finite element model 


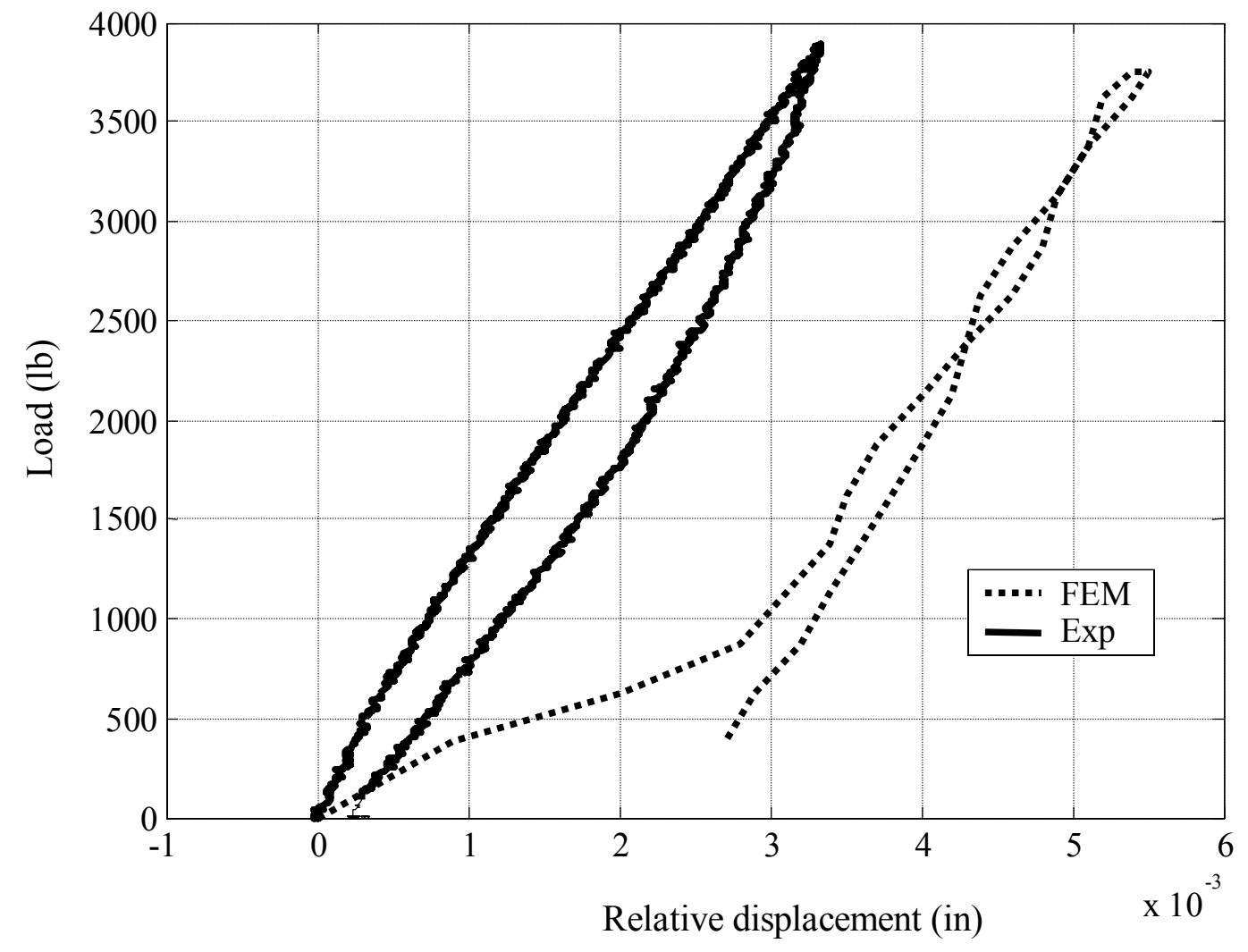

Figure 5.11 - Relative displacement at the joints of polymer shokbar specimen from experiment and finite element model 


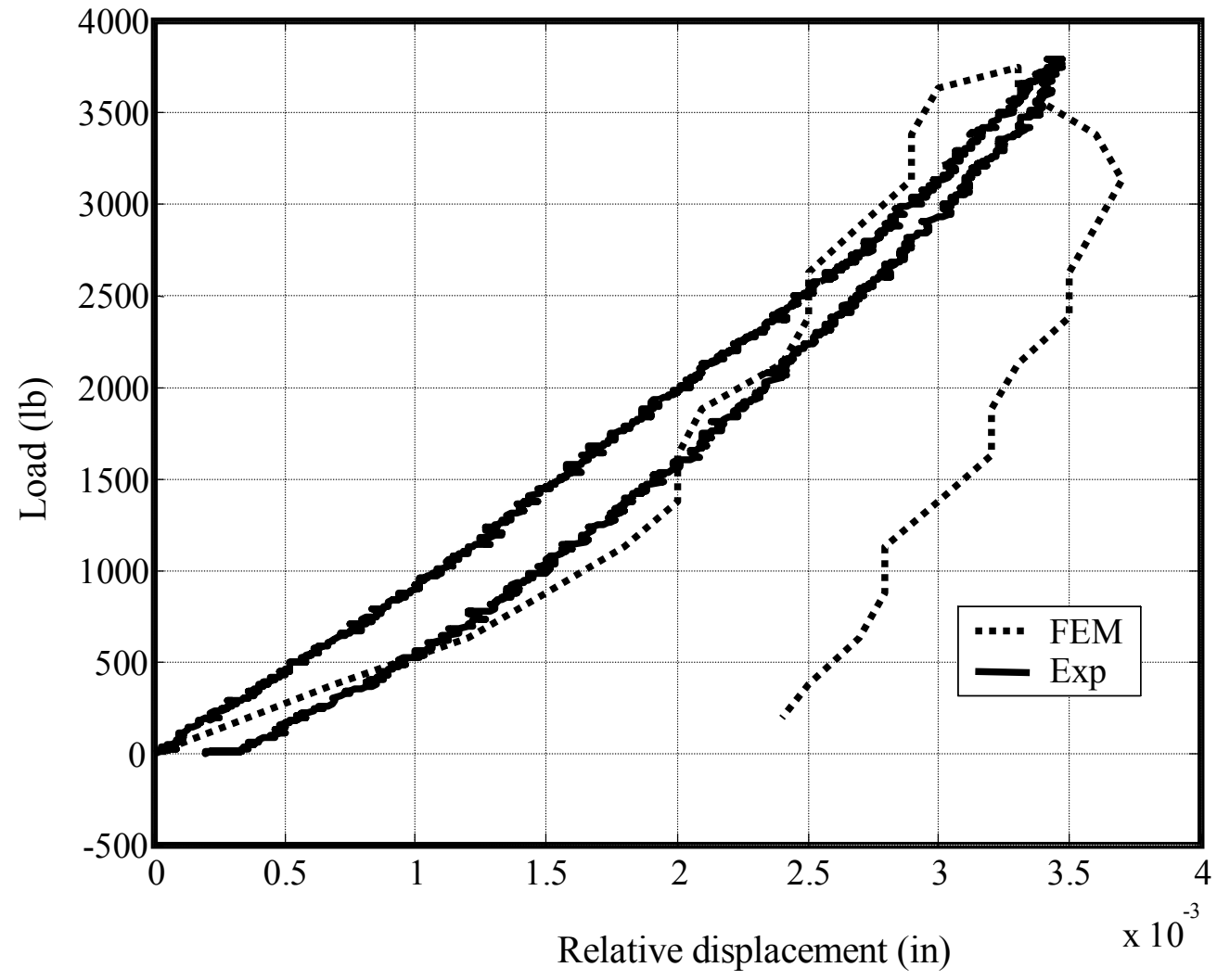

Figure 5.12 - Relative displacement at the joints of steel shokbar specimen from experiment and finite element model 


\section{CHAPTER SIX \\ CONCLUSIONS AND FUTURE RESEARCH NEEDS}

\subsection{CONCLUSIONS}

This study focused on studying the behavior of Shokbars (a new load transferring device across rigid pavement joints) versus traditional regular dowel subjected to static and fatigue loading. The nature and magnitude of stresses at bar/concrete interface, relative displacement at joints, and strains in bars were examined in both experimental and finite element models. The results from the experiments on simulated joints verified the finite element results. Based on the results from experimental study and finite element models, the following conclusions can be withdrawn.

1. The experimental and numerical results verified the existence of two types of stresses at the dowel-concrete interface, i.e., the development of compressive stresses at the top and bottom and tensile stresses at both sides of dowel/shokbar.

2. The tensile stresses are found to be at the level of the allowable tensile strength of the concrete at the sides of the dowel bar and responsible for the initiation of tensile crack at the sides.

3. The results from experiments and finite element model proved that the shokbar is capable of reducing the compressive and tensile stresses at dowel/concrete interface. Polymer shokbar and steel shokbar succeeded in reducing tensile and compressive strains at bar/concrete interface by at least 2 to 3 times compared to regular dowel bars.

4. The results from fatigue loading for 5 million cycles showed that compressive and tensile strains at Shokbar/concrete interface were observed to be steady with minimal changes, while tensile strains at dowel/concrete interface recorded an increase by almost double their initial values. Shokbars also maintained steady values of relative displacement across joints through all cycles of fatigue loading.

5. Calculated values of bearing stresses from recorded strain indicate that the largest values were found in the regular dowel specimens both under static and fatigue loading.

6. The finite element models developed produced results, which matched experimental values with those from the experimental setup. The 3D finite element modeling techniques proved to be reliable for studying the state and magnitude of stresses at bar/concrete interface within this study. 
7. The test rig built for the purpose of testing simulated doweled joint specimens proved reliable for monitoring joints characteristics.

\subsection{FUTURE RESEARCH NEEDS}

The current study identified the performance of dowelled concrete joints versus Shokbars subjected to fatigue load. The state and magnitude of stresses in the concrete around the dowel/shokbar, relative displacements at the joints and straining action of the dowel/shokbar were studied.

1. Shokbars need to be implemented in the field to study their effect on the performance of real concrete pavement joints.

2. More research is needed to study the characteristics of joints due to the application of combined fatigue and thermal loads.

3. During this study, it was found that no value of the coefficient of friction between the regular dowels and concrete is available in the literature. Identification of this parameter is needed.

4. More research is needed to identify the effect of concrete curing at early stages of pavement constructions on the joints characteristics. This study will give information about the stresses developed around the dowel/shokbars due to shrinkage of concrete as the variation of moisture content and temperature in the slab at early stages. 


\section{REFERENCES}

American Society of Civil Engineers, (1995), "Coating Protection for Reinforcement: State of the Art," Final Report, American Society of Civil Engineers, Thomas Telford Limited, London, England.

Ioannides, A.M., and Donnelly, J.P. (1988), Three-dimensional analysis of slab on stress dependent foundation. Transportation research record 1196, TRB, National research council, Washington, D.C., pp.72-84.

Analytical Modeling of Rock-Structure Interaction, (1973), Volumes 1-3. Reports AD761-648, 649,650, Advanced Research Projects Agency of U.S.Department of Defense and U.S.Bureau of Mines.

ASCE Report card on America's Infrastructures (2001).

The AASHTO road test-Pavement research (1962). Special report 61E, Highway Research Board.

Channakeshava, C., Barzegar, F., and Voyiadjis, G. (1993). Nonlinear finite element analysis of plain concrete pavement with doweled joints. Journal of transportation engineering, 199(5), pp 763-781.

Chatti, K., Lysmer, J., and Monismith, C.L. (1994), Dynamic finite element analysis of jointed concrete pavements. Transportation research record 1449, TRB, National research council, Washington, D.C., pp. 79-90.

Cioko, A.T., Nussbaum, P.J., and Colley, B.E. (1979), "Load Transfer of Dowel Bars and Star Lugs", Final report, Construction Technology Laboratories, Skokie, IL.

Eddie, D., (1999), “Fiber Reinforced Polymer Dowels for Concrete Pavements". Masters Thesis, University of Manitoba. 
Eddie, D., Shalaby, A., and Rizkalla, S. (2001). "Glass Fiber Reinforced Polymer Dowels for Concrete Pavements", ACI Structural Journal, Vol. 98, No. 2, pp. 201-206.

Friberg, B.F. (1938), "Load and Deflection Characteristics of Dowels in Transverse Joints of Concrete Pavements", Proceeding of the Highways Research Board 18 (National Research Council, Washington, DC), pp 140-154.

Hammons, M. (1997), "Development of an Analysis system for Discontinuities in Rigid Airfield Pavements," US Corps of Engineers, Waterways Experiment Station, Technical Report; GL-97-3.

Ioannides, A.M., Barenberg E.J., and Thompson M.R. (1984), Finite element model with stress dependent support. Transportation research record 954, pages 10-16, Washington D.C. TRB, National Research Council.

Neeraj, J. Buch. (1995). "Development of empirical-mechanistic based faulting models in the design of plain jointed concrete pavements," Ph.D. Thesis, Texas A\&M University.

Ozbeki, M.A., Kilareski, W.P., and Anderson, D.A. (1985). "Evaluation for jointed concrete pavements," Transportation Research Record 1043.

Porter, M.L., Barnes, B., Hughes, B., and Viswanath, K. (1993) "Non-Corrosive Tie Reinforcing and Dowel Bars for Highway Pavement Slabs". Final Report, HR-343 submitted to Highway Division of the Iowa Department of transportation and Iowa Highway Research Board. Iowa State University, Engineering Research Institute, Ames, IA.

Porter, M.L., and Braun, R.L. (1997), "Preliminary Assessment of the Potential Use of Alternative Materials for Concrete Highway Paving Joints," Iowa State University, Engineering Research Institute, Ames, IA. 
Riad, M.Y., (2001). "Stress Concentration around dowel bars in jointed rigid concrete pavements," M.S. thesis, West Virginia University, Morgantown.

Sargand, S.M., and Hazen, G.A. (1994), "Evaluation of Pavement Joint Performance". Final Report \# 14474(0) Submitted to Ohio Department of Transportation and Federal Highway Administration, Ohio University.

Sargand, S. (2000). "Performance of dowel bars and rigid pavement," Draft final report, Federal highway administration, Open house and Workshop, Ohio University, Athens, Ohio.

Shoukry, S.N., and William, G. (1998). 3D FEM Analysis of load transfer efficiency, Proceeding, First national symposium on 3D finite element modeling for pavement analysis and design, pp 40-50, Charleston, WV.

Shoukry, S.N., and William, G.W. (2001).“Identification of Critical Stress Concentration around Dowel Bars". Report No. MUTC\#7, West Virginia Department of Transportation.

Shoukry, S.N., William, G.W., and Riad, M. (2002), "Characteristics of Concrete Contact Stresses in Doweled Transverse Joints". International Journal of Pavement Engineering, Vol. 3 (2), pp. 117-129.

Snyder, M.B. (1989). "Dowel load transfer systems for full depth repairs of jointed Portland cement pavements," PhD thesis, University of Illinois, Urbana, Illinois.

Snyder, M.B., Embacher, R.A., and Odden, T.D. (2001), "Using the Minnesota Accelerated Loading Facility to Test Retrofit Dowel Load Transfer Systems". Transportation Research Record No. 1769, pp. 134-141

Tabatabaie, A.M and Barenbeg, E.J. (1980), Structural analysis of concrete pavements. Transportation Engineering Journal, ASCE, 106(TE5): 832-849. 
Tayabji, S.D., and Colley, B.E. (1986). Analysis of jointed concrete pavements. Technical report FHWS-RD-86-041, FHWA.

Uddin, W., Hackett, R.M., Joseph, A., Pan, Z., and Crowly, A.B. (1996). Threedimensional finite element analysis of plain concrete pavement having discontinuities. Transportation research record 1482, pp 26-32, Washington D.C.

Wang, S.K., Sargious, M., and Yau, K.C. (1972). Advanced analysis of rigid pavements.Transportation engineering journal, ASCE, 98(TEI): 37-44.

Westergaard, H.M. (1927). "Temperature variations and consequent product by daily and seasonal temperature cycles in concrete slabs," Concrete construction engineering, Vol 36, No. 6, pp 201-215.

William G., and Shoukry S.N., (2000), “3D Finite Element Analysis of Temperature Induced Stresses in Doweled Jointed Concrete Pavements", Proceedings of second International Symposium on 3D Finite Element Pavement Analysis and Design, Charleston, WV, pp 3-23.

Zaghloul, S.M., White T.D., and Kuczeck, T. (1994). Evaluation of heavy load damage effect on concrete on concrete using 3-dimensional, nonlinear dynamic analysis. Transportation research record 1449, Washington, D.C., pp. 123-133. 


\section{APPENDIX - I}

\section{CALIBRATION SHEETS OF LVDTS USED:}
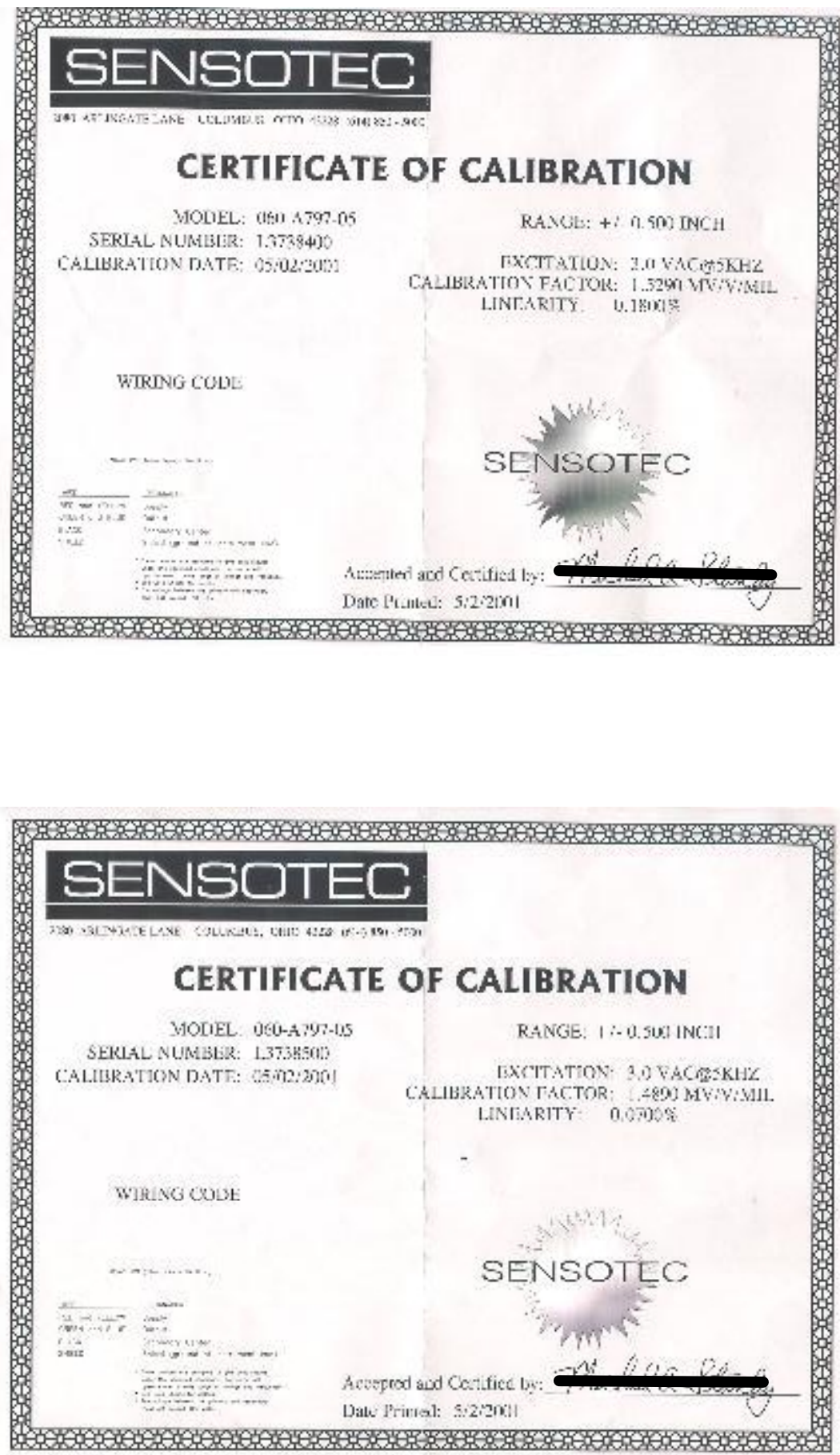


\section{APPENDIX - II}

Regular dowel bar

\begin{tabular}{|c|c|c|c|c|c|c|c|c|c|c|c|c|}
\hline specimen & joint \# & 0 & 500,000 & $1,000,000$ & $1,500,000$ & $2,000,000$ & $2,500,000$ & $3,000,000$ & $3,500,000$ & $4,000,000$ & $4,500,000$ & $5,000,000$ \\
\hline spec. 1 & $\begin{array}{l}1 \\
2\end{array}$ & $\begin{array}{l}-147.6 \\
-601.5 \\
\end{array}$ & $\begin{array}{c}-130 \\
-675.3333 \\
\end{array}$ & $\begin{array}{l}-129.1429 \\
-692.5714\end{array}$ & $\begin{array}{l}-126.5 \\
-704.5 \\
\end{array}$ & $\begin{array}{l}-124.5 \\
-698.3 \\
\end{array}$ & $\begin{array}{l}-122.5 \\
-577.2\end{array}$ & $\begin{array}{c}-124.6667 \\
-551.5\end{array}$ & $\begin{array}{c}-129.8571 \\
-559 \\
\end{array}$ & $\begin{array}{c}-128.3333 \\
-562 \\
\end{array}$ & $\begin{array}{c}-118.5 \\
-555.8333 \\
\end{array}$ & $\begin{array}{c}-131 \\
-548.6667 \\
\end{array}$ \\
\hline \multirow{2}{*}{ spec. 2} & 1 & -426.5 & -450 & -454 & -447 & -442.5 & -427.5 & -408.5 & -422 & -425 & -424 & -404.6 \\
\hline & 2 & -860.5 & -856.5 & -856.5 & -880.5 & -882.5 & -861.5 & -856 & -877 & -874.5 & -871 & -863 \\
\hline \multirow{2}{*}{ spec. 3} & 1 & -103.1667 & -113.5 & -122 & -125.3333 & -125.25 & -125.1667 & -125.6667 & -125.5 & -128.8333 & -126.3333 & -128.3333 \\
\hline & 2 & -384.6 & -386.8333 & -364.1667 & -366.3333 & -365.25 & -367.6667 & -368.5 & -354.5 & -362.1667 & -358.3333 & -360 \\
\hline \multicolumn{2}{|c|}{ Mean average } & -420.6444 & -435.3611 & -436.3968 & -441.6944 & -439.7167 & -413.5889 & -405.8056 & -411.3095 & -413.4722 & -409 & -405.9333 \\
\hline
\end{tabular}

Polymershokbar

\begin{tabular}{|c|c|c|c|c|c|c|c|c|c|c|c|c|}
\hline specimen & cycles & 0 & 500,000 & $1,000,000$ & $1,500,000$ & $2,000,000$ & $2,500,000$ & $3,000,000$ & $3,500,000$ & $4,000,000$ & $4,500,000$ & $5,000,000$ \\
\hline spec 1 & $\begin{array}{l}j 1 \\
j 2\end{array}$ & \begin{tabular}{|c|}
-113.5 \\
-376.6667 \\
\end{tabular} & $\begin{array}{l}-147.3333 \\
-376.6667 \\
\end{array}$ & $\begin{array}{l}-158.17 \\
-316.92 \\
\end{array}$ & $\begin{array}{l}-178.08 \\
-303.92 \\
\end{array}$ & $\begin{array}{l}-177.75 \\
-296.92 \\
\end{array}$ & $\begin{array}{l}-168.3333 \\
-298.3333 \\
\end{array}$ & $\begin{array}{l}-166.8333 \\
-302.6667 \\
\end{array}$ & $\begin{array}{l}-157.92 \\
-296.25\end{array}$ & $\begin{array}{c}-153.46 \\
-293.042\end{array}$ & $\begin{array}{c}-149 \\
-289.8333\end{array}$ & $\begin{array}{c}-155.3333 \\
-292.5\end{array}$ \\
\hline spec 2 & $\begin{array}{l}j 1 \\
j 2\end{array}$ & \begin{tabular}{|c|}
$\mid-210$ \\
-376.6667
\end{tabular} & \begin{tabular}{|l|}
-105.3333 \\
-253.1667 \\
\end{tabular} & $\begin{array}{l}-129.8333 \\
-248.3333 \\
\end{array}$ & $\begin{array}{c}-119 \\
-250.6667\end{array}$ & $\begin{array}{c}-112 \\
-239.1667 \\
\end{array}$ & $\begin{array}{l}-165.75 \\
-237.17 \\
\end{array}$ & \begin{tabular}{|c|}
-219.5 \\
-235.1667
\end{tabular} & \begin{tabular}{|l|}
-145.8333 \\
-239.1667 \\
\end{tabular} & $\begin{array}{l}-146.12 \\
-233.78\end{array}$ & $\begin{array}{l}-146.5 \\
-228.4\end{array}$ & $\begin{array}{c}-147.1667 \\
-221\end{array}$ \\
\hline spec 3 & $\begin{array}{l}j 1 \\
j 2\end{array}$ & $\begin{array}{c}-511 \\
-246.5\end{array}$ & $\begin{array}{c}-570.5 \\
-158\end{array}$ & $\begin{array}{c}-531 \\
-150.5\end{array}$ & $\begin{array}{r}-534.5 \\
-143.25\end{array}$ & $\begin{array}{l}-538 \\
-136\end{array}$ & $\begin{array}{c}-506.5 \\
-134\end{array}$ & $\begin{array}{c}-506.5 \\
-134\end{array}$ & $\begin{array}{c}-494.5 \\
-136\end{array}$ & $\begin{array}{c}-507 \\
-136.5\end{array}$ & $\begin{array}{l}-500 \\
-134\end{array}$ & $\begin{array}{l}-492 \\
-137\end{array}$ \\
\hline Mean a & verage & -305.7222 & -268.5 & -255.7928 & -254.9028 & -249.9728 & -251.6811 & -260.7778 & -244.945 & -244.9837 & -241.2889 & -240.8333 \\
\hline
\end{tabular}

Steel shokbar

\begin{tabular}{|c|c|c|c|c|c|c|c|c|c|c|c|c|}
\hline specimen & joint \# & 0 & 500,000 & $1,000,000$ & $1,500,000$ & $2,000,000$ & $2,500,000$ & $3,000,000$ & $3,500,000$ & $4,000,000$ & $4,500,000$ & $5,000,000$ \\
\hline spec 1 & $\begin{array}{l}1 \\
\mathrm{j} 2\end{array}$ & $\begin{array}{c}-136.166 \\
-727.5 \\
\end{array}$ & $\begin{array}{l}67 \\
33 \\
\end{array}$ & $\begin{array}{r}-123 \\
-42 \\
\end{array}$ & $\begin{array}{l}-12 \\
-38 \\
\end{array}$ & & $\begin{array}{c}-140.8333 \\
-343.5 \\
\end{array}$ & $\begin{array}{c}-142 \\
-333.3333 \\
\end{array}$ & $\begin{array}{l}667 \\
.5 \\
\end{array}$ & $\begin{array}{l}22 \\
33 \\
\end{array}$ & 926 & $\begin{array}{c}-124.3333 \\
-280 \\
\end{array}$ \\
\hline c 2 & $\begin{array}{l}j 1 \\
j 2\end{array}$ & \begin{tabular}{|c|}
-107 \\
-269.1667 \\
\end{tabular} & $\begin{array}{l}-113.1667 \\
-243.1667 \\
\end{array}$ & $\begin{array}{c}-116.1667 \\
-232.5 \\
\end{array}$ & \begin{tabular}{|l|}
-115.8333 \\
-232.3333 \\
\end{tabular} & \begin{tabular}{|l|}
-114.8333 \\
-234.8333 \\
\end{tabular} & $\begin{array}{c}-114 \\
-232.5 \\
\end{array}$ & $\begin{array}{c}-121 \\
-248.8 \\
\end{array}$ & \begin{tabular}{|c|}
-117.6667 \\
-234.2 \\
\end{tabular} & \begin{tabular}{|l|}
-120.8333 \\
-237.3333 \\
\end{tabular} & \begin{tabular}{|c|}
-118.5 \\
-235.6667 \\
\end{tabular} & $\begin{array}{l}-117.8333 \\
-238.8333 \\
\end{array}$ \\
\hline spec 3 & $\begin{array}{l}\mathrm{j} 1 \\
\mathrm{j} 2\end{array}$ & \begin{tabular}{|c|}
-139.5 \\
-345.1667 \\
\end{tabular} & $\begin{array}{l}-139.5 \\
-351.5 \\
\end{array}$ & \begin{tabular}{|c|}
-132.8333 \\
-325 \\
\end{tabular} & $\begin{array}{l}-15 \\
-3 \\
\end{array}$ & \begin{tabular}{|l|}
-12 \\
-31 \\
\end{tabular} & $\begin{array}{r}-13 \\
-3 \\
\end{array}$ & $\begin{array}{c}-142 \\
-312.1667 \\
\end{array}$ & $\begin{array}{r}-133 \\
-333 . \\
\end{array}$ & $\begin{array}{r}-1 \\
-354 \\
\end{array}$ & $\begin{array}{l}833 \\
25 \\
\end{array}$ & $\begin{array}{l}-127 \\
-316 \\
\end{array}$ \\
\hline rean & age & -287.4167 & 250.1389 & -226.1389 & -217.7355 & -213.1528 & -212.7777 & -216.55 & -210.1583 & -211.2315 & -206.1914 & -200.8333 \\
\hline
\end{tabular}

\section{Compressive Strains at bar/concrete interface (Bottom zone of stationary end sections)}




\begin{tabular}{|c|c|c|c|c|c|c|c|c|c|c|c|c|}
\hline specimen & joint \# & 0 & 500,000 & $1,000,000$ & $1,500,000$ & $2,000,000$ & $2,500,000$ & $3,000,000$ & $3,500,000$ & $4,000,000$ & $4,500,000$ & $5,000,000$ \\
\hline spec 1 & $\begin{array}{l}j 1 \\
j 2\end{array}$ & $\begin{array}{c}213.6667 \\
141\end{array}$ & $\begin{array}{l}192.1667 \\
205.6667\end{array}$ & $\begin{array}{l}193.7143 \\
212.8571\end{array}$ & $\begin{array}{l}192.6667 \\
211.3333\end{array}$ & $\begin{array}{l}206.3333 \\
304.9667\end{array}$ & $\begin{array}{c}220 \\
398.6\end{array}$ & $\begin{array}{l}224.2857 \\
457.6571\end{array}$ & $\begin{array}{l}228.5714 \\
516.7143\end{array}$ & $\begin{array}{c}231.5 \\
561\end{array}$ & $\begin{array}{l}230.3333 \\
572.1667\end{array}$ & $\begin{array}{c}228 \\
587.8333\end{array}$ \\
\hline cnen? & j1 & - & - & - & - & - & - & - & - & - & - & - \\
\hline spete & $\mathrm{j} 2$ & 114 & 106.5 & 102.5 & 85 & 88.5 & 74 & 92.25 & 110.5 & 121 & 120 & 117.8 \\
\hline spec 3 & $\begin{array}{l}j 1 \\
\text { j2 }\end{array}$ & $\begin{array}{c}150 \\
-\end{array}$ & $\begin{array}{c}146.833 \\
-\end{array}$ & $\begin{array}{c}142.833 \\
-\end{array}$ & $\begin{array}{c}155 \\
-\end{array}$ & $\begin{array}{c}153.67 \\
-\end{array}$ & $\begin{array}{c}151.4185 \\
-\end{array}$ & $\begin{array}{c}149.167 \\
-\end{array}$ & $\begin{array}{c}143.167 \\
-\end{array}$ & $\begin{array}{c}150.667 \\
-\end{array}$ & $\begin{array}{c}144.833 \\
-\end{array}$ & $\begin{array}{c}151.5 \\
-\end{array}$ \\
\hline \multicolumn{2}{|c|}{ Mean average } & 154.6667 & 162.7916 & 162.9761 & 161 & 188.3675 & 211.0046 & 230.84 & 249.7382 & 266.0418 & 266.8333 & 271.2833 \\
\hline
\end{tabular}

Polymer shokbar

\begin{tabular}{|c|c|c|c|c|c|c|c|c|c|c|c|c|}
\hline specimen & joint \# & 0 & 500,000 & $1,000,000$ & $1,500,000$ & $2,000,000$ & $2,500,000$ & $3,000,000$ & $3,500,000$ & $4,000,000$ & $4,500,000$ & $5,000,000$ \\
\hline spec 1 & $\begin{array}{l}j 1 \\
j 2\end{array}$ & $\begin{array}{c}- \\
39.83333\end{array}$ & $\begin{array}{c}- \\
34.16667\end{array}$ & $\begin{array}{c}- \\
32.667\end{array}$ & $\begin{array}{c}- \\
39.417\end{array}$ & $\begin{array}{c}- \\
48.333\end{array}$ & $\begin{array}{c}- \\
49\end{array}$ & $\begin{array}{c}- \\
50.17\end{array}$ & $\begin{array}{c}- \\
47.9185\end{array}$ & $\begin{array}{c}- \\
45.667\end{array}$ & $\begin{array}{c}-\overline{-} \\
45.3335\end{array}$ & $\begin{array}{c}- \\
45\end{array}$ \\
\hline spec 2 & $\begin{array}{l}\mathrm{j} 1 \\
\mathrm{j} 2\end{array}$ & $\begin{array}{c}24.83333 \\
-\end{array}$ & $\begin{array}{c}6.666667 \\
-\end{array}$ & $\begin{array}{c}8.833333 \\
-\end{array}$ & $\begin{array}{c}10.16667 \\
-\end{array}$ & $\begin{array}{c}9.5 \\
-\end{array}$ & $\begin{array}{c}14.08333 \\
-\end{array}$ & $\begin{array}{c}18.66667 \\
-\end{array}$ & $\begin{array}{c}16.5 \\
-\end{array}$ & $\begin{array}{c}17.16667 \\
-\end{array}$ & $\begin{array}{c}17.83333 \\
-\end{array}$ & $\begin{array}{c}18.83333 \\
-\end{array}$ \\
\hline spec 3 & $\begin{array}{l}\mathrm{j} 1 \\
\mathrm{j} 2\end{array}$ & $\begin{array}{c}- \\
43.5\end{array}$ & $\begin{array}{c}- \\
37.5\end{array}$ & $\begin{array}{c}- \\
35.5\end{array}$ & $\begin{array}{c}- \\
33.5\end{array}$ & $\begin{array}{c}- \\
31.5\end{array}$ & $\begin{array}{c}- \\
32\end{array}$ & $\begin{array}{c}- \\
32.5\end{array}$ & $\begin{array}{c}- \\
34\end{array}$ & $\begin{array}{c}- \\
33\end{array}$ & $\begin{array}{c}- \\
33.5\end{array}$ & $\begin{array}{c}- \\
34.25\end{array}$ \\
\hline \multicolumn{2}{|c|}{ Mean average } & 36.05556 & 26.11111 & 25.66678 & 27.69456 & 29.77767 & 31.69444 & 33.77889 & 32.80617 & 31.94456 & 32.22228 & 32.69444 \\
\hline
\end{tabular}

Steel shokbar

\begin{tabular}{|c|c|c|c|c|c|c|c|c|c|c|c|c|}
\hline specimen & $\begin{array}{c}\text { cycles } \\
\text { joint \# }\end{array}$ & 0 & 500,000 & $1,000,000$ & $1,500,000$ & $2,000,000$ & $2,500,000$ & $3,000,000$ & $3,500,000$ & $4,000,000$ & $4,500,000$ & $5,000,000$ \\
\hline \multirow{2}{*}{ spec 1 } & $\mathrm{j} 1$ & 35.33333 & 33.66667 & 33.16667 & 33 & 33.5 & 36.16667 & 36.83333 & 34.33333 & 33.5 & 32.66667 & 31.83333 \\
& $\mathrm{j} 2$ & 32.83333 & 29 & 22.66667 & 19.83333 & 19.33333 & 19.83333 & 18.83333 & 17.5 & 16.66667 & 15.83333 & 15 \\
\hline \multirow{2}{*}{ spec 2 } & $\mathrm{j} 1$ & - & - & - & - & - & - & - & - & - & - & - \\
& $\mathrm{j} 2$ & 23.5 & 20.66667 & 22.83333 & 19.33333 & 19.33333 & 20.16667 & 25 & 28.16667 & 20 & 17 & 18.5 \\
\hline \multirow{2}{*}{ spec 3 } & $\mathrm{j} 1$ & 39 & 38.25 & 37.25 & 37.79 & 37.45 & 37.667 & 37.00022 & 36.33344 & 35.66667 & 35.91667 & 36.16667 \\
& $\mathrm{j} 2$ & 14.8 & 12.2 & 12.167 & 11.875 & 12.125 & 13.45 & 13.02 & 12.59 & 12.16 & 12.16333 & 12.16667 \\
\hline \multicolumn{2}{|l|}{ Mean average } & 27.53333 & 25.02917 & 23.72925 & 24.36633 & 24.34833 & 25.45673 & 26.13738 & 25.78469 & 23.59867 & 22.716 & 22.73333 \\
\hline
\end{tabular}

Tensile stains at bar/concrete interface (tension 1) 
Regular dowel

\begin{tabular}{|c|c|c|c|c|c|c|c|c|c|c|c|c|}
\hline specimen & joint \# & 0 & 500,000 & $1,000,000$ & $1,500,000$ & $2,000,000$ & $2,500,000$ & $3,000,000$ & $3,500,000$ & $4,000,000$ & $4,500,000$ & $5,000,000$ \\
\hline spec 1 & $\begin{array}{l}j 1 \\
j 2\end{array}$ & $\begin{array}{c}32.4 \\
- \\
\end{array}$ & $\begin{array}{c}30.66667 \\
-\quad \\
\end{array}$ & $\begin{array}{c}29.09 \\
- \\
\end{array}$ & $\begin{array}{c}28.6 \\
- \\
\end{array}$ & $\begin{array}{c}30.6 \\
- \\
\end{array}$ & $\begin{array}{c}32.66667 \\
- \\
\end{array}$ & $\begin{array}{c}34 \\
- \\
\end{array}$ & $\begin{array}{c}34 \\
- \\
\end{array}$ & $\begin{array}{c}34 \\
- \\
\end{array}$ & $\begin{array}{c}35.16667 \\
- \\
\end{array}$ & $\begin{array}{c}35 \\
- \\
\end{array}$ \\
\hline spec 2 & $\begin{array}{l}\mathrm{j} 1 \\
\mathrm{j} 2\end{array}$ & $\begin{array}{c}14.25 \\
37 \\
\end{array}$ & $\begin{array}{l}12 \\
37 \\
\end{array}$ & $\begin{array}{l}11 \\
17 \\
\end{array}$ & $\begin{array}{l}12 \\
16 \\
\end{array}$ & $\begin{array}{l}10.5 \\
18.5 \\
\end{array}$ & $\begin{array}{c}11 \\
24.5 \\
\end{array}$ & $\begin{array}{l}11 \\
15 \\
\end{array}$ & $\begin{array}{l}11 \\
18 \\
\end{array}$ & $\begin{array}{l}11 \\
23 \\
\end{array}$ & $\begin{array}{c}9 \\
17.66667 \\
\end{array}$ & $\begin{array}{c}10 \\
17.8 \\
\end{array}$ \\
\hline spec 3 & $\begin{array}{l}\text { j1 } \\
\text { j2 }\end{array}$ & $\begin{array}{l}32.6 \\
60.5\end{array}$ & $\begin{array}{c}24.16667 \\
69.2\end{array}$ & $\begin{array}{c}18.2 \\
63.16667\end{array}$ & $\begin{array}{l}19.6 \\
59.6\end{array}$ & $\begin{array}{l}23.25 \\
55.75\end{array}$ & $\begin{array}{c}23 \\
55.83\end{array}$ & $\begin{array}{c}20.5 \\
56\end{array}$ & $\begin{array}{l}20.33333 \\
55.16667\end{array}$ & $\begin{array}{c}19.5 \\
55.66667\end{array}$ & $\begin{array}{l}21.16667 \\
59.16667\end{array}$ & $\begin{array}{c}21 \\
56.5\end{array}$ \\
\hline Mean a & verage & 35.35 & 34.60667 & 27.69133 & 27.16 & 27.72 & 29.39933 & 27.3 & 27.7 & 28.63333 & 28.43333 & 28.06 \\
\hline
\end{tabular}

Polymer shokbar

\begin{tabular}{|c|c|c|c|c|c|c|c|c|c|c|c|c|}
\hline specimen & joint \# & 0 & 500,000 & $1,000,000$ & $1,500,000$ & $2,000,000$ & $2,500,000$ & $3,000,000$ & $3,500,000$ & $4,000,000$ & $4,500,000$ & $5,000,000$ \\
\hline spec 1 & $\begin{array}{l}j 1 \\
j 2\end{array}$ & $\begin{array}{c}- \\
25.66667\end{array}$ & $\begin{array}{c}- \\
26.5\end{array}$ & $\begin{array}{c}- \\
18.08\end{array}$ & $\begin{array}{c}- \\
16.83\end{array}$ & $\begin{array}{c}- \\
23.58\end{array}$ & $\begin{array}{c}- \\
23.16667\end{array}$ & $\begin{array}{c}- \\
24.17\end{array}$ & $\begin{array}{c}- \\
22.94667\end{array}$ & $\begin{array}{c}- \\
21.72333\end{array}$ & $\begin{array}{c}- \\
20.5\end{array}$ & $\begin{array}{c}- \\
22.33\end{array}$ \\
\hline spec 2 & $\begin{array}{l}\mathrm{j} 1 \\
\mathrm{j} 2\end{array}$ & $\begin{array}{l}14.83333 \\
44.83333 \\
\end{array}$ & $\begin{array}{l}2.5 \\
51 \\
\end{array}$ & \begin{tabular}{|l|}
3.833333 \\
48.66667 \\
\end{tabular} & $\begin{array}{c}5 \\
47 \\
\end{array}$ & $\begin{array}{c}5 \\
47.75 \\
\end{array}$ & $\begin{array}{r}8.67 \\
49.08 \\
\end{array}$ & \begin{tabular}{|l|}
12.33333 \\
49.66667 \\
\end{tabular} & \begin{tabular}{|l|}
9.666667 \\
48.83333 \\
\end{tabular} & \begin{tabular}{|l|}
9.916667 \\
49.91667 \\
\end{tabular} & \begin{tabular}{|c|}
10.16667 \\
51 \\
\end{tabular} & \begin{tabular}{|l|}
10.83333 \\
51.16667 \\
\end{tabular} \\
\hline spec 3 & $\begin{array}{l}\text { j1 } \\
\text { j2 }\end{array}$ & $\begin{array}{c}11.5 \\
-\end{array}$ & $\begin{array}{c}18 \\
-\end{array}$ & $\begin{array}{c}19.5 \\
-\end{array}$ & $\begin{array}{c}15.5 \\
-\end{array}$ & $\begin{array}{c}11.5 \\
-\end{array}$ & $\begin{array}{c}10.75 \\
-\end{array}$ & $\begin{array}{c}10 \\
-\end{array}$ & $\begin{array}{c}14 \\
-\end{array}$ & $\begin{array}{c}7.5 \\
-\end{array}$ & $\begin{array}{c}10.5 \\
-\end{array}$ & $\begin{array}{c}11 \\
-\end{array}$ \\
\hline Mean a & verage & 24.20833 & 24.5 & 22.52 & 21.0825 & 21.9575 & 22.91667 & 24.0425 & 23.86167 & 22.26417 & 23.04167 & 23.8325 \\
\hline
\end{tabular}

Steel shokbar

\begin{tabular}{|c|c|c|c|c|c|c|c|c|c|c|c|c|}
\hline specimen & joint \# & 0 & 500,000 & $1,000,000$ & $1,500,000$ & $2,000,000$ & $2,500,000$ & $3,000,000$ & $3,500,000$ & $4,000,000$ & $4,500,000$ & $5,000,000$ \\
\hline spec 1 & $\begin{array}{l}j 1 \\
j 2\end{array}$ & $\begin{array}{c}15.16667 \\
12.5\end{array}$ & $\begin{array}{l}14 \\
10\end{array}$ & $\begin{array}{l}22.66667 \\
7.666667\end{array}$ & $\begin{array}{c}13.66667 \\
6.5\end{array}$ & $\begin{array}{l}14.7 \\
6.08\end{array}$ & $\begin{array}{c}15.08 \\
6\end{array}$ & $\begin{array}{c}15.33333 \\
6\end{array}$ & $\begin{array}{c}14.5 \\
5.833333\end{array}$ & $\begin{array}{l}14.11111 \\
4.944444\end{array}$ & $\begin{array}{l}13.85185 \\
4.351852\end{array}$ & \begin{tabular}{|l|}
13.33333 \\
3.166667
\end{tabular} \\
\hline spec 2 & $\begin{array}{l}\mathrm{j} 1 \\
\mathrm{j} 2\end{array}$ & $\begin{array}{c}18.5 \\
-\end{array}$ & $\begin{array}{c}16.33333 \\
-\end{array}$ & $\begin{array}{c}18.33333 \\
-\end{array}$ & $\begin{array}{c}18.66667 \\
-\end{array}$ & $\begin{array}{c}18.16667 \\
-\end{array}$ & $\begin{array}{c}18.16667 \\
-\end{array}$ & $\begin{array}{c}19.16667 \\
-\end{array}$ & $\begin{array}{c}20 \\
-\end{array}$ & $\begin{array}{c}20 \\
-\end{array}$ & $\begin{array}{c}19.83333 \\
-\end{array}$ & $\begin{array}{c}20.16667 \\
-\end{array}$ \\
\hline spec 3 & $\begin{array}{l}\mathrm{j} 1 \\
\mathrm{j} 2\end{array}$ & $\begin{array}{c}12 \\
14.33333\end{array}$ & \begin{tabular}{|l|}
13.83333 \\
12.16667 \\
\end{tabular} & $\begin{array}{c}11.41 \\
11.9\end{array}$ & $\begin{array}{l}11.45 \\
11.79\end{array}$ & $\begin{array}{c}11.54 \\
11.875\end{array}$ & $\begin{array}{c}11.67 \\
11.917\end{array}$ & \begin{tabular}{|c|}
12 \\
11.83333 \\
\end{tabular} & \begin{tabular}{|c|}
11.33333 \\
11.75 \\
\end{tabular} & \begin{tabular}{|l|}
10.66667 \\
11.66667 \\
\end{tabular} & \begin{tabular}{|l|}
10.83333 \\
11.66667 \\
\end{tabular} & \begin{tabular}{|c|}
11 \\
11.66667
\end{tabular} \\
\hline \multicolumn{2}{|c|}{ Mean average } & 14.5 & 13.26667 & 14.39533 & 12.41467 & 12.47233 & 12.56673 & \begin{tabular}{|l|}
12.86667 \\
\end{tabular} & \begin{tabular}{|l|}
12.68333 \\
\end{tabular} & \begin{tabular}{|l|}
12.27778 \\
\end{tabular} & \begin{tabular}{|l|}
12.10741 \\
\end{tabular} & 11.86667 \\
\hline
\end{tabular}

Tensile Strains about 0.7 inches from bar/concrete interface (tension 2) 


\section{APPENDIX-III}

Regular dowel bar

\begin{tabular}{|c|c|c|c|c|c|c|c|c|c|c|c|c|}
\hline specimen & cycles & 0 & 500,000 & $1,000,000$ & $1,500,000$ & $2,000,000$ & $2,500,000$ & $3,000,000$ & $3,500,000$ & $4,000,000$ & $4,500,000$ & $5,000,000$ \\
\hline spec. 1 & $\begin{array}{l}1 \\
2\end{array}$ & $\begin{array}{c}0.006067 \\
0.0033\end{array}$ & $\begin{array}{c}0.00636 \\
0.0046\end{array}$ & $\begin{array}{c}0.005816 \\
0.0038\end{array}$ & $\begin{array}{c}0.004835 \\
0.0033\end{array}$ & $\begin{array}{c}0.005198 \\
0.0035\end{array}$ & $\begin{array}{c}0.004598 \\
0.0031\end{array}$ & $\begin{array}{c}0.005148 \\
0.0029\end{array}$ & $\begin{array}{c}0.005 \\
0.0027\end{array}$ & $\begin{array}{c}0.005243 \\
0.0029\end{array}$ & $\begin{array}{c}0.005219 \\
0.0029\end{array}$ & $\begin{array}{c}0.003893 \\
0.0037\end{array}$ \\
\hline spec. 2 & $\begin{array}{l}1 \\
2\end{array}$ & $\begin{array}{c}0.005 \\
0.0032\end{array}$ & $\begin{array}{c}0.006 \\
0.0031\end{array}$ & $\begin{array}{l}0.0057 \\
0.0036\end{array}$ & $\begin{array}{l}0.0035 \\
0.0026\end{array}$ & $\begin{array}{c}0.003 \\
0.0033\end{array}$ & $\begin{array}{l}0.0019 \\
0.0019\end{array}$ & $\begin{array}{l}0.0022 \\
0.0022\end{array}$ & $\begin{array}{l}0.0029 \\
0.0027\end{array}$ & $\begin{array}{l}0.0029 \\
0.0024\end{array}$ & $\begin{array}{l}0.0028 \\
0.0023\end{array}$ & $\begin{array}{c}0.0027 \\
0.002\end{array}$ \\
\hline spec. 3 & $\begin{array}{l}1 \\
2\end{array}$ & $\begin{array}{l}0.0023 \\
0.0016\end{array}$ & $\begin{array}{l}0.0019 \\
0.0012\end{array}$ & $\begin{array}{l}0.0019 \\
0.0012\end{array}$ & $\begin{array}{c}0.002 \\
0.0015\end{array}$ & $\begin{array}{c}0.002 \\
0.0015\end{array}$ & $\begin{array}{l}0.0022 \\
0.0015\end{array}$ & $\begin{array}{l}0.0021 \\
0.0011\end{array}$ & $\begin{array}{l}0.0022 \\
0.0015\end{array}$ & $\begin{array}{c}0.002 \\
0.0014\end{array}$ & $\begin{array}{c}0.002 \\
0.0015\end{array}$ & $\begin{array}{l}0.0021 \\
0.0011\end{array}$ \\
\hline \multicolumn{2}{|c|}{ Mean average } & 0.0036 & 0.0039 & 0.0037 & 0.003 & 0.0031 & 0.0025 & 0.0026 & 0.0028 & 0.0028 & 0.0028 & 0.0026 \\
\hline
\end{tabular}

Polymer shokbar

\begin{tabular}{|c|c|c|c|c|c|c|c|c|c|c|c|c|}
\hline specimen & joint \# & 0 & 500,000 & $1,000,000$ & $1,500,000$ & $2,000,000$ & $2,500,000$ & $3,000,000$ & $3,500,000$ & $4,000,000$ & $4,500,000$ & $5,000,000$ \\
\hline \multirow[t]{2}{*}{ spec. 1} & 1 & 0.0022 & 0.001 & 0.0012 & 0.0026 & 0.0024 & 0.0019 & 0.0009 & 0.001 & 0.0012 & 0.0017 & 0.003 \\
\hline & 2 & 0.0021 & 0.0019 & 0.0016 & 0.0011 & 0.0012 & 0.0022 & 0.0022 & 0.0019 & 0.0015 & 0.0011 & 0.0006 \\
\hline \multirow[t]{2}{*}{ spec. 2} & 1 & 0.006 & 0.0061 & 0.0061 & 0.0057 & 0.006 & 0.0066 & 0.0068 & 0.0063 & 0.0065 & 0.0068 & 0.0069 \\
\hline & 2 & 0.0022 & 0.002 & 0.0021 & 0.0021 & 0.0019 & 0.0019 & 0.0021 & 0.0021 & 0.0021 & 0.0021 & 0.0014 \\
\hline \multirow[t]{2}{*}{ spec. 3} & 7 & 0.0032 & 0.0029 & 0.0045 & 0.004 & 0.0033 & 0.0031 & 0.0031 & 0.0031 & 0.0034 & 0.0035 & 0.0036 \\
\hline & 2 & 0.0036 & 0.0046 & 0.0049 & 0.0047 & 0.0045 & 0.0043 & 0.0042 & 0.0043 & 0.0048 & 0.0041 & 0.0043 \\
\hline \multicolumn{2}{|c|}{ Mean average } & 0.003217 & 0.003083 & 0.0034 & 0.003367 & 0.003217 & 0.003333 & 0.003217 & 0.003117 & 0.00325 & 0.003217 & 0.0033 \\
\hline
\end{tabular}

Steel shokbar

\begin{tabular}{|c|c|c|c|c|c|c|c|c|c|c|c|c|}
\hline specimen & joint \# & 0 & 500,000 & $1,000,000$ & $1,500,000$ & $2,000,000$ & $2,500,000$ & $3,000,000$ & $3,500,000$ & $4,000,000$ & $4,500,000$ & $5,000,000$ \\
\hline \multirow[t]{2}{*}{ spec. 1} & 1 & 0.0008 & 0.0016 & 0.0021 & 0.0017 & 0.002 & 0.0017 & 0.0017 & 0.0016 & 0.0017 & 0.0018 & 0.0019 \\
\hline & 2 & 0.0036 & 0.0026 & 0.003 & 0.0031 & 0.003 & 0.0032 & 0.0026 & 0.0031 & 0.0037 & 0.0034 & 0.0031 \\
\hline \multirow[t]{2}{*}{ spec. 2} & 1 & 0.0043 & 0.0044 & 0.0045 & 0.0044 & 0.0046 & 0.0046 & 0.0048 & 0.0048 & 0.0046 & 0.0045 & 0.0044 \\
\hline & 2 & 0.0054 & 0.0052 & 0.0051 & 0.0052 & 0.0049 & 0.0051 & 0.0054 & 0.0053 & 0.0054 & 0.0056 & 0.0056 \\
\hline \multirow[t]{2}{*}{ spec. 3} & 1 & 0.0019 & 0.0017 & 0.002 & 0.0022 & 0.0016 & 0.0006 & 0.0011 & 0.0011 & 0.0016 & 0.0017 & 0.0017 \\
\hline & 2 & 0.0042 & 0.0038 & 0.0039 & 0.004 & 0.0039 & 0.0039 & 0.0037 & 0.0036 & 0.0035 & 0.0037 & 0.0038 \\
\hline \multicolumn{2}{|c|}{ Mean average } & 0.003367 & 0.003217 & 0.003433 & 0.003433 & 0.003333 & 0.003183 & 0.003217 & 0.00325 & 0.003417 & 0.00345 & 0.003417 \\
\hline
\end{tabular}

Vertical relative displacement across joints 


\section{APPENDIX-IV}

\begin{tabular}{|c|c|c|c|c|c|c|}
\hline $\begin{array}{c}\text { Specimen } \\
\text { No }\end{array}$ & $\begin{array}{l}\text { Loading } \\
\text { cycles }\end{array}$ & $\begin{array}{c}\text { Bending } \\
\text { moment } \\
\text { (Ib.in) }\end{array}$ & $\begin{array}{l}\text { Shearing } \\
\text { force } \\
\text { (lb) }\end{array}$ & $\begin{array}{l}\text { Modulus } \\
\text { of dowel } \\
\text { support }\end{array}$ & $\begin{array}{c}\text { Bar } \\
\text { relative } \\
\text { stiffness } \\
\text { (Ib/in3) }\end{array}$ & $\begin{array}{l}\text { Bearing } \\
\text { stress } \\
\text { (Ib/in2) }\end{array}$ \\
\hline \multirow{11}{*}{$\begin{array}{l}\overline{0} \\
\text { की }\end{array}$} & 0 & 199.8814 & 1439.3 & 255000 & 0.385808 & 841.5 \\
\hline & 500000 & 194.2034 & 1236.757 & 135000 & 0.329094 & 618.3 \\
\hline & 1000000 & 173.5189 & 1189.827 & 160000 & 0.343373 & 611.5231587 \\
\hline & 1500000 & 319.0605 & 1320.591 & 220000 & 0.371828 & 721.9407745 \\
\hline & 2000000 & 216.4451 & 1263.405 & 200000 & 0.363073 & 696.2822252 \\
\hline & 2500000 & 392.7269 & 1364.544 & 235000 & 0.37801 & 734.7829861 \\
\hline & 3000000 & 320.4765 & 1398.079 & 270000 & 0.39136 & 791.2716763 \\
\hline & 3500000 & 220.8451 & 1402.008 & 315000 & 0.406737 & 856.128 \\
\hline & 4000000 & 108.8851 & 1385.625 & 300000 & 0.401806 & 864.7568988 \\
\hline & 4500000 & 111.1244 & 1384.927 & 302000 & 0.402474 & 864.0383299 \\
\hline & 5000000 & 63.46042 & 1324.361 & 284000 & 0.396338 & 823.6 \\
\hline \multirow{11}{*}{$\begin{array}{l}\sim \\
0 \\
\mathbb{0} \\
\text { की }\end{array}$} & 0 & 864.6502 & 650.286 & 55500 & 0.263517 & 177.6 \\
\hline & 500000 & 680.959 & 591.8271 & 56000 & 0.264109 & 173.9320158 \\
\hline & 1000000 & - & 489.0151 & - & - & - \\
\hline & 1500000 & - & 560.615 & - & - & - \\
\hline & 2000000 & - & 535.8909 & - & - & - \\
\hline & 2500000 & - & 611.834 & - & - & - \\
\hline & 3000000 & - & 306.935 & - & - & - \\
\hline & 3500000 & - & 20.64658 & - & - & - \\
\hline & 4000000 & - & 48.98003 & - & - & - \\
\hline & 4500000 & - & 100.2716 & - & - & - \\
\hline & 5000000 & - & 128.9884 & - & - & - \\
\hline \multirow{11}{*}{$\begin{array}{l}\text { m } \\
\dot{\Phi} \\
\text { की }\end{array}$} & 0 & 713.5882 & 1144.503 & 350000 & 0.417593 & 560 \\
\hline & 500000 & 762.5645 & 1144.503 & 495000 & 0.455394 & 580.6484099 \\
\hline & 1000000 & 763.1293 & 1123.694 & 453000 & 0.445411 & 558.0597173 \\
\hline & 1500000 & 766.6787 & - & - & - & - \\
\hline & 2000000 & 766.6814 & - & - & - & - \\
\hline & 2500000 & 760.0526 & - & - & - & - \\
\hline & 3000000 & 738.2212 & - & - & - & - \\
\hline & 3500000 & 743.9385 & - & - & - & - \\
\hline & 4000000 & 731.993 & - & - & - & - \\
\hline & 4500000 & 721.7407 & - & - & - & - \\
\hline & 5000000 & 715.6247 & - & - & - & - \\
\hline
\end{tabular}

Calculations of Bearing stress at regular dowel specimens 


\begin{tabular}{|c|c|c|c|c|c|c|}
\hline Specimen No & $\begin{array}{l}\text { Loading } \\
\text { cycles }\end{array}$ & $\begin{array}{c}\text { Bending } \\
\text { moment } \\
\text { (Ib.in) }\end{array}$ & $\begin{array}{l}\text { Shearing } \\
\text { force } \\
\text { (lb) }\end{array}$ & $\begin{array}{l}\text { Modulus } \\
\text { of dowel } \\
\text { support }\end{array}$ & $\begin{array}{c}\text { Bar } \\
\text { relative } \\
\text { stiffness } \\
\text { (lb/in3) }\end{array}$ & $\begin{array}{c}\text { Bearing } \\
\text { stress } \\
\text { (Ib/in2) }\end{array}$ \\
\hline \multirow{11}{*}{$\begin{array}{l}- \\
\dot{\Phi} \\
\text { की }\end{array}$} & 0 & 40.76277 & 606.9336 & 153000 & 0.339554 & 321.3 \\
\hline & 500000 & 19.77018 & 468.8009 & 130000 & 0.326003 & 241.1372549 \\
\hline & 1000000 & 3.651401 & 383.6003 & 128000 & 0.324742 & 198.6619711 \\
\hline & 1500000 & 80.49305 & 386.7034 & 180000 & 0.353634 & 200.7647584 \\
\hline & 2000000 & 80.388 & 399.9285 & 165000 & 0.346025 & 204.6130738 \\
\hline & 2500000 & 68.30543 & 435.3307 & 90500 & 0.297782 & 197.7517993 \\
\hline & 3000000 & 65.406 & 472.3596 & 100000 & 0.305306 & 224.3742351 \\
\hline & 3500000 & 78.26782 & 429.7269 & 110000 & 0.312669 & 208.1781976 \\
\hline & 4000000 & 91.12963 & 387.0943 & 122000 & 0.320868 & 188.040526 \\
\hline & 4500000 & 98.27199 & 352.2495 & 150000 & 0.337877 & 165.0299196 \\
\hline & 5000000 & 79.82088 & 370.9722 & 425000 & 0.438362 & 234.4473938 \\
\hline \multirow{11}{*}{$\begin{array}{l}\text { N } \\
0 \\
0 \\
\text { के }\end{array}$} & 0 & 10.8381 & 761.2681 & 205000 & 0.365321 & 444.1666667 \\
\hline & 500000 & 136.7332 & 1274.211 & 428000 & 0.439134 & 855.4005602 \\
\hline & 1000000 & 226.4977 & 1323.785 & 411000 & 0.434707 & 850.3340909 \\
\hline & 1500000 & 300.9147 & 1338.76 & 395000 & 0.430413 & 829.5 \\
\hline & 2000000 & 358.8015 & 1413.041 & 480000 & 0.451904 & 906.5454545 \\
\hline & 2500000 & 386.2467 & 1393.889 & 460000 & 0.447121 & 868.1807229 \\
\hline & 3000000 & 400.4024 & 1290.47 & 350000 & 0.417593 & 751.937751 \\
\hline & 3500000 & 402.1616 & 1446.56 & 415000 & 0.435761 & 883.4825615 \\
\hline & 4000000 & 404.0124 & 1404.175 & 405000 & 0.433112 & 850.6157804 \\
\hline & 4500000 & 405.8632 & 1361.789 & 400000 & 0.431769 & 828.6792453 \\
\hline & 5000000 & 403.7912 & 1360.398 & 630001 & 0.483695 & 903.0014333 \\
\hline \multirow{11}{*}{$\begin{array}{l}\infty \\
\dot{0} \\
\text { की }\end{array}$} & 0 & 422.9736 & 1321.381 & 187500 & 0.357262 & 675 \\
\hline & 500000 & 548.7414 & 975.7815 & 83000 & 0.291411 & 380.5044532 \\
\hline & 1000000 & 547.0747 & 852.7848 & 62000 & 0.270916 & 303.8 \\
\hline & 1500000 & 558.1257 & 918.0701 & 73000 & 0.282206 & 345.7772936 \\
\hline & 2000000 & 569.5543 & 998.2913 & 85000 & 0.293151 & 386.7297393 \\
\hline & 2500000 & 557.3612 & 868.1436 & 75000 & 0.28412 & 325.586157 \\
\hline & 3000000 & 540.7184 & 741.943 & 61000 & 0.269816 & 257.8455814 \\
\hline & 3500000 & 532.9376 & 765.3003 & 62000 & 0.270916 & 268.2803738 \\
\hline & 4000000 & 543.6942 & 775.0242 & 56000 & 0.264109 & 268.4859813 \\
\hline & 4500000 & 560.9195 & 790.6926 & 68500 & 0.277753 & 281.0680931 \\
\hline & 5000000 & 551.8898 & 787.7242 & 65500 & 0.274661 & 279.9704553 \\
\hline
\end{tabular}

Calculations of Bearing stress at Polymer shokbar specimens 


\begin{tabular}{|c|c|c|c|c|c|c|}
\hline $\begin{array}{l}\text { Specimen } \\
\text { No }\end{array}$ & $\begin{array}{l}\text { Loading } \\
\text { cycles }\end{array}$ & $\begin{array}{c}\text { Bending } \\
\text { moment } \\
\text { (Ib.in) }\end{array}$ & $\begin{array}{l}\text { Shearing } \\
\text { force } \\
\text { (Ib) }\end{array}$ & $\begin{array}{l}\text { Modulus } \\
\text { of dowel } \\
\text { support }\end{array}$ & $\begin{array}{c}\text { Bar } \\
\text { relative } \\
\text { stiffness } \\
\text { (lb/in3) }\end{array}$ & $\begin{array}{l}\text { Bearing } \\
\text { stress } \\
\text { (Ib/in2) }\end{array}$ \\
\hline \multirow{11}{*}{$\begin{array}{l}- \\
\dot{\Phi} \\
\text { की }\end{array}$} & 0 & 701.1196 & 1165.313 & 140000 & 0.332099 & 499.3333333 \\
\hline & 500000 & 664.7668 & 1128.448 & 190000 & 0.358447 & 503.2565756 \\
\hline & 1000000 & 668.4288 & 1103.435 & 165000 & 0.346025 & 488.370694 \\
\hline & 1500000 & 664.1642 & 1105.322 & 154000 & 0.340107 & 478.5247863 \\
\hline & 2000000 & 649.435 & 1118.492 & 165000 & 0.346025 & 495.349711 \\
\hline & 2500000 & 636.8259 & 1120.085 & 157000 & 0.341752 & 495.1157658 \\
\hline & 3000000 & 635.3787 & 1112.53 & 198000 & 0.362162 & 514.0197674 \\
\hline & 3500000 & 636.7 & 1072.846 & 130000 & 0.326003 & 406.3993528 \\
\hline & 4000000 & 637.61 & 1071.007 & 118000 & 0.318205 & 441.6531883 \\
\hline & 4500000 & 640.218 & 1083.211 & 135000 & 0.329094 & 459.2159309 \\
\hline & 5000000 & 642.8259 & 1095.415 & 160000 & 0.343373 & 489.6600554 \\
\hline \multirow{11}{*}{$\begin{array}{l}\text { N } \\
\dot{0} \\
\stackrel{0}{0}\end{array}$} & 0 & 299.7262 & 353.7556 & 17000 & 0.196042 & 92.36666667 \\
\hline & 500000 & 118.7935 & 199.6992 & 9300 & 0.1686 & 48.36100108 \\
\hline & 1000000 & - & 672.5113 & - & - & 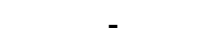 \\
\hline & 1500000 & - & 700.0307 & - & - & - \\
\hline & 2000000 & - & 741.2578 & - & - & - \\
\hline & 2500000 & - & 702.6329 & - & - & - \\
\hline & 3000000 & - & 647.1179 & - & - & - \\
\hline & 3500000 & - & 548.5959 & - & - & - \\
\hline & 4000000 & - & 360.4581 & - & - & - \\
\hline & 4500000 & - & 172.3203 & - & - & - \\
\hline & 5000000 & - & 79.3265 & - & - & - \\
\hline \multirow{11}{*}{$\begin{array}{l}m \\
\dot{\Phi} \\
\text { की }\end{array}$} & 0 & 451.2678 & 1061.267 & 108000 & 0.311238 & 457.2 \\
\hline & 500000 & 482.1301 & 1146.237 & 138000 & 0.330907 & 521.2931452 \\
\hline & 1000000 & 487.715 & 1181.663 & 138000 & 0.330907 & 541.052 \\
\hline & 1500000 & 484.4226 & 1210.399 & 135000 & 0.329094 & 540.2034783 \\
\hline & 2000000 & 484.6138 & 1219.069 & 145000 & 0.335026 & 570.3333333 \\
\hline & 2500000 & 492.0977 & 1503.461 & 200000 & 0.363073 & 772.1745673 \\
\hline & 3000000 & 494.1911 & 1512.132 & 211000 & 0.367965 & 781.4975945 \\
\hline & 3500000 & 487.6446 & 1533.374 & 232000 & 0.376797 & 829.7522267 \\
\hline & 4000000 & 488.2978 & 1526.004 & 230000 & 0.375983 & 812.3286573 \\
\hline & 4500000 & 492.2857 & 1555.484 & 220000 & 0.371828 & 818.7592304 \\
\hline & 5000000 & 0.001733 & 1586.698 & 255000 & 0.385808 & 977.5 \\
\hline
\end{tabular}

Calculations of Bearing stress at Steel shokbar specimens 


\begin{tabular}{|r|r|r|r|}
\hline Cycles & \multicolumn{3}{|c|}{ Device } \\
\cline { 2 - 4 } & \multicolumn{1}{|c|}{$\begin{array}{c}\text { Regular } \\
\text { dowel }\end{array}$} & $\begin{array}{c}\text { Polymer } \\
\text { shokbar }\end{array}$ & $\begin{array}{c}\text { Steel } \\
\text { shokbar }\end{array}$ \\
\hline 0 & 526.3666667 & 480.1555556 & 349.63333 \\
500000 & 457.6268086 & 492.3474228 & 357.63691 \\
1000000 & 584.791438 & 450.9320207 & 514.71135 \\
1500000 & 721.9407745 & 458.680684 & 509.36413 \\
2000000 & 696.2822252 & 499.2960892 & 532.84152 \\
2500000 & 734.7829861 & 463.8395597 & 633.64517 \\
3000000 & 791.2716763 & 411.3858558 & 647.75868 \\
3500000 & 856.128 & 453.313711 & 618.07579 \\
4000000 & 864.7568988 & 435.7140959 & 626.99092 \\
4500000 & 864.0383299 & 424.9257527 & 638.98758 \\
5000000 & 823.6 & 472.4730942 & 730.90613 \\
\hline
\end{tabular}

Summary of mean average calculations of bearing stresses 